\title{
Tris DBA Abrogates Tumor Progression in Hepatocellular Carcinoma and Multiple Myeloma Preclinical Models by Affecting Multiple Oncogenic Proteins
}

\section{Loukik Arora}

National University of Singapore

Chakrabhavi Dhananjaya Mohan

University of Mysore

Chulwon Kim

Kyung Hee University

Shobith Rangappa

Adichunchanagiri Institute of Medical Sciences

Amudha Deivasigamani

National Cancer Centre

Alan Prem Kumar

National University of Singapore

Ajaikumar B Kunnumakkara

Indian Institute of Technology Guwahati

Manoj Garg

Amity University

Kanchugarakoppal S. Rangappa

University of Mysore

Kam Man Hui ( $\square$ cmrhkm@nccs.com.sg)

National Cancer Centre

Gautam Sethi

National University of Singapore

Kwang Seok Ahn ( $\square$ ksahn@khu.ac.kr)

Kyung Hee University

\section{Research}

Keywords: Tris DBA, STAT3 signaling inhibitor, Orthotopic, Xenograft, antitumor, SHP2

Posted Date: November 4th, 2020 
DOl: https://doi.org/10.21203/rs.3.rs-100294/v1

License: (c) (1) This work is licensed under a Creative Commons Attribution 4.0 International License. Read Full License 


\section{Abstract}

Background: STAT3 is an oncogenic transcription factor that controls the expression of genes associated with proliferation, apoptotic resistance, malignant transformation, and metastasis. Persistent activation of STAT3 is observed in many types of human malignancies including hepatocellular carcinoma (HCC) and multiple myeloma (MM).

Methods: Here, we have investigated the action of Tris(dibenzylideneacetone) dipalladium 0 (Tris DBA), a palladium complex on STAT3 signaling cascade in HCC and MM. The cytotoxic and proapoptotic activity of Tris DBA was evaluated by various biochemical assays. The action of Tris DBA on cytokineinduced/constitutive activation of STAT3, non-receptor tyrosine kinases (NRTKs), and expression of STAT3 driven genes was evaluated. Nuclear translocation of STAT3 and its DNA interaction was also studied. The antitumor activity of Tris DBA was investigated in two different preclinical studies namely, xenograft MM and orthotopic HCC mice models.

Results: Tris DBA decreased cell viability, increased the apoptosis, and inhibited the activation of STAT3 and NRTKs. Tris DBA downmodulated the nuclear translocation of STAT3 and reduced its DNA binding ability. It upregulated expression of SHP2 (protein and mRNA) to induce STAT3 dephosphorylation and inhibition of SHP2 reversed this effect. It downregulated the expression of STAT3-driven genes and suppressed cell motility. Tris DBA significantly inhibited tumor growth in xenograft MM and orthotopic HCC mice models with reduction in the expression of various prosurvival biomarkers in MM tumor tissues without displaying any significant toxicity.

Conclusions: Tris DBA functions as a good inhibitor of STAT3 signaling in preclinical HCC and MM models.

\section{Background}

Cancer is a prominent public health concern and the second major cause of death globally after cardiovascular disease and both its incidence and mortality rates are increasing every year (1-3). Hepatocellular carcinoma (HCC) is the leading type of liver cancer which affected 0.8 million people in 2012 throughout the globe (4) and the 5-year survival rate has been estimated to be between $5-14 \%$ which is critically low (5). Hepatitis B infection remains the leading risk factor of HCC followed by nonalcoholic fatty liver disease, alcoholic hepatitis, aflatoxin B1 intake, and hemochromatosis (6). HCC may be often detected at metastatic stage, which drastically reduces the treatment efficacy and options $(7,8)$. Multiple myeloma (MM) stands second among hematological malignancies in the western countries contributing approximately $10 \%$ of hematological malignancies (9-11). Although precise risk factors are not clearly listed, factors such as age, gender, race, and family history are often believed to contribute to the development of MM (12).

Signal transducer and activator of transcription 3 (STAT3) can be aberrantly activated in solid and haematological cancers including HCC and MM respectively (13-16). A number of studies have 
demonstrated the critical role of STAT3 in malignant transformation and progression. STAT family comprises of seven members- STAT1, STAT2, STAT3, STAT4, STAT5a, STAT5b, and STAT6 (17-20). STAT1, STAT3, and STAT5 are widely studied in the cancer context, among which STAT3 stands in the forefront (21-23). STAT3 is predominantly activated by IL-6 family cytokines transiently in non-diseased conditions. In the canonical signaling, the binding of IL-6 to its receptor results in the activation of gp130, and other nonreceptor tyrosine kinases (NRTKs) such as JAK, and Src (24). The phosphorylated NRTKs or some of the activated receptor tyrosine kinases (such as EGFR) phosphorylates STAT3 ${ }^{\mathrm{Y} 705}$ and activates it (25-27). The phosphorylated monomer undergoes dimerization with another monomer to translocate into the nucleus through specific importin $(28,29)$. STAT3-binding sites have been identified in the promoter region of several genes that are involved in cell growth and proliferation, inflammation, prosurvival, antiapoptosis, proangiogenic, and metastasis (30-32). The overexpression of STAT3 targeted genes due to its persistent activation in cancers provide enormous growth potential to the cancer cells and encourage the advancement of the disease. Therefore, mitigation of the STAT3 cascade may provide a significant clinical benefit to patients.

Tris(dibenzylideneacetone)dipalladium(0) (Tris DBA) is an organometallic complex compound where two palladium atoms are bound to the alkene units of three dibenzylideneacetone (33). The compound is moderately soluble in organic solvents. The antitumor potential of Tris DBA in few cancer models have been analysed previously. Bhandarkar and colleagues demonstrated that Tris DBA can reduce melanoma cell proliferation by inhibiting the activation of MAPK, Akt, STAT3, phospho-S6 kinase, and downregulated the expression of N-myristoyltransferase-1 (34). Tris DBA decreased proliferation and showed an additive cytotoxic effect with proteasome inhibitors such as bortezomib and carfilzomib towards MM cells (35). In addition, Tris DBA regulated the expression of the Bcl-2 family proteins by targeting ribosomal protein $\mathrm{S} 6$ in primary chronic lymphocytic leukemia B-cells (36). Tris DBA has been proposed to target $\mathrm{N}$ myristoyltransferase 1 to induce growth-inhibitory and antimetastatic activity in pancreatic cancer cells (37). These findings have established Tris DBA as a promising anticancer agent, although its precise mechanism of action is yet to be explored. In the present study, we have evaluated the effect of Tri DBA on STAT3 signaling in HCC and MM cells and its antitumor efficacy in preclinical settings.

\section{Methods}

\section{Reagents}

Tris DBA, MTT, Tris, glycine, NaCl, SDS, BSA, IL-6, EGF, and pervanadate were procured from SigmaAldrich. The structure of Tris DBA is provided as figure 1A. The stock solution of Tris DBA $(10 \mathrm{mmol} / \mathrm{L}$ stock) was prepared in dimethylsulfoxide (DMSO) and stored at $4^{\circ} \mathrm{C}$. Tris DBA was further diluted with cell culture medium as per the requirements. Cell culture media (Dulbecco's Modified Eagle Medium [DMEM], and Roswell Park Memorial Institute [RPMI]), and fetal bovine serum (FBS) were purchased from Life Technologies. Rabbit or mouse monoclonal and polyclonal antibodies against Bak, Bcl-2, PARP, survivin, Mcl-1, SHP-2, PTP1B were obtained from Santa Cruz Biotechnology. Antibodies against 
phospho-STAT3 (Tyr705), STAT3, phospho-JAK1/2, JAK1/2, caspase-3, phospho-Src, Src, cyclin D1, SHP1, and $\beta$-Actin were purchased from Cell Signaling Technology.

\section{Cell lines}

HepG2 cell line was obtained from American Type Culture Collection. Huh-7 cell line was obtained from Japanese Collection of Research Bioresources (JCRB) Cell Bank (Osaka, Japan) and HCCLM3 cell line was a kind gift from Professor Zhao-You Tang at the Liver Cancer Institute (Zhongshan Hospital, Fudan University, Shanghai, China). MM cells (U266 and RPMI-8226 [both bortezomib resistant and sensitive]) were a kind gift from Prof. Wee Joo Chng (Cancer Science Institute, Singapore). HCC cells were cultured in Dulbecco's modified Eagle's medium (DMEM) with 10\% FBS. All MM cell lines were cultured in RPMI1640 medium with $10 \%$ FBS.

\section{MTT assay}

The cytotoxic effect of Tris DBA towards MM and HCC cells was evaluated by the in vitro cytotoxicity assay using MTT dye as reported earlier $(38,39)$.

\section{Annexin V assay}

Flow cytometric analysis was performed to determine the extent of apoptosis in MM and HCC cells using Annexin V and PI staining as described previously (40).

\section{Cell cycle analysis using flow cytometry}

The alignment of tumor cells in different phases of the cell cycle was analyzed using flow cytometry by staining with $\mathrm{Pl}$ as reported earlier $(41,42)$. The cell pellet was suspended in propidium iodide $(2.5 \mu \mathrm{g} / \mathrm{ml})$ and RNAse $(0.5 \mathrm{mg} / \mathrm{ml}$ RNase A in PBS) after treatment and analyzed using flow cytometry.

\section{Western blotting}

The cells were incubated with Tris DBA for given time points at given doses and lysed using MPer lysis buffer (Thermo Scientific) as described previously $(43,44)$.

\section{DNA binding assay}

The effect of Tris DBA on DNA interaction ability of STAT3 was assessed using the TransAM assay kit (Active Motif, Carlsbad, $\mathrm{CA}$,). The experiment was done as per the directions from the manufacturer as described previously (45).

\section{Immunocytochemistry for STAT3 distribution}

The cells were seeded in Ibidi glass-bottom dishes in complete medium and treated with Tris DBA or vehicle control for $2 \mathrm{~h}$ and then fixed with $10 \%$ buffered formalin after washing with PBS. These cells were treated with Triton-X 100 for permeabilization followed by blocking with goat serum (5\%) for $1 \mathrm{~h}$. 
Thereafter, the preparation is treated with monoclonal mouse anti-STAT3 antibody (1:100 dilution) overnight at $4^{\circ} \mathrm{C}$ followed by rinsing with PBS and incubated in goat anti-mouse secondary antibody (Alexa-Fluor 568) for $1 \mathrm{~h}$. The cells were then washed and counterstained with DAPI to stain the nuclei. The cells were analyzed immediately under a confocal microscope (Nikon A1).

\section{RNA isolation and reverse transcription polymerase chain reaction (RT-PCR)}

The cells were incubated with Tris DBA, washed, and suspended in Trizol reagent (Invitrogen, Carlsbad, $\mathrm{CA}$ ) and reverse transcribed as discussed earlier (46).

\section{Real-time quantitative PCR}

Total RNA was isolated from the cells using Trizol reagent and subjected to real-time quantitative PCR analysis as reported previously (47).

\section{Transfection with SHP2 siRNA}

We used the Neon ${ }^{\text {TM }}$ Transfection System (Invitrogen, Carlsbad, CA) to transfect cells with SHP2 siRNA. Briefly, cells and SHP2 siRNA (100ng/ $\mu$ l) were taken into a clean, dry, sterile centrifuge tube and following aspiration of cell-siRNA cocktail using Neon Tip in Neon Pipette to restrain the formation of air bubbles. Thereafter, Neon Pipette was placed into the Neon Tube which has Neon Electrolytic Buffer E. Next cells were subjected to a pulse of 1,150 voltage with a width of 30 for transfection. $48 \mathrm{~h}$ post-transfection, cells were incubated with Tris DBA and the cell lysate was prepared and analyzed for various proteins.

\section{In vitro migration assay}

This experiment was performed to determine the action of Tris DBA on migration as described before (48, 49).

\section{Invasion assay}

This assay was carried out to assess the anti-invasive property of Tris DBA on HCC and MM cells using the Bio-Coat Matrigel invasion assay system (BD Biosciences, San Jose, CA) as elaborated upon previously (50).

\section{In vivo acute toxicity studies}

All the in vivo acute toxicity experiments were carried out as per the approved procedures by the SingHealth Institutional Animal Use and Care Committee (protocol number: 2013/SHS/870). Eight-weekold NCr nude male mice (Invivos, Singapore) were used to perform toxicity-related experiments. The experimental animals were administered intraperitoneally with $0.1 \%$ DMSO or $25,50,100$, and $200 \mathrm{mg}$ of Tris DBA. The experimental animals were monitored regularly for any changes in feed and water consumption, body weight, behavior, physical appearance, movement, and other criteria up to the eighth 
day. On the last day, animals were sacrificed by cardiac puncture and blood was collected for further analysis for biochemical analysis.

\section{Xenograft MM mouse model}

In vivo xenograft tumor experiments were carried out as per the approved procedures by KHU Institutional Animal Care and Use Committee [KHUASP(SE)-17-110]. The subcutaneous xenograft MM mouse model was established by injecting U266 cells to the right flank of six-week-old athymic nu/nu female mice (NARA Biotech, Korea). The mice were randomly distributed into three groups ( $n=6 /$ group) upon tumor reaching the size of $0.25 \mathrm{~cm}$. The first group served as control which was intraperitoneally administered with PBS $(200 \mu \mathrm{L}$, i.p. thrice/week). The second and third groups intraperitoneally received Tris DBA (50 $\mathrm{mg} / \mathrm{kg}$, thrice/week) and (100 mg/kg, thrice/week) respectively for four weeks. All mice were sacrificed after one week and primary tumors were collected for subsequent analysis.

\section{Immunohistochemical analysis of MM tumor samples}

The tumors collected from xenograft experiments were processed using phosphate-buffered formalin $(10 \%)$ and impregnated in the paraffin blocks. Thereafter, they were subjected to cutting, deparaffinization using xylene and dehydration using graded alcohol. The slides were boiled in sodium citrate $(10 \mathrm{mM}, \mathrm{pH}$ 6.0) for $30 \mathrm{~min}$ to retrieve antigens. This is followed by immunohistochemistry using the kit obtained from Vector Laboratories (ImmPRESS ${ }^{\mathrm{TM}}$ Reagent Kit). In brief, hydrogen peroxide (3\%) and blocking reagent were used to quench tissue-derived peroxidases and to block non-specific interactions. Further, sections were treated with various antibodies for overnight. The next day, slides were repeatedly rinsed with PBS and incubated with ImmPRESS ${ }^{\mathrm{TM}}$ reagent. 3, 3-diaminobenzidine tetrahydrochloride (DAB) reagent was used as a substrate to identify immunoreactive species. Next, Gill's hematoxylin was used to counterstain the sections followed by the photography of sections using the Olympus microscope (20x). Positive cells appeared brown and quantified using the Image-Pro Plus 6.0 software package (Media Cybernetics, Inc.)

\section{Orthotopic HCC tumor model}

In vivo orthotopic tumor experiments were carried out as per the approved procedures by the SingHealth Institutional Animal Use and Care Committee (protocol number: 2013/SHS/870) and as reported earlier $(51,52)$. The orthotopic HCC mouse model was established by placing a small piece of tumor-derived from HCCLM3-Luc cells. The mice were randomly distributed into three groups upon the bioluminescence signal reaching $10^{6}$. The first group served as control which was intraperitoneally administered with $0.1 \%$ DMSO (thrice/week). The second and third groups intraperitoneally received Tris DBA (50 mg/kg, thrice/week) and (200 mg/kg, thrice/week) respectively for four weeks. The tumor progression/regression was recorded weekly twice by quantifying the bioluminescence signals. Experimental animals were sacrificed by $\mathrm{CO}_{2}$ inhalation. Tumor tissues were harvested and stored at $-80^{\circ} \mathrm{C}$ for further processes.

\section{Statistical analysis}


The obtained numerical data are presented as the mean \pm SD unless otherwise mentioned. Student's ttest or one-way ANOVA were employed to measure statistical significance.

\section{Results}

Tris DBA decreased the viability and increased the subG1 population of HCC and MM cells.

We deciphered the action of Tris DBA on the viability of HCC and MM cells by MTT assay. For this, we used HCC (HCCLM3, Huh7, HepG2), MM (U266), and bortezomib-resistant/sensitive MM (RPMI-8226) cell lines. All the cells responded to Tris DBA, which resulted in a significant decrease of viability thus indicating the cytotoxic effect of Tris DBA on both types of cancer cells (Fig. 1B). Flow cytometric analysis revealed that the treatment with Tris DBA significantly increased the subG1 cell population up to $80 \%$ in $\mathrm{HCC}$ and MM cells (Fig. 1C). However, the subG1 cell population is relatively less (30\%) in bortezomib-resistant RPMI-8226 cells.

\section{Tris DBA induced apoptosis of HCC and MM cells.}

We performed FITC-Annexin V-PI staining to verify the action of Tris DBA is inducing apoptosis and observed ta dose-dependent elevation in the percentage of apoptotic cells in all the tested cell lines (Fig. 2A). The percentage of the apoptotic population in bortezomib-resistant MM cells were relatively lower than the sensitive counterpart.

\section{Tris DBA altered STAT3 phosphorylation in tumor cells.}

Initially, we examined the effect of Tris DBA on activation of STAT3 in HCC and MM cells. Tris DBA significantly reduced the constitutively activated STAT3 in U266 and HCCLM3 cells (Fig. 1B). RPMI-8226 has a basal level of phospho-STAT3 ${ }^{\mathrm{Y} 705}$ expression and treatment of these cells with IL- 6 triggered the phosphorylation of STAT3 ${ }^{\mathrm{Y} 705}$ in time- and dosage-dependent manner (Fig. 1C, upper panels). The treatment with Tris DBA resulted in suppression of IL-6 driven STAT3 activation without a change in the total STAT3 expression (Fig. 1C, lower panel).

\section{Tris DBA decreased nuclear localization and ablated the binding of STAT3.}

Next, we deciphered the action of Tris DBA on the cellular distribution of STAT3 in HCCLM3 cells. Tris DBA downregulated the nuclear pool of STAT3 in HCCLM3 cells compared with vehicle-treated samples as demonstrated by the results of immunocytochemistry (Fig. 3A). Further, we prepared the nuclear extract of DMSO/Tris DBA treated cells and analyzed whether Tris DBA also influences the DNA interaction ability of STAT3. We observed a significant reduction in the DNA interaction ability of STAT3 in different tumor cells (Fig. 3B). We also observed an inhibition of IL-6 triggered DNA binding of STAT3 in RPMI-8226 cells (Fig. 3B), thus indicating that Tris DBA may interfere with STAT3 activation and subsequent gene transcription.

Tris DBA inhibited the phosphorylation of upstream kinases of STAT3 signaling. 
Next, we measured the potential of Tris DBA treatment on the phosphorylation of upstream kinases regulating STAT3 signaling such as JAK1, JAK2, and Src in HCC and MM cells. We observed a significant decline in the constitutive activation of JAK1, JAK2, Src in U266 cells, and JAK2, Src in HCCLM3 cells (Fig. 4A). We also investigated the effect of Tris DBA on IL-6-induced phosphorylation of JAK1 and JAK2 in RPMI-8226 cells. We observed a substantial reduction in the IL-6 induced activation of JAK1 and JAK2 (Fig. 4B), thereby indicating that Tris DBA suppresses the activity of upstream kinases to modulate STAT3 functions.

\section{Tris DBA altered the expression of SHP2.}

We further determined the action of pervanadate on Tris DBA induced STAT3 inhibition in MM cells. The exposure to pervanadate reversed the Tris DBA induced STAT3 inhibition thereby indicating the involvement of protein tyrosine phosphatases (PTPs) (Fig. 4C). The action of Tris DBA on the cellular levels of major PTPs such as SHP1, SHP2, and PTP1B was measured. Interestingly, Tris DBA elevated the protein levels of SHP2 in a dosage- and time-dependent fashion (Fig. 4D). We also observed that treatment with Tris DBA increased the mRNA expression of SHP2, thus indicating that this protein may be regulated at the transcriptional level (Fig. 4E). However, a substantial change was not noted in the expression of SHP1 and PTP1B proteins (Fig. 4F).

\section{Depletion of SHP2 reverses the Tris DBA induced STAT3 inhibition.}

We transfected U266 cells with siRNA direct towards SHP2 to study the specificity of Tris DBA towards the STAT3 signaling pathway. The treatment of Tris DBA alone decreased STAT3 phosphorylation with a corresponding increase in SHP2. The deletion of SHP2 using siRNA resulted in the restoration of STAT3 phosphorylation and Tris DBA did not affect the STAT3 activation in SHP2-depleted cells (Fig. 4G). The cells treated with scrambled siRNA served as control. These results substantiated the role of SHP2 in mediating the STAT3 inhibitory actions of Tris DBA.

\section{Tris DBA altered the expression oncogenic proteins.}

We determined the action of Tris DBA on the expression of STAT3 driven proteins in MM (Fig. 5A) and HCC cells (Fig. 5B). Consistent with inhibition of STAT3 phosphorylation, Tris DBA downregulated the expression of oncogenic factors such as cyclin D1, Bcl-2, Mcl1, survivin with an upregulation of proapoptotic factor such as Bak protein in the tested cell lines. Furthermore, Tris DBA also promoted the cleavage of caspase-3 and PARP thus, indicating that cells are undergoing apoptosis (Figs. 5A and 5B).

\section{Tris DBA significantly modulated the migratory and invasive potential.}

Next, we measured the outcome of Tris DBA on cellular motility using invasion and migration assay systems. Tris DBA significantly suppressed the invasion of U266, RPMI-8226 (sensitive and resistant), and HCCLM3 cells in a concentration-dependent fashion (Fig. 6A). In addition, significant anti-migratory effects were observed in Tris DBA treated HCCLM3 cells (Fig. 6B). 


\section{Tris DBA did not display toxicity in preclinical studies.}

We next determined the sub-lethal doses of Tris DBA to perform in vivo tumor studies by measuring its toxicity. For this, male NCr nude mice were injected with Tris DBA $(25,50,100$, and $200 \mathrm{mg} / \mathrm{kg} / \mathrm{day})$ for eight days and experimental animals were regularly monitored. The mice-group which received DMSO $(0.1 \%)$ served as control. We did not observe significant changes in Tris DBA treated group of animals relative to the DMSO treated group in terms of body weight, water and feed consumption (Fig. 7). Notably, no significant alterations were observed in the activity of liver function marker enzymes such as alanine aminotransferase (ALT), and aspartate aminotransferase (AST) (Fig. 7), thereby suggesting that Tri DBA did not exhibit significant toxicity in tested animals.

\section{Tris DBA imparted antitumor effect in xenograft MM and orthotopic HCC mice models.}

We investigated the anticancer activity of Tris DBA in xenograft MM and the orthotopic HCC mice models. We subcutaneously implanted U266 cells to the right flank of six weeks old athymic nu/nu female mice to establish the xenograft tumor model. When tumor size attained $0.25 \mathrm{~cm}$, the mice were randomly divided into three groups $(n=6)$. The first group served as a control. The second and third groups received an intraperitoneal injection of Tris DBA (50 mg/kg, thrice a week; and $100 \mathrm{mg} / \mathrm{kg}$, thrice a week, respectively). At the end of four weeks, we observed a significant reduction in the volume of tumors in the $100 \mathrm{mg} / \mathrm{kg}$ treated group $(\mathrm{p}<0.01)($ Fig. $8 \mathrm{~A})$.

To verify the antitumor effect of Tris DBA on solid tumors, we next established an orthotopic HCC mouse model as described in methods and randomly distributed into three groups. The first group was used as control. The second and third group animals were intraperitoneally injected with Tris DBA $(50 \mathrm{mg} / \mathrm{kg}$, thrice a week; and $200 \mathrm{mg} / \mathrm{kg}$, thrice a week, respectively) for four weeks and the tumor burden was measured by a non-invasive technique of bioluminescence. Tris DBA significantly inhibited the tumor growth in both the groups $(p=0.0007)$ (Fig. 8B).

Tris DBA reduced the number of Ki67 + cells in tumor tissues from the xenograft MM mouse model.

We next processed the MM tumor tissue samples and performed immunohistochemical analysis to determine the proliferation index. Tumor tissues from Tris DBA treated mice displayed a marked reduction in the levels of Ki-67+ cells in a dose-dependent fashion (Fig. 9A). These results suggest that Tris DBA may also induce its antitumor activities by reducing the proliferation of cancer cells.

\section{Tris DBA repressed the activation of STAT3 signaling proteins in tumor tissues.}

We further analyzed the phosphorylation status of STAT3, JAK1, and JAK2 proteins in the tumor tissues of the xenograft MM mouse model. We observed a substantial reduction in the phosphorylation of STAT3, JAK1, and JAK2 in the tumor tissues of mice treated with $100 \mathrm{mg} / \mathrm{kg}$ of Tris DBA (Fig. 9B). These results establish that the lowering of tumor burden by Tris DBA could be due to the abrogation of the STAT3 signaling pathway. 


\section{Tris DBA modulated the expression of apoptosis-related proteins.}

We profiled the apoptosis-related proteins (Bcl-2, Bcl-xL, Survivin, PARP, and procaspase 3 ) in tumor tissues of the xenograft MM mouse model. We observed a marked decrease in Bcl-2, Bcl-xL, Survivin, fulllength PARP and procaspase-3 (Fig. 9C), thus indicating that Tris DBA can interfere with tumor development by inducing apoptosis in tumor cells.

\section{Discussion}

Aberrant activation of STAT3 is often observed in numerous human malignancies including MM, leukemias, lymphomas, breast, ovary, melanoma, glioma, head and neck, liver, and kidney cancers (5355). A few studies have demonstrated that deregulated STAT3 activation has not been observed in the normal tissues adjacent to tumors $(56,57)$. Additionally, the expression of STAT3 in tumor tissue serves as a predictive marker of prognosis and elevated STAT3 expression is associated with reduced prognostic ability and worse 3-year overall survival rate of human solid tumors (58-61). The constitutive activation of STAT3 can be controlled by various mechanisms including the loss of negative regulators (PTPs, SOCS, and PIAS), the formation of positive feedback mechanisms in the tumor microenvironment, elevated activity of upstream kinases, and somatic mutations in the STAT3 gene (62). For instance, elevated levels of IL- 6 is produced due to positive feedback mechanism in the tumor microenvironment, which may regulate the persistent phosphorylation of STAT3 signaling in human cancers (63-65).

Here we have evaluated the action of Tris DBA on the STAT3 signaling in HCC and MM cell-based studies and preclinical settings. Tris DBA was initially described as an inhibitor of $\mathrm{N}$-myristoyltransferase 1 and here we have comprehensively demonstrated its mode-of-action in two different tumor models. Tris DBA decreased the viability of both types of cancer cell lines (HCC and MM) and caused a pronounced inhibition of STAT3 activation. DNA undergoes fragmentation in the cells that are committed to apoptosis due to activation of caspases and thus they are known as hypodiploid cells, which are marked as subG1 cell population $(66,67)$. We observed an increased amount of subG1 cell population on treatment with Tris DBA in the flowcytometric analysis. The pro-apoptotic actions of drug were further confirmed by FITC conjugated Annexin-V-PI staining. To understand the underlying molecular mechanism of Tris DBA induced cytotoxicity, we evaluated the potential of Tris DBA to modify STAT3 phosphorylation in tumor cells and noticed a marked decline in the activation of STAT3 in all the tested cell lines.

An enormous number of studies have reported that STAT3 phosphorylation is essential for its translocation into the nucleus to express the target genes (68-71). In contrast to our findings, Kay and colleagues have demonstrated that Tris DBA did not significantly inhibit the activation of STAT3 in primary chronic lymphocytic leukemia B-cells (36). However, we hypothesized that the cytotoxic efficacy of Tris DBA could be due to the alteration of STAT3 signaling cascade. We next evaluated the effect of Tris DBA on IL-6 stimulated STAT3 phosphorylation. RPMI-8226 cells lack persistently activated form of STAT3 and IL- 6 can function to promote the activation of STAT3 signaling $(46,72)$. Bone marrow microenvironment contains several growth factors along with IL- 6 released by bone matrix, and 
osteoblasts creating an ideal for promotion of oncogenesis in various cancers including MM (73). Therefore, it is apt to have an inhibitor that can counteract the effect of IL-6 induced signaling. We observed a significant decrease in IL-6 driven STAT3 phosphorylation in MM cells.

Phosphorylation of STAT3 ${ }^{\mathrm{Y} 705}$ is crucial for its translocation to the nucleus to transcribe the downstream genes. The substitution of tyrosine with phenylalanine using site-directed mutagenesis can cause a substantial decrease of PIAS3-STAT3 complex and their nuclear localization despite EGF-induction (74). Tris DBA downregulated the levels of nuclear STAT3 and suppressed the DNA binding ability of nuclear STAT3. This could be due to the inhibition of STAT3 phosphorylation, which is essential for nuclear localization and target gene expression. We next determined the action of Tris DBA on the activation status of STAT3 upstream NRTKs such as JAK1, JAK2, and Src in MM and HCC cells. Phosphorylation of these kinases was inhibited in both types of cancer cells. Moreover, cytokine-induced activation of these NRTKs was also downregulated indicating that abrogation of STAT3 phosphorylation may be caused through the inhibition of upstream signaling partner proteins.

The phosphorylation state of STAT3 signaling proteins can also be regulated by a class of protein tyrosine phosphatases (PTPs) including SHP1, SHP2, PTPEC, PTP1B, and CD 45 (75-77). Therefore, we treated U266 cells with Tris DBA and pervanadate, a broad range phosphatase inhibitor and tested for the activation of STAT3. Interestingly, pervanadate treatment reversed the Tris DBA driven STAT3 inhibition. This indicated that PTP is involved in the Tris DBA induced STAT3 signaling inhibition. We again treated U266 cells with pervanadate and Tris DBA and analyzed the expression of major PTPs such as SHP1, SHP2, and PTP1B. We observed a substantial enhancement in the levels of both SHP2 mRNA and protein. The treatment of U266 cells with SHP2-directed siRNA resulted in the loss of SHP2 protein and further treatment of these cells with Tris DBA displayed no effect on STAT3 phosphorylation. However, further investigation may be required to understand the relationship between the expression of SHP2 and Tris DBA in MM cells. Not surprisingly, SHP2 suppressed the proliferation of esophageal squamous cell cancer by inhibiting STAT3 phosphorylation and depletion of SHP2 resulted in the attenuation of cisplatin sensitivity (78).

Bortezomib is the first proteasome inhibitor approved by the US FDA for the treatment of various malignancies (79). Li and colleagues reported that bortezomib can increase the expression of phosphorylated STAT3 and STAT3 in head and neck squamous cell carcinoma cells, which may contribute to a substantial reduction in its therapeutic efficacy, and co-treatment of bortezomib with a STAT3 inhibitor has been suggested for better anticancer effects (80). Guan and coworkers have further demonstrated that bortezomib resistance in MM may be partly mediated through activated STAT3 signaling (81). We tested the potency of Tris DBA towards bortezomib resistant RPMI-8226 cells. Tris DBA showed relatively less cytotoxicity compared to bortezomib resistant RPMI-8226 cells compared with bortezomib sensitive RPMI-8226 cells. Tris DBA also substantially decreased the levels of oncogenic proteins including Mcl-1, cyclin D1, and Bcl-2 in all the tested cell lines. During apoptosis, procaspase 3 undergoes cleavage on receiving signals from activated caspase 8 and 9 to induce apoptosis $(82,83)$. 
We observed a marked cleavage of procaspase-3 and downstream effector PARP indicating that cells are undergoing apoptosis on treatment with Tris DBA.

STAT3 can also regulate the activation of key transcription factors such as Snail and Twist which mediate epithelial-mesenchymal transition (EMT) process, and in turn, metastasis of cancer cells to the distant organs (84). IL-6 has been reported to activate STAT3 to promote EMT through induction of Snail expression in cancers $(85,86)$. Phosphorylated STAT3 also triggered the expression of the Twist gene to promote oncogenic functions (87). Next, we determined the efficacy of Tris DBA on invasion and migration of cancer cells. Tris DBA significantly blocked the cell motility in both the assay systems. The inhibition of migration and invasion could be due to suppression of the STAT3-dependent EMT process.

Interestingly, Tris DBA was observed to be non-toxic (up to $200 \mathrm{mg} / \mathrm{kg}$ body weight) in acute toxicity studies conducted in mice. Next, we examined its antitumor potential in a xenograft MM and an orthotopic HCC mouse models. Tris DBA displayed significant antitumor activities and it effectively abrogated the tumor progression in both the preclinical models. It has been also reported that Tris DBA did not induce local nor systemic toxicity at $40 \mathrm{mg} / \mathrm{kg} /$ day in the A375 melanoma mouse model (34). Importantly, Tris DBA downmodulated the expression of activated JAK1, JAK2 and STAT3, and Ki-67 in MM tumor tissues. These results are consistent with the outcome of our various cell-based assays as summarized in Fig. 10.

\section{Conclusions}

Tris DBA has been demonstrated as a potent inhibitor of STAT3 signaling cascade in MM and HCC cell lines and preclinical models for the first time. It can be reconciled that Tris DBA is a broad-spectrum anticancer agent and further research may be warranted to completely understand its off-targets and its possible potential clinical application.

\section{Abbreviations}

ALT: alanine aminotransferase; AST: aspartate aminotransferase; BSA: Bovine serum albumin; DAPI: 4',6Diamidino-2-phenylindole; DMEM: Dulbecco's modified eagle medium; DMSO: Dimethylsulfoxide; EGFR: Epidermal growth factor receptor; EMT: Epithelial-mesenchymal transition; FBS: Fetal bovine serum; FITC: Fluorescein isothiocyanate; FGFR: Fibroblast growth factor receptor; HCC: Hepatocellular carcinoma; HRP: Horseradish peroxidase; IL-6: Interleukin-6; JAK: Janus kinase; MAPK: Mitogen-activated protein kinase; MM: Multiple myeloma; MTT: 3-(4,5-Dimethylthiazol-2-yl)-2,5-diphenyltetrazolium bromide; NRTK: Non-receptor tyrosine kinase; PARP: Poly(ADP-ribose) polymerase; PBS: Phosphate buffered saline; PCR: Polymerase chain reaction; PIAS: Protein inhibitor of activated STAT; PI: Propidium iodide; PTP: Protein tyrosine phosphatase; PTP1B: Protein tyrosine phosphatase 1B; PTP $\varepsilon$ C: Protein tyrosine phosphatase $\varepsilon$ cytosolic; RPMI: Roswell park memorial institute; SHP1/2: Src homology 2 domain-containing protein tyrosine phosphatase 1/2; siRNA: Small interfering RNA; SOCS: Suppressor of cytokine signaling; STAT: Signal transducer and activator of transcription; Tris DBA: Tris(dibenzylideneacetone)dipalladium 0. 


\section{Declarations}

Acknowledgements

K.S.R., thanks to the University Grants Commission, New Delhi for providing the Basic Science Research faculty fellowship. K.S.R., and C.D.M., thanks DST-Promotion of University Research and Scientific (PURSE), Institution of Excellence, University of Mysore for providing laboratory facility.

\section{Authors Contributions}

Experiments performed by: L. A., J.H. L., A.D.

Study design, data interpretation: L.A., C.D.M., K.S.R., G.S., M.G., A.K., A.P.K.

Writing of the manuscript: L.A., C.D.M., S.R., K.S.R., G.S., K.S.A., H.K.M.,

\section{Funding}

This work was supported by NUHS Seed grant to Dr. Gautam Sethi. This work was also supported by a National Research Foundation of Korea (NRF) grant funded by the Korean government (MSIP) (NRF2017M3A9E4065333 and 2018R1D1A1B07042969).

\section{Availability of data and materials}

The data will be made available by the authors upon request.

\section{Ethics approval}

All the in vivo experiments were carried out as per the approved procedures by the SingHealth Institutional Animal Use and Care Committee and KHU Institutional Animal Care and Use Committee.

\section{Consent for publication}

All authors give consent for the submission and publication of the manuscript.

\section{Competing interests}

The authors declare that they have no competing interests.

\section{References}

1. Bray F, Ferlay J, Soerjomataram I, Siegel RL, Torre LA, Jemal A. Global cancer statistics 2018 : GLOBOCAN estimates of incidence and mortality worldwide for 36 cancers in 185 countries. CA: A Cancer Journal for Clinicians. 2018;68(6):394-424. 
2. Rajendran P, Li F, Manu KA, Shanmugam MK, Loo SY, Kumar AP, et al. Y-Tocotrienol is a novel inhibitor of constitutive and inducible STAT3 signalling pathway in human hepatocellular carcinoma: potential role as an antiproliferative, pro-apoptotic and chemosensitizing agent. British journal of pharmacology. 2011;163(2):283-98.

3. Balakumar P, Maung-U K, Jagadeesh G. Prevalence and prevention of cardiovascular disease and diabetes mellitus. Pharmacological Research. 2016;113:600-9.

4. Ghouri YA, Mian I, Rowe JH. Review of hepatocellular carcinoma: Epidemiology, etiology, and carcinogenesis. J Carcinog. 2017;16:1-.

5. Sarveazad A, Agah S, Babahajian A, Amini N, Bahardoust M. Predictors of 5 year survival rate in hepatocellular carcinoma patients. J Res Med Sci. 2019;24:86-.

6. Mohan CD, Bharathkumar H, Bulusu KC, Pandey V, Rangappa S, Fuchs JE, et al. Development of a novel azaspirane that targets the Janus kinase-signal transducer and activator of transcription (STAT) pathway in hepatocellular carcinoma in vitro and in vivo. The Journal of biological chemistry. 2014;289(49):34296-307.

7. Rajendran P, Li F, Shanmugam MK, Vali S, Abbasi T, Kapoor S, et al. Honokiol inhibits signal transducer and activator of transcription-3 signaling, proliferation, and survival of hepatocellular carcinoma cells via the protein tyrosine phosphatase SHP-1. Journal of cellular physiology. 2012;227(5):2184-95.

8. Swamy SG, Kameshwar VH, Shubha PB, Looi CY, Shanmugam MK, Arfuso F, et al. Targeting multiple oncogenic pathways for the treatment of hepatocellular carcinoma. Targeted oncology. 2017;12(1):110.

9. Hu J, Hu WX. Targeting signaling pathways in multiple myeloma: Pathogenesis and implication for treatments. Cancer letters. 2018;414:214-21.

10. Arora L, Kumar AP, Arfuso F, Chng WJ, Sethi G. The Role of Signal Transducer and Activator of Transcription 3 (STAT3) and Its Targeted Inhibition in Hematological Malignancies. Cancers (Basel). 2018;10(9):327.

11. Collins CD. Multiple myeloma. Cancer Imaging. 2010;10(1):20-31.

12. Kannaiyan R, Hay HS, Rajendran P, Li F, Shanmugam MK, Vali S, et al. Celastrol inhibits proliferation and induces chemosensitization through down-regulation of NF-KB and STAT3 regulated gene products in multiple myeloma cells. British journal of pharmacology. 2011;164(5):1506-21.

13. Lee JH, Kim C, Lee J, Um JY, Sethi G, Ahn KS. Arctiin is a pharmacological inhibitor of STAT3 phosphorylation at tyrosine 705 residue and potentiates bortezomib-induced apoptotic and antiangiogenic effects in human multiple myeloma cells. Phytomedicine : international journal of phytotherapy and phytopharmacology. 2019;55:282-92.

14. Lee M, Hirpara JL, Eu JQ, Sethi G, Wang L, Goh BC, et al. Targeting STAT3 and oxidative phosphorylation in oncogene-addicted tumors. Redox biology. 2019;25:101073.

15. Lee JH, Kim C, Ko J-H, Jung YY, Jung SH, Kim E, et al. Casticin inhibits growth and enhances ionizing radiation-induced apoptosis through the suppression of STAT3 signaling cascade. Journal of 
cellular biochemistry. 2019;120(6):9787-98.

16. Lee JH, Kim C, Baek SH, Ko JH, Lee SG, Yang WM, et al. Capsazepine inhibits JAK/STAT3 signaling, tumor growth, and cell survival in prostate cancer. Oncotarget. 2017;8(11):17700-11.

17. Lee JH, Kim C, Lee S-G, Sethi G, Ahn KS. Ophiopogonin D, a Steroidal Glycoside Abrogates STAT3 Signaling Cascade and Exhibits Anti-Cancer Activity by Causing GSH/GSSG Imbalance in Lung Carcinoma. Cancers. 2018;10(11):427.

18. Siveen KS, Sikka S, Surana R, Dai X, Zhang J, Kumar AP, et al. Targeting the STAT3 signaling pathway in cancer: role of synthetic and natural inhibitors. Biochimica et biophysica acta. 2014;1845(2):136-54.

19. Wong ALA, Hirpara JL, Pervaiz S, Eu JQ, Sethi G, Goh BC. Do STAT3 inhibitors have potential in the future for cancer therapy? Expert opinion on investigational drugs. 2017;26(8):883-7.

20. Baek SH, Ko JH, Lee H, Jung J, Kong M, Lee JW, et al. Resveratrol inhibits STAT3 signaling pathway through the induction of SOCS-1: Role in apoptosis induction and radiosensitization in head and neck tumor cells. Phytomedicine : international journal of phytotherapy and phytopharmacology. 2016;23(5):566-77.

21. Baek SH, Lee JH, Kim C, Ko J-H, Ryu S-H, Lee S-G, et al. Ginkgolic Acid C 17:1, Derived from Ginkgo biloba Leaves, Suppresses Constitutive and Inducible STAT3 Activation through Induction of PTEN and SHP-1 Tyrosine Phosphatase. Molecules. 2017;22(2):276.

22. Chai EZ, Siveen KS, Shanmugam MK, Arfuso F, Sethi G. Analysis of the intricate relationship between chronic inflammation and cancer. The Biochemical journal. 2015;468(1):1-15.

23. Loh CY, Arya A, Naema AF, Wong WF, Sethi G, Looi CY. Signal Transducer and Activator of Transcription (STATs) Proteins in Cancer and Inflammation: Functions and Therapeutic Implication. Frontiers in oncology. 2019;9:48.

24. Mohan CD, Rangappa S, Preetham HD, Chandra Nayak S, Gupta VK, Basappa S, et al. Targeting STAT3 signaling pathway in cancer by agents derived from Mother Nature. Seminars in cancer biology. 2020.

25. Baburajeev CP, Mohan CD, Patil GS, Rangappa S, Pandey V, Sebastian A, et al. Nano-cuprous oxide catalyzed one-pot synthesis of a carbazole-based STAT3 inhibitor: a facile approach via intramolecular C-N bond formation reactions. RSC Advances. 2016;6(43):36775-85.

26. Lee JH, Mohan CD, Basappa S, Rangappa S, Chinnathambi A, Alahmadi TA, et al. The IkB Kinase Inhibitor ACHP Targets the STAT3 Signaling Pathway in Human Non-Small Cell Lung Carcinoma Cells. Biomolecules. 2019;9(12):875.

27. Lee JH, Rangappa S, Mohan CD, Basappa, Sethi G, Lin Z-X, et al. Brusatol, a Nrf2 Inhibitor Targets STAT3 Signaling Cascade in Head and Neck Squamous Cell Carcinoma. Biomolecules. 2019;9(10):550.

28. Chai EZ, Shanmugam MK, Arfuso F, Dharmarajan A, Wang C, Kumar AP, et al. Targeting transcription factor STAT3 for cancer prevention and therapy. Pharmacology \& therapeutics. 2016;162:86-97. 
29. Tan SM, Li F, Rajendran P, Kumar AP, Hui KM, Sethi G. Identification of beta-escin as a novel inhibitor of signal transducer and activator of transcription 3/Janus-activated kinase 2 signaling pathway that suppresses proliferation and induces apoptosis in human hepatocellular carcinoma cells. The Journal of pharmacology and experimental therapeutics. 2010;334(1):285-93.

30. Lee JH, Kim C, Sethi G, Ahn KS. Brassinin inhibits STAT3 signaling pathway through modulation of PIAS-3 and SOCS-3 expression and sensitizes human lung cancer xenograft in nude mice to paclitaxel. Oncotarget. 2015;6(8):6386-405.

31. Zhang J, Ahn KS, Kim C, Shanmugam MK, Siveen KS, Arfuso F, et al. Nimbolide-Induced Oxidative Stress Abrogates STAT3 Signaling Cascade and Inhibits Tumor Growth in Transgenic Adenocarcinoma of Mouse Prostate Model. Antioxidants \& redox signaling. 2016;24(11):575-89.

32. Rajendran P, Li F, Shanmugam MK, Kannaiyan R, Goh JN, Wong KF, et al. Celastrol suppresses growth and induces apoptosis of human hepatocellular carcinoma through the modulation of STAT3/JAK2 signaling cascade in vitro and in vivo. Cancer prevention research (Philadelphia, Pa). 2012;5(4):631-43.

33. Pierpont CG, Mazza MC. Crystal and molecular structure of tris(dibenzylideneacetone)dipalladium(0). Inorganic Chemistry. 1974;13(8):1891-5.

34. Bhandarkar SS, Bromberg J, Carrillo C, Selvakumar P, Sharma RK, Perry BN, et al. Tris (dibenzylideneacetone) dipalladium, a N-myristoyltransferase-1 inhibitor, is effective against melanoma growth in vitro and in vivo. Clin Cancer Res. 2008;14(18):5743-8.

35. de la Puente P, Azab F, Muz B, Luderer M, Arbiser J, Azab AK. Tris DBA palladium overcomes hypoxiamediated drug resistance in multiple myeloma. Leukemia \& lymphoma. 2016;57(7):1677-86.

36. Kay NE, Sassoon T, Secreto C, Sinha S, Shanafelt TD, Ghosh AK, et al. Tris (dibenzylideneacetone) dipalladium: a small-molecule palladium complex is effective in inducing apoptosis in chronic lymphocytic leukemia B-cells. Leukemia \& lymphoma. 2016;57(10):2409-16.

37. Diaz B, Ostapoff KT, Toombs JE, Lo J, Bonner MY, Curatolo A, et al. Tris DBA palladium is highly effective against growth and metastasis of pancreatic cancer in an orthotopic model. Oncotarget. 2016;7(32):51569-80.

38. Rakesh KS, Jagadish S, Swaroop TR, Mohan CD, Ashwini N, Harsha KB, et al. Anti-Cancer Activity of 2,4-Disubstituted Thiophene Derivatives: Dual Inhibitors of Lipoxygenase and Cyclooxygenase. Medicinal chemistry (Shariqah (United Arab Emirates)). 2015;11(5):462-72.

39. Rakesh KS, Jagadish S, Balaji KS, Zameer F, Swaroop TR, Mohan CD, et al. 3,5-Disubstituted Isoxazole Derivatives: Potential Inhibitors of Inflammation and Cancer. Inflammation. 2016;39(1):269-80.

40. Keerthy HK, Garg M, Mohan CD, Madan V, Kanojia D, Shobith R, et al. Synthesis and characterization of novel 2-amino-chromene-nitriles that target Bcl-2 in acute myeloid leukemia cell lines. PLoS One. 2014;9(9):e107118.

41. Mohan CD, Anilkumar NC, Rangappa S, Shanmugam MK, Mishra S, Chinnathambi A, et al. Novel 1,3,4-0xadiazole Induces Anticancer Activity by Targeting NF-KB in Hepatocellular Carcinoma Cells. 
Frontiers in oncology. 2018;8:42.

42. Pandey V, Wang B, Mohan CD, Raquib AR, Rangappa S, Srinivasa V, et al. Discovery of a smallmolecule inhibitor of specific serine residue BAD phosphorylation. Proceedings of the National Academy of Sciences of the United States of America. 2018;115(44):E10505-e14.

43. Keerthy HK, Mohan CD, Sivaraman Siveen K, Fuchs JE, Rangappa S, Sundaram MS, et al. Novel synthetic biscoumarins target tumor necrosis factor-a in hepatocellular carcinoma in vitro and in vivo. The Journal of biological chemistry. 2014;289(46):31879-90.

44. Bharathkumar H, Paricharak S, Dinesh KR, Siveen KS, Fuchs JE, Rangappa S, et al. Synthesis, biological evaluation and in silico and in vitro mode-of-action analysis of novel dihydropyrimidones targeting PPAR-y. RSC Advances. 2014;4(85):45143-6.

45. Rajendran P, Li F, Shanmugam MK, Kannaiyan R, Goh JN, Wong KF, et al. Celastrol Suppresses Growth and Induces Apoptosis of Human Hepatocellular Carcinoma through the Modulation of STAT3/JAK2 Signaling Cascade $<$ em $>$ In Vitro $</$ em $>$ and $<$ em $>$ In Vivo $</$ em $>$. Cancer Prevention Research. 2012;5(4):631-43.

46. Kim SM, Lee JH, Sethi G, Kim C, Baek SH, Nam D, et al. Bergamottin, a natural furanocoumarin obtained from grapefruit juice induces chemosensitization and apoptosis through the inhibition of STAT3 signaling pathway in tumor cells. Cancer letters. 2014;354(1):153-63.

47. Baburajeev CP, Mohan CD, Rangappa S, Mason DJ, Fuchs JE, Bender A, et al. Identification of Novel Class of Triazolo-Thiadiazoles as Potent Inhibitors of Human Heparanase and their Anticancer Activity. BMC cancer. 2017;17(1):235.

48. Sebastian A, Pandey V, Mohan CD, Chia YT, Rangappa S, Mathai J, et al. Novel Adamantanyl-Based Thiadiazolyl Pyrazoles Targeting EGFR in Triple-Negative Breast Cancer. ACS Omega. 2016;1(6):1412-24.

49. Neelgundmath M, Dinesh KR, Mohan CD, Li F, Dai X, Siveen KS, et al. Novel synthetic coumarins that targets NF-KB in Hepatocellular carcinoma. Bioorganic \& medicinal chemistry letters. 2015;25(4):8937.

50. Baburajeev CP, Dhananjaya Mohan C, Ananda H, Rangappa S, Fuchs JE, Jagadish S, et al. Development of Novel Triazolo-Thiadiazoles from Heterogeneous "Green” Catalysis as Protein Tyrosine Phosphatase 1B Inhibitors. Scientific Reports. 2015;5(1):14195.

51. Dai X, Wang L, Deivasigamni A, Looi CY, Karthikeyan C, Trivedi P, et al. A novel benzimidazole derivative, MBIC inhibits tumor growth and promotes apoptosis via activation of ROS-dependent JNK signaling pathway in hepatocellular carcinoma. Oncotarget. 2017;8(8):12831-42.

52. Mohan CD, Bharathkumar H, Dukanya, Rangappa S, Shanmugam MK, Chinnathambi A, et al. NSubstituted Pyrido-1,4-Oxazin-3-Ones Induce Apoptosis of Hepatocellular Carcinoma Cells by Targeting NF-KB Signaling Pathway. Frontiers in pharmacology. 2018;9:1125.

53. Shanmugam MK, Rajendran P, Li F, Kim C, Sikka S, Siveen KS, et al. Abrogation of STAT3 signaling cascade by zerumbone inhibits proliferation and induces apoptosis in renal cell carcinoma xenograft mouse model. Molecular carcinogenesis. 2015;54(10):971-85. 
54. Sulaiman NB, Mohan CD, Basappa S, Pandey V, Rangappa S, Bharathkumar H, et al. An azaspirane derivative suppresses growth and induces apoptosis of ER-positive and ER-negative breast cancer cells through the modulation of JAK2/STAT3 signaling pathway. International journal of oncology. 2016;49(3):1221-9.

55. Jung YY, Lee JH, Nam D, Narula AS, Namjoshi OA, Blough BE, et al. Anti-myeloma Effects of Icariin Are Mediated Through the Attenuation of JAK/STAT3-Dependent Signaling Cascade. Frontiers in pharmacology. 2018;9:531.

56. Guo C, Yang G, Khun K, Kong X, Levy D, Lee P, et al. Activation of Stat3 in renal tumors. Am J Transl Res. 2009;1(3):283-90.

57. Lo H-W, Cao X, Zhu H, Ali-Osman F. Constitutively activated STAT3 frequently coexpresses with epidermal growth factor receptor in high-grade gliomas and targeting STAT3 sensitizes them to Iressa and alkylators. Clin Cancer Res. 2008;14(19):6042-54.

58. Wu P, Wu D, Zhao L, Huang L, Shen G, Huang J, et al. Prognostic role of STAT3 in solid tumors: a systematic review and meta-analysis. Oncotarget. 2016;7(15):19863-83.

59. Liu Y, Huang J, Li W, Chen Y, Liu X, Wang J. Meta-analysis of STAT3 and phospho-STAT3 expression and survival of patients with breast cancer. Oncotarget. 2018;9(16):13060-7.

60. Tong M, Wang J, Jiang N, Pan H, Li D. Correlation between p-STAT3 overexpression and prognosis in lung cancer: A systematic review and meta-analysis. PLOS ONE. 2017;12(8):e0182282.

61. Ji K, Zhang M, Chu Q, Gan Y, Ren H, Zhang L, et al. The Role of p-STAT3 as a Prognostic and Clinicopathological Marker in Colorectal Cancer: A Systematic Review and Meta-Analysis. PLOS ONE. 2016;11(8):e0160125.

62. Shanmugam MK, Lee JH, Chai EZ, Kanchi MM, Kar S, Arfuso F, et al. Cancer prevention and therapy through the modulation of transcription factors by bioactive natural compounds. Seminars in cancer biology. 2016;40-41:35-47.

63. Chonov DC, Ignatova MMK, Ananiev JR, Gulubova MV. IL-6 Activities in the Tumour Microenvironment. Part 1. Open Access Maced J Med Sci. 2019;7(14):2391-8.

64. Kim C, Lee SG, Yang WM, Arfuso F, Um JY, Kumar AP, et al. Formononetin-induced oxidative stress abrogates the activation of STAT3/5 signaling axis and suppresses the tumor growth in multiple myeloma preclinical model. Cancer letters. 2018;431:123-41.

65. Ko H, Lee HJ, Kim SH, Kim T, Han TY, Suh Y-G, et al. Novel Galiellalactone Analogues Can Target STAT3 Phosphorylation and Cause Apoptosis in Triple-Negative Breast Cancer. Biomolecules. 2019;9(5).

66. Roopashree R, Mohan CD, Swaroop TR, Jagadish S, Raghava B, Balaji KS, et al. Novel synthetic bisbenzimidazole that targets angiogenesis in Ehrlich ascites carcinoma bearing mice. Bioorganic \& medicinal chemistry letters. 2015;25(12):2589-93.

67. Nirvanappa AC, Mohan CD, Rangappa S, Ananda H, Sukhorukov AY, Shanmugam MK, et al. Novel Synthetic Oxazines Target NF-KB in Colon Cancer In Vitro and Inflammatory Bowel Disease In Vivo. PLoS One. 2016;11(9):e0163209. 
68. Dai X, Ahn KS, Kim C, Siveen KS, Ong TH, Shanmugam MK, et al. Ascochlorin, an isoprenoid antibiotic inhibits growth and invasion of hepatocellular carcinoma by targeting STAT3 signaling cascade through the induction of PIAS3. Molecular oncology. 2015;9(4):818-33.

69. Lee JH, Kim C, Kim SH, Sethi G, Ahn KS. Farnesol inhibits tumor growth and enhances the anticancer effects of bortezomib in multiple myeloma xenograft mouse model through the modulation of STAT3 signaling pathway. Cancer letters. 2015;360(2):280-93.

70. Subramaniam A, Shanmugam MK, Ong TH, Li F, Perumal E, Chen L, et al. Emodin inhibits growth and induces apoptosis in an orthotopic hepatocellular carcinoma model by blocking activation of STAT3. British journal of pharmacology. 2013;170(4):807-21.

71. Subramaniam A, Shanmugam MK, Perumal E, Li F, Nachiyappan A, Dai X, et al. Potential role of signal transducer and activator of transcription (STAT)3 signaling pathway in inflammation, survival, proliferation and invasion of hepatocellular carcinoma. Biochimica et biophysica acta. 2013;1835(1):46-60.

72. Sethi G, Chatterjee S, Rajendran P, Li F, Shanmugam MK, Wong KF, et al. Inhibition of STAT3 dimerization and acetylation by garcinol suppresses the growth of human hepatocellular carcinoma in vitro and in vivo. Molecular cancer. 2014;13:66.

73. Harmer D, Falank C, Reagan MR. Interleukin-6 Interweaves the Bone Marrow Microenvironment, Bone Loss, and Multiple Myeloma. Front Endocrinol (Lausanne). 2019;9:788-.

74. Dabir S, Kluge A, Dowlati A. The association and nuclear translocation of the PIAS3-STAT3 complex is ligand and time dependent. Mol Cancer Res. 2009;7(11):1854-60.

75. Zhang H-F, Lai R. STAT3 in Cancer-Friend or Foe? Cancers. 2014;6(3):1408-40.

76. Johnston PA, Grandis JR. STAT3 signaling: anticancer strategies and challenges. Molecular interventions. 2011;11(1):18-26.

77. Li F, Rajendran P, Sethi G. Thymoquinone inhibits proliferation, induces apoptosis and chemosensitizes human multiple myeloma cells through suppression of signal transducer and activator of transcription 3 activation pathway. British journal of pharmacology. 2010;161(3):541-54.

78. Qi C, Han T, Tang H, Huang K, Min J, Li J, et al. Shp2 Inhibits Proliferation of Esophageal Squamous Cell Cancer via Dephosphorylation of Stat3. Int J Mol Sci. 2017;18(1):134.

79. Chen D, Frezza M, Schmitt S, Kanwar J, Dou QP. Bortezomib as the first proteasome inhibitor anticancer drug: current status and future perspectives. Curr Cancer Drug Targets. 2011;11(3):23953.

80. Li C, Zang Y, Sen M, Leeman-Neill RJ, Man DS, Grandis JR, et al. Bortezomib up-regulates activated signal transducer and activator of transcription-3 and synergizes with inhibitors of signal transducer and activator of transcription-3 to promote head and neck squamous cell carcinoma cell death. Molecular cancer therapeutics. 2009;8(8):2211-20.

81. Guan M, Zhu L, Somlo G, Hughes A, Zhou B, Yen Y. Bortezomib therapeutic effect is associated with expression of FGFR3 in multiple myeloma cells. Anticancer research. 2009;29(1):1-9. 
82. Mohan CD, Srinivasa V, Rangappa S, Mervin L, Mohan S, Paricharak S, et al. TrisubstitutedImidazoles Induce Apoptosis in Human Breast Cancer Cells by Targeting the Oncogenic PI3K/Akt/mTOR Signaling Pathway. PLoS One. 2016;11(4):e0153155.

83. Anusha S, Mohan CD, Ananda H, Baburajeev CP, Rangappa S, Mathai J, et al. Adamantyl-tetheredbiphenylic compounds induce apoptosis in cancer cells by targeting $\mathrm{Bcl}$ homologs. Bioorganic \& medicinal chemistry letters. 2016;26(3):1056-60.

84. Yeung KT, Yang J. Epithelial-mesenchymal transition in tumor metastasis. Molecular oncology. 2017;11(1):28-39.

85. Yadav A, Kumar B, Datta J, Teknos TN, Kumar P. IL-6 promotes head and neck tumor metastasis by inducing epithelial-mesenchymal transition via the JAK-STAT3-SNAIL signaling pathway. Mol Cancer Res. 2011;9(12):1658-67.

86. Lamouille S, Xu J, Derynck R. Molecular mechanisms of epithelial-mesenchymal transition. Nature reviews Molecular cell biology. 2014;15(3):178-96.

87. Cheng GZ, Zhang WZ, Sun M, Wang Q, Coppola D, Mansour M, et al. Twist is transcriptionally induced by activation of STAT3 and mediates STAT3 oncogenic function. The Journal of biological chemistry. 2008;283(21):14665-73.

\section{Figures}


<smiles>O=C(/C=C/c1ccccc1)/C=C/c1ccccc1</smiles>
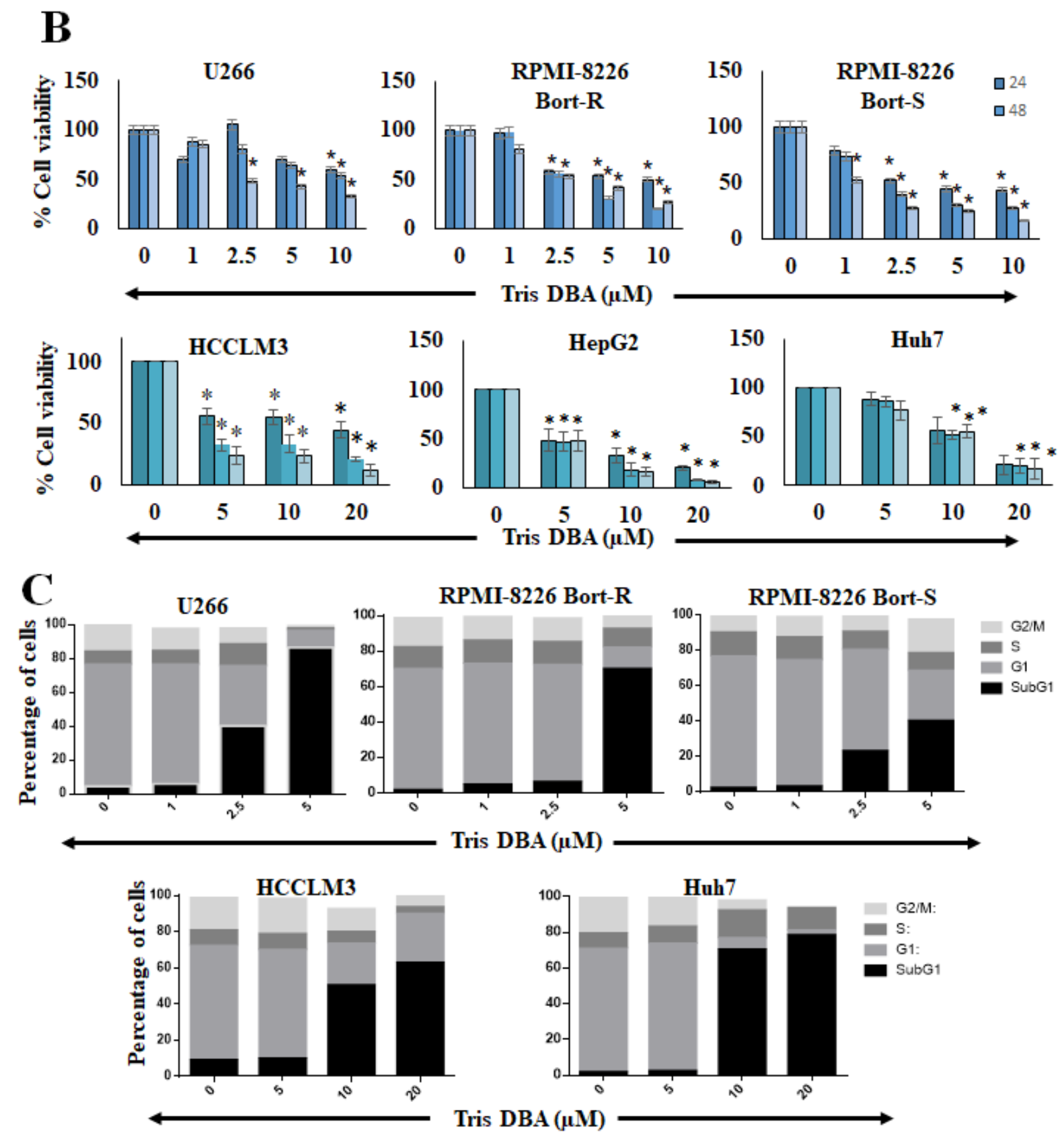

\section{Figure 1}

Tris DBA decreases the cell viability. (A) The structure of Tris DBA. (B) The efficacy of Tris DBA on the viability of MM (U266, and RPMI-8226) and HCC (HCCLM3, HepG2, and Huh7) cells was examined by MTT assay at different time-points and concentrations. Bars indicate standard deviation; ${ }^{*} p<0.05$ versus no treatment (no treatment is $0.1 \%$ DMSO). The experiments were repeated thrice. (C) MM (U266, and 
RPMI-8226) and HCC (HCCLM3, HepG2, and Huh7) cells were incubated with Tris DBA and analyzed using flow cytometry to determine the distribution of cells across the cell cycle.
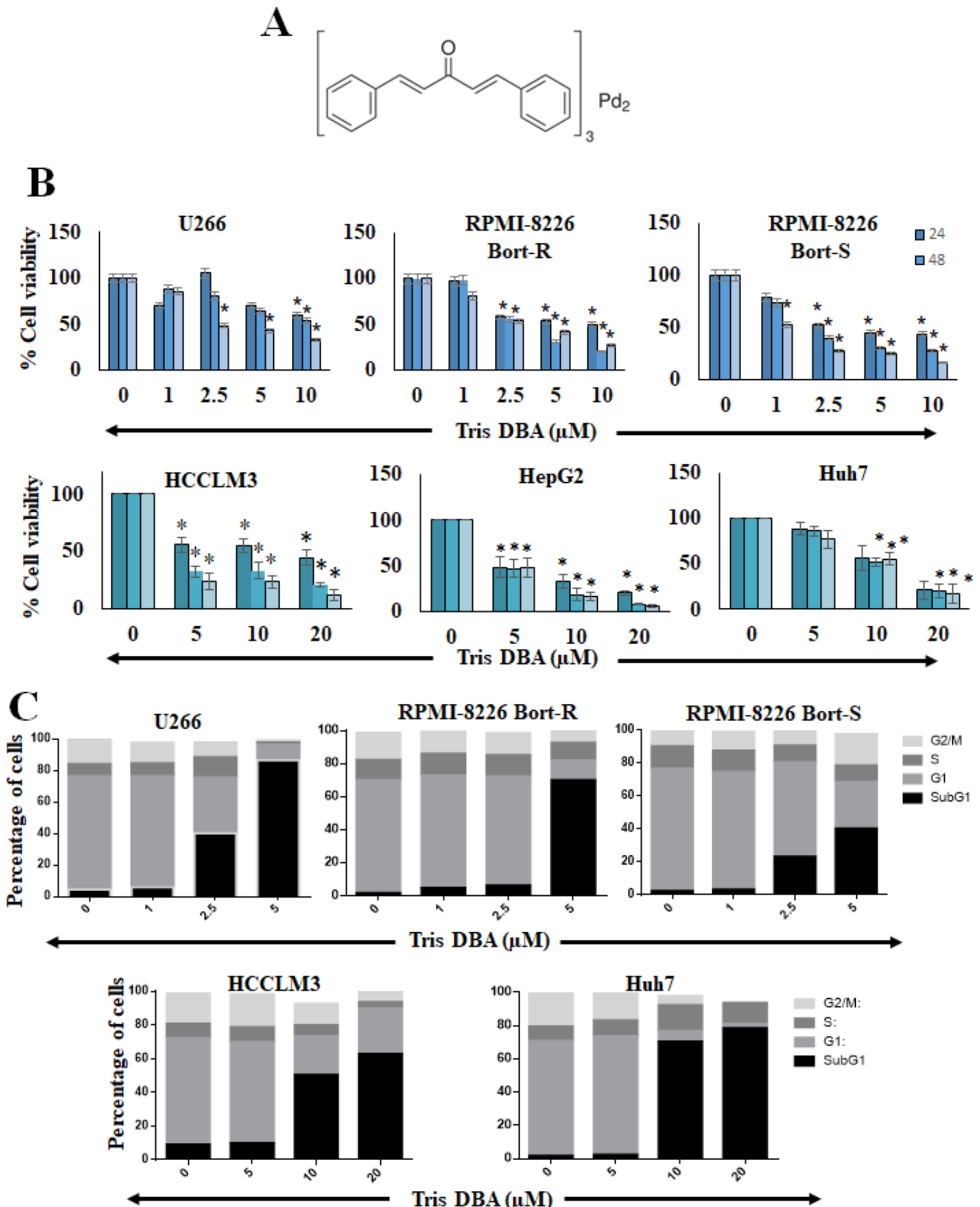

Huh 7

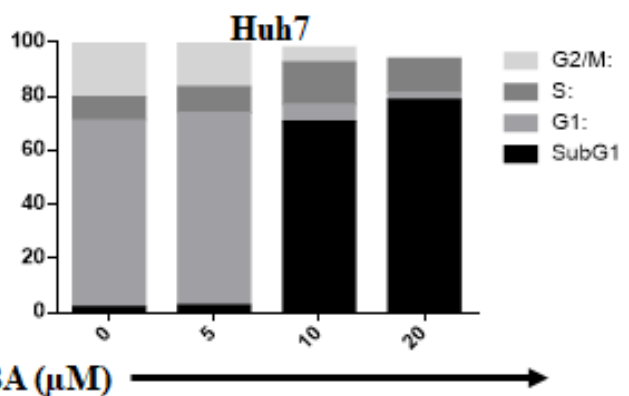

Figure 1

Tris DBA decreases the cell viability. (A) The structure of Tris DBA. (B) The efficacy of Tris DBA on the viability of MM (U266, and RPMI-8226) and HCC (HCCLM3, HepG2, and Huh7) cells was examined by MTT assay at different time-points and concentrations. Bars indicate standard deviation; ${ }^{*} p<0.05$ versus 
no treatment (no treatment is $0.1 \%$ DMSO). The experiments were repeated thrice. (C) MM (U266, and RPMI-8226) and HCC (HCCLM3, HepG2, and Huh7) cells were incubated with Tris DBA and analyzed using flow cytometry to determine the distribution of cells across the cell cycle.
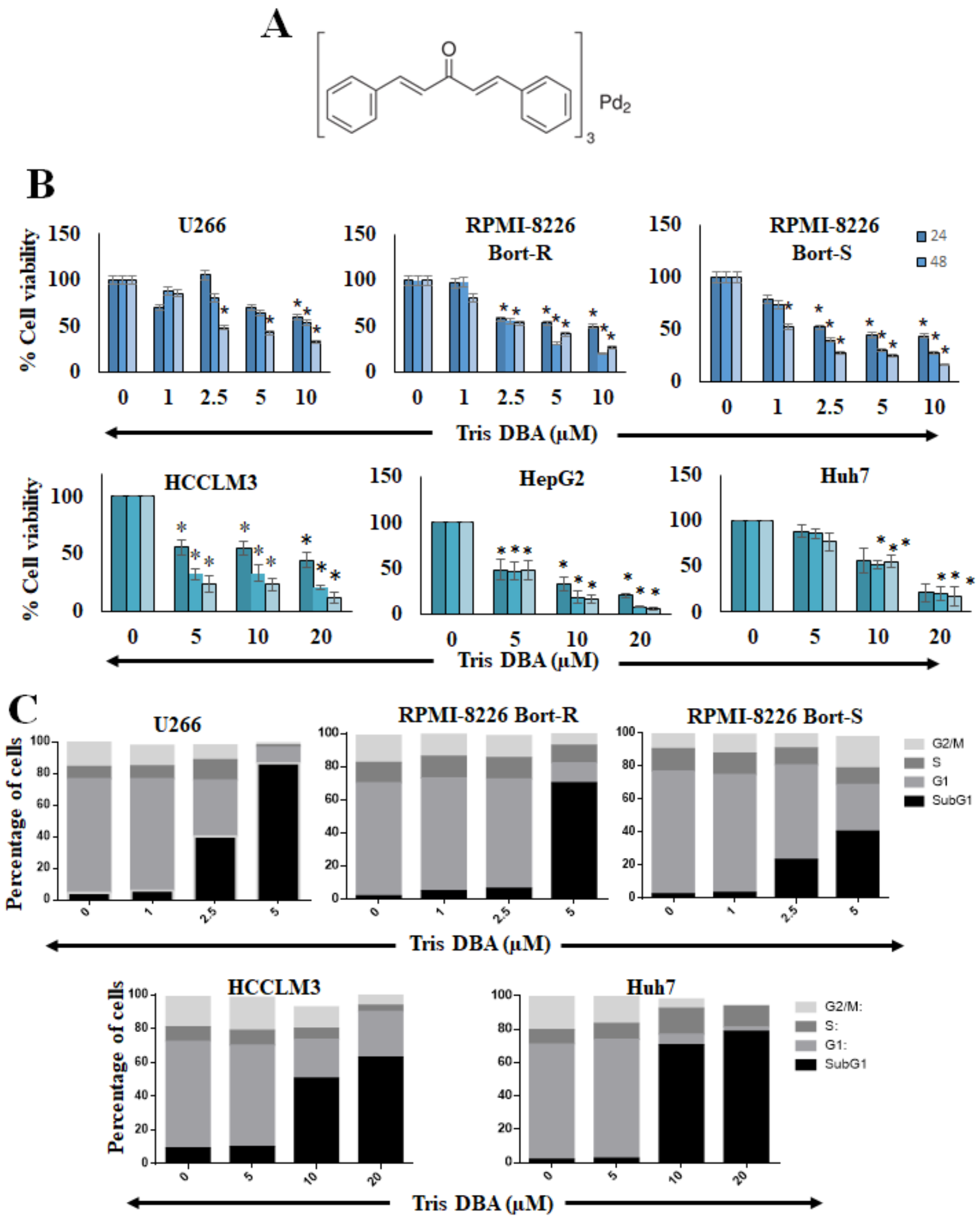

Tris DBA ( $\mu M)$

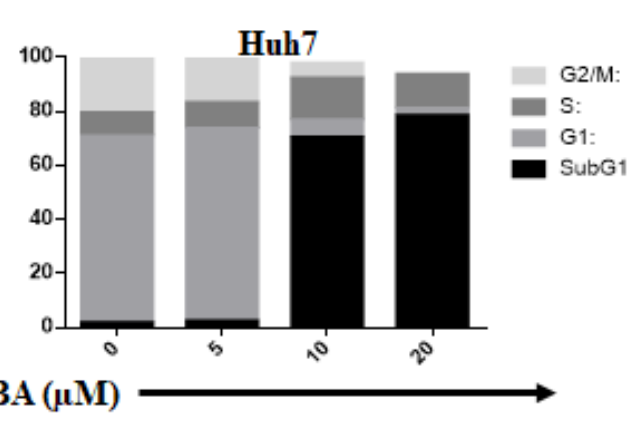

Figure 1

Tris DBA decreases the cell viability. (A) The structure of Tris DBA. (B) The efficacy of Tris DBA on the viability of MM (U266, and RPMI-8226) and HCC (HCCLM3, HepG2, and Huh7) cells was examined by 
MTT assay at different time-points and concentrations. Bars indicate standard deviation; ${ }^{*} p<0.05$ versus no treatment (no treatment is $0.1 \%$ DMSO). The experiments were repeated thrice. (C) MM (U266, and RPMI-8226) and HCC (HCCLM3, HepG2, and Huh7) cells were incubated with Tris DBA and analyzed using flow cytometry to determine the distribution of cells across the cell cycle.
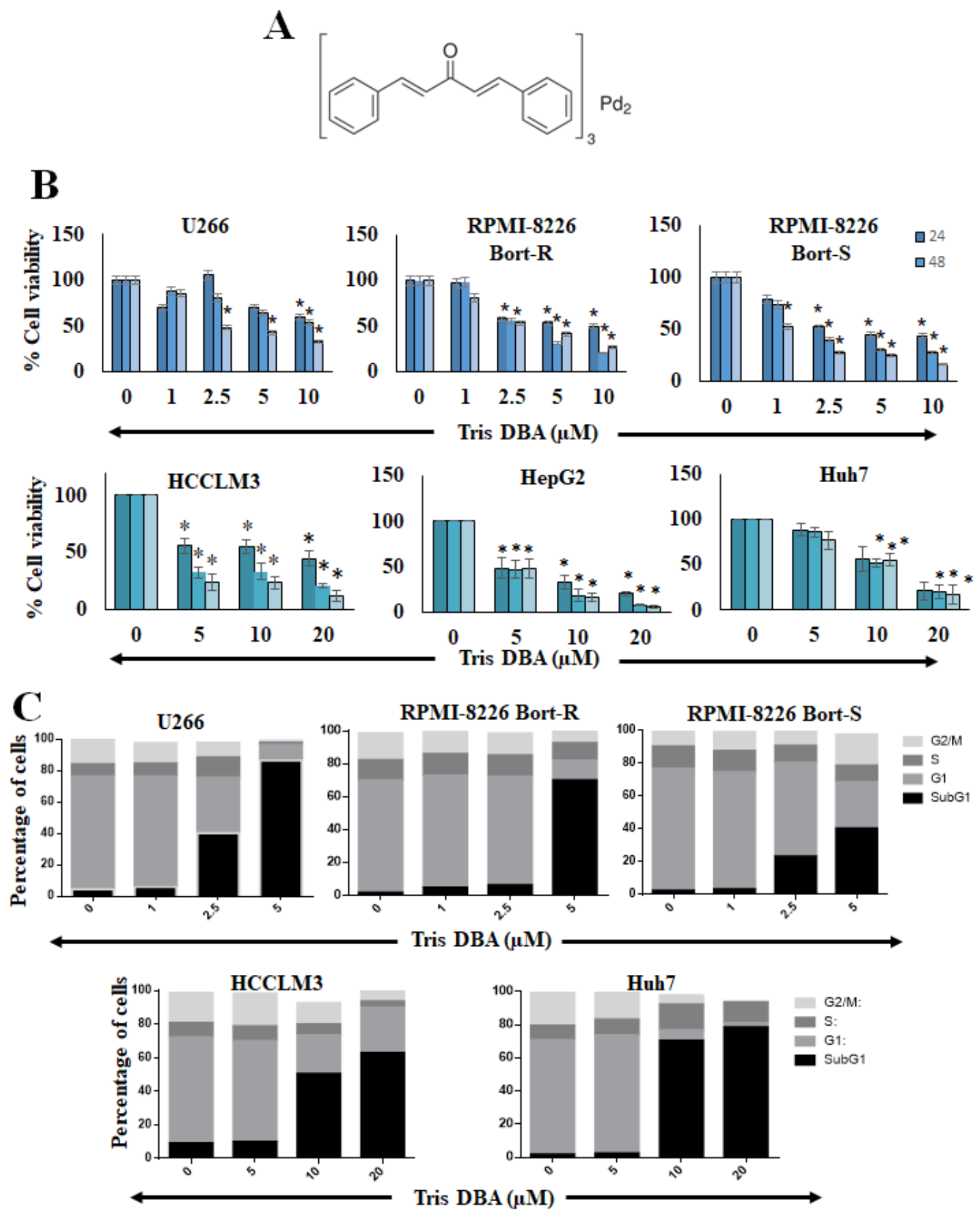

Tris DBA $(\mu \mathrm{M})$

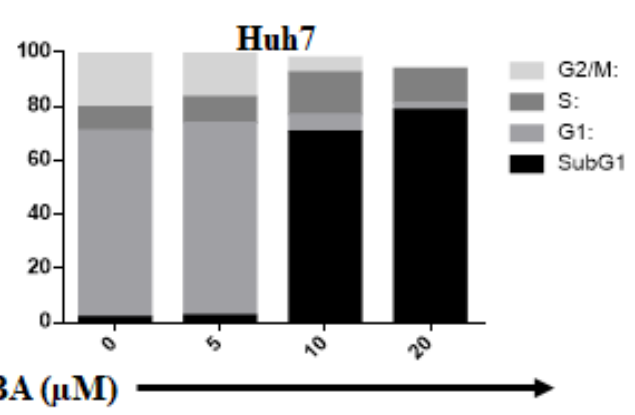

Figure 1 
Tris DBA decreases the cell viability. (A) The structure of Tris DBA. (B) The efficacy of Tris DBA on the viability of MM (U266, and RPMI-8226) and HCC (HCCLM3, HepG2, and Huh7) cells was examined by MTT assay at different time-points and concentrations. Bars indicate standard deviation; ${ }^{*} p<0.05$ versus no treatment (no treatment is $0.1 \%$ DMSO). The experiments were repeated thrice. (C) MM (U266, and RPMI-8226) and HCC (HCCLM3, HepG2, and Huh7) cells were incubated with Tris DBA and analyzed using flow cytometry to determine the distribution of cells across the cell cycle.
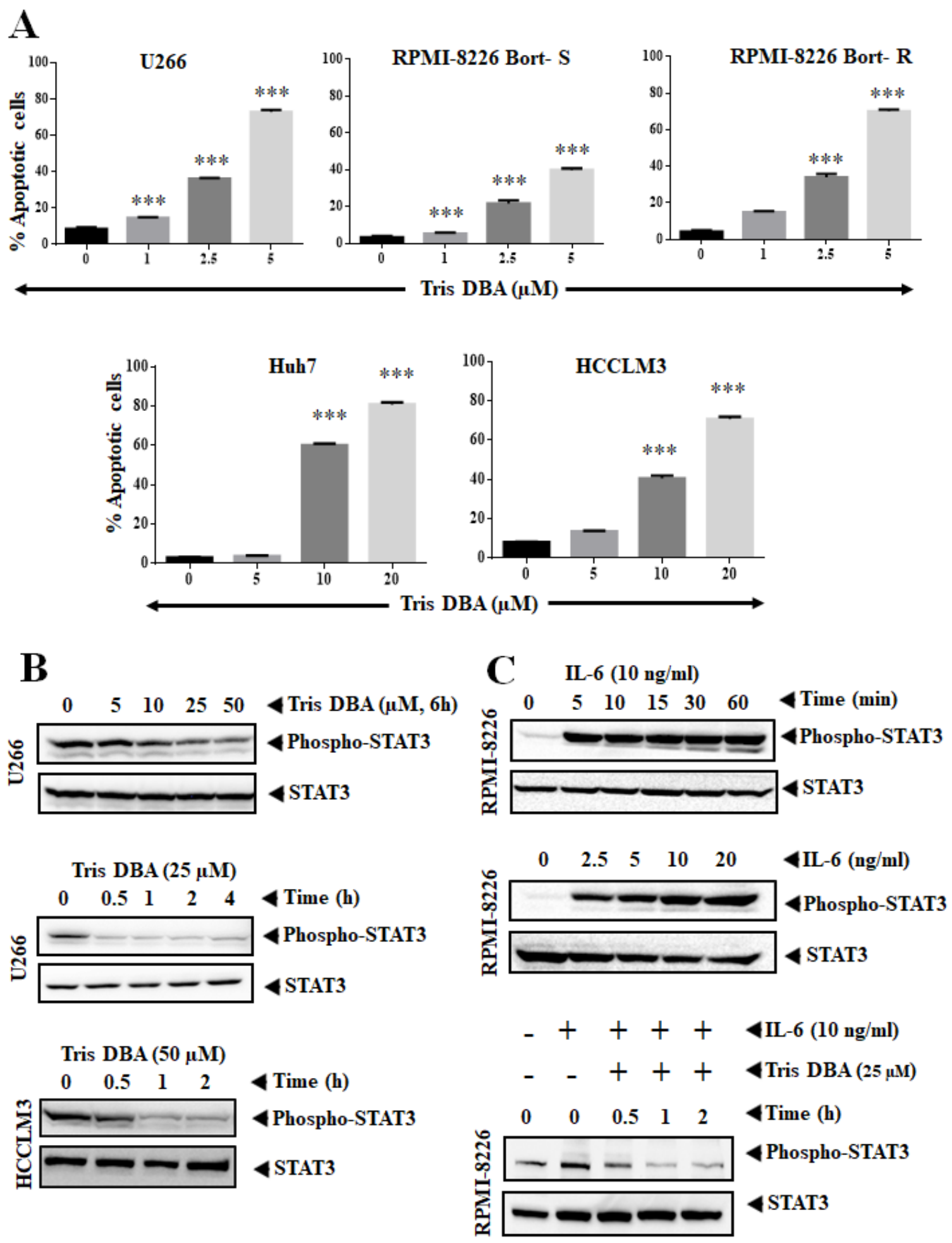

Figure 2 
Tris DBA induces apoptosis and mitigates the STAT3 activation. (A) MM (U266, and RPMI-8226) and HCC (Huh7, and HCCLM3) cells were treated with Tris DBA and treated with FITC-Annexin V and PI to quantify the early and late apoptotic cells. Bars indicate standard deviation; $n=3 ; * \star \star p<0.001$ versus no treatment. (B) U266 and HCCLM3 cells were exposed to Tris DBA at indicated concentrations and time points and cell lysates were used for SDS-PAGE and Western blotting to analyze phospho-STAT3/STAT3 expression. (C) RPMI-8226 cells were incubated with Tris DBA $(25 \mu \mathrm{M})$ at given time points and induced with IL-6 $(10 \mathrm{ng} / \mathrm{ml})$. The cell lysates were used for SDS-PAGE and Western blotting to analyze phosphoSTAT3/STAT3 expression. 

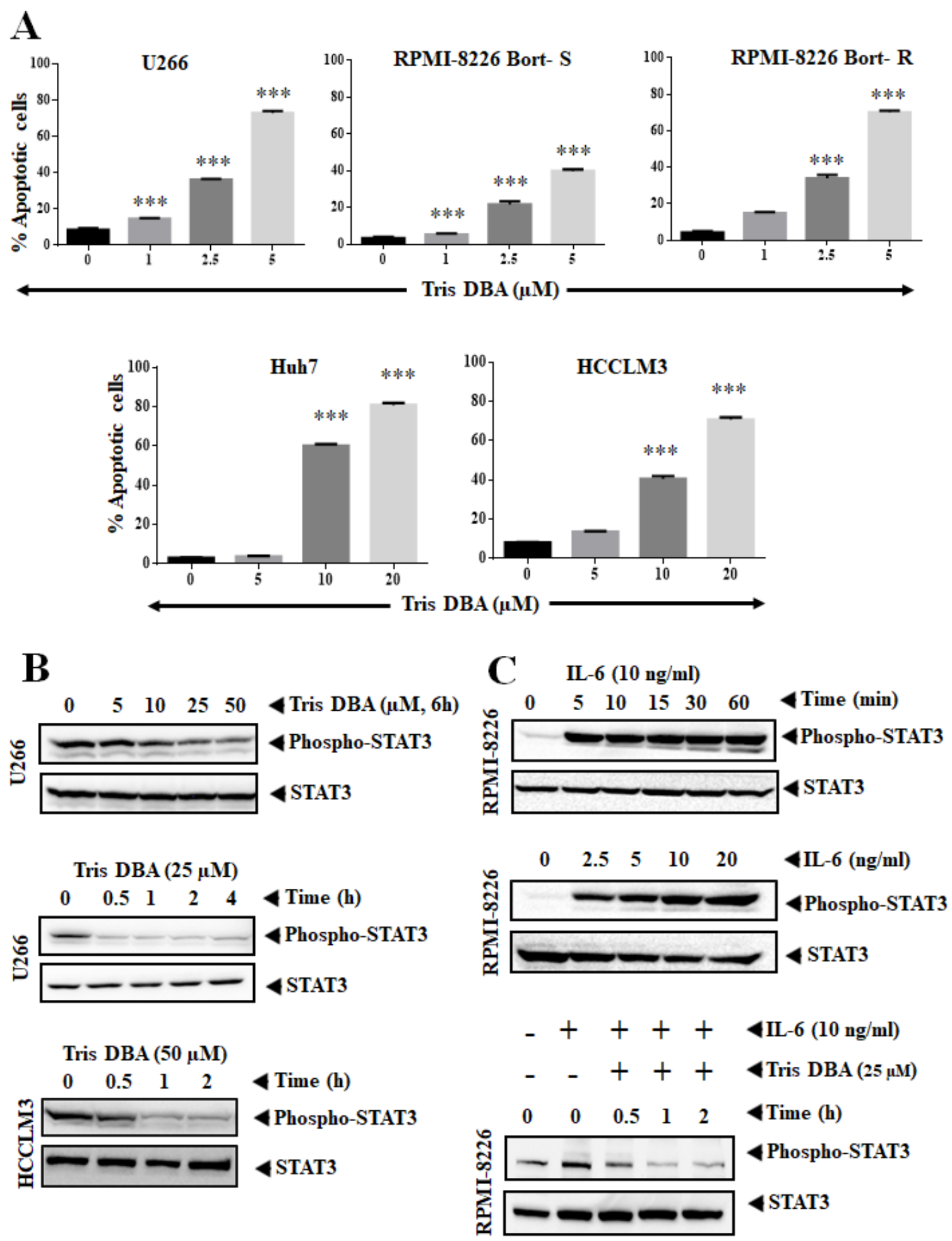

\section{Figure 2}

Tris DBA induces apoptosis and mitigates the STAT3 activation. (A) MM (U266, and RPMI-8226) and HCC (Huh7, and HCCLM3) cells were treated with Tris DBA and treated with FITC-Annexin V and PI to quantify the early and late apoptotic cells. Bars indicate standard deviation; $n=3 ; \star \star \star x p 0.001$ versus no treatment. (B) U266 and HCCLM3 cells were exposed to Tris DBA at indicated concentrations and time points and cell lysates were used for SDS-PAGE and Western blotting to analyze phospho-STAT3/STAT3 expression. 
(C) RPMI-8226 cells were incubated with Tris DBA $(25 \mu \mathrm{M})$ at given time points and induced with IL-6 $(10 \mathrm{ng} / \mathrm{ml})$. The cell lysates were used for SDS-PAGE and Western blotting to analyze phosphoSTAT3/STAT3 expression.
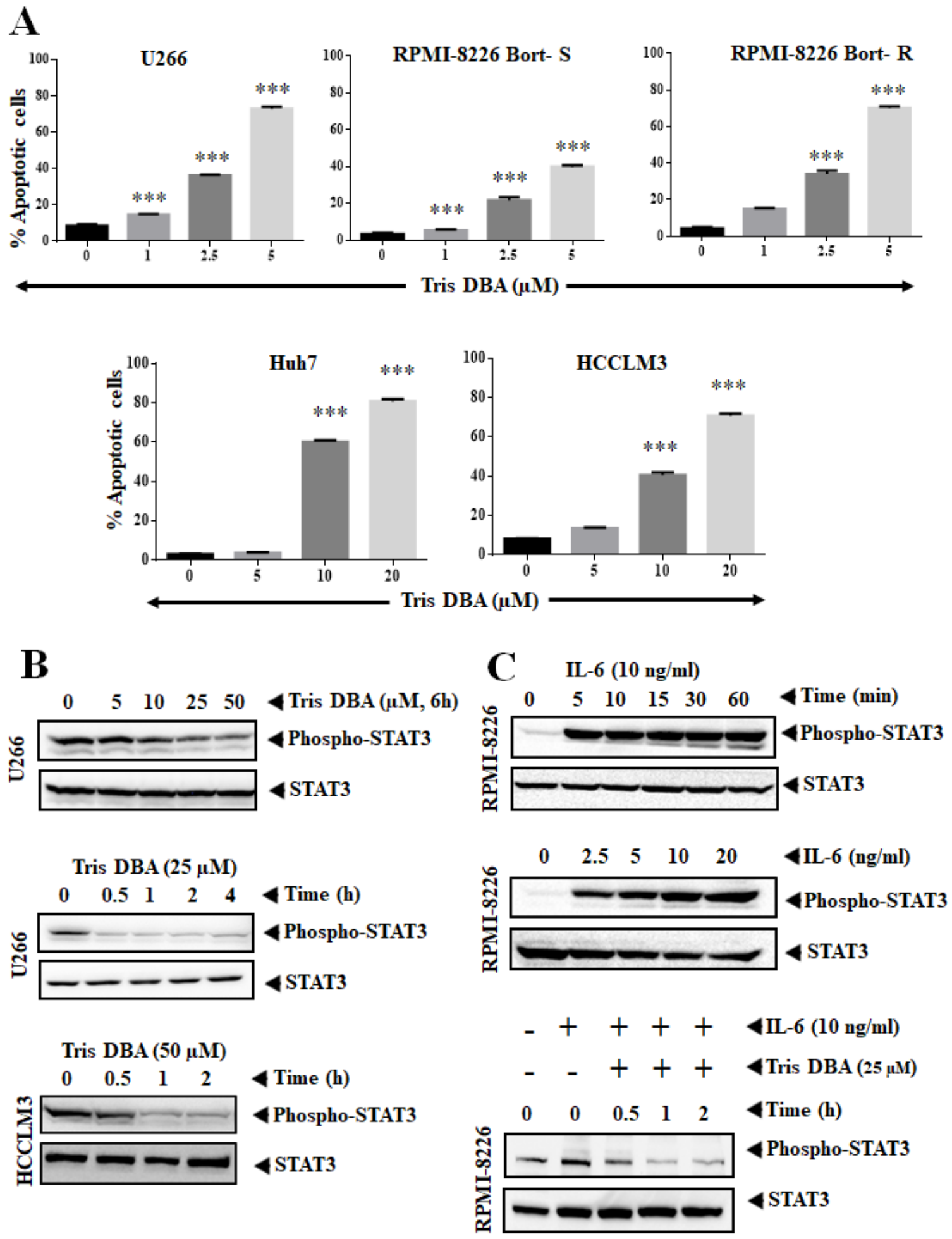

Figure 2

Tris DBA induces apoptosis and mitigates the STAT3 activation. (A) MM (U266, and RPMI-8226) and HCC (Huh7, and HCCLM3) cells were treated with Tris DBA and treated with FITC-Annexin V and PI to quantify 
the early and late apoptotic cells. Bars indicate standard deviation; $n=3 ; \star \star \star p<0.001$ versus no treatment. (B) U266 and HCCLM3 cells were exposed to Tris DBA at indicated concentrations and time points and cell lysates were used for SDS-PAGE and Western blotting to analyze phospho-STAT3/STAT3 expression. (C) RPMI-8226 cells were incubated with Tris DBA $(25 \mu \mathrm{M})$ at given time points and induced with IL-6 $(10 \mathrm{ng} / \mathrm{ml})$. The cell lysates were used for SDS-PAGE and Western blotting to analyze phosphoSTAT3/STAT3 expression.
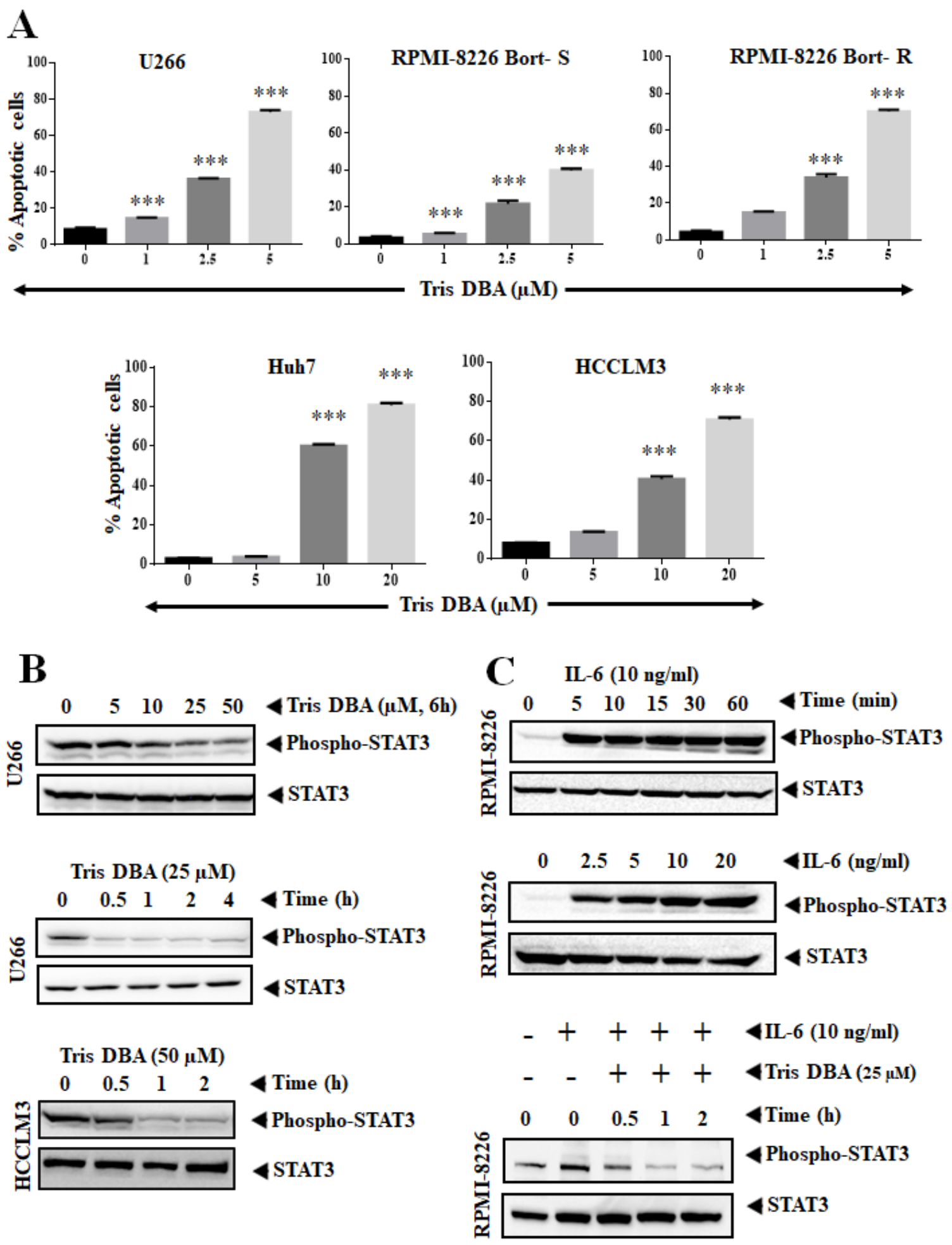

Figure 2 
Tris DBA induces apoptosis and mitigates the STAT3 activation. (A) MM (U266, and RPMI-8226) and HCC (Huh7, and HCCLM3) cells were treated with Tris DBA and treated with FITC-Annexin V and PI to quantify the early and late apoptotic cells. Bars indicate standard deviation; $n=3 ; * \star \star p<0.001$ versus no treatment. (B) U266 and HCCLM3 cells were exposed to Tris DBA at indicated concentrations and time points and cell lysates were used for SDS-PAGE and Western blotting to analyze phospho-STAT3/STAT3 expression. (C) RPMI-8226 cells were incubated with Tris DBA $(25 \mu \mathrm{M})$ at given time points and induced with IL-6 $(10 \mathrm{ng} / \mathrm{ml})$. The cell lysates were used for SDS-PAGE and Western blotting to analyze phosphoSTAT3/STAT3 expression. 

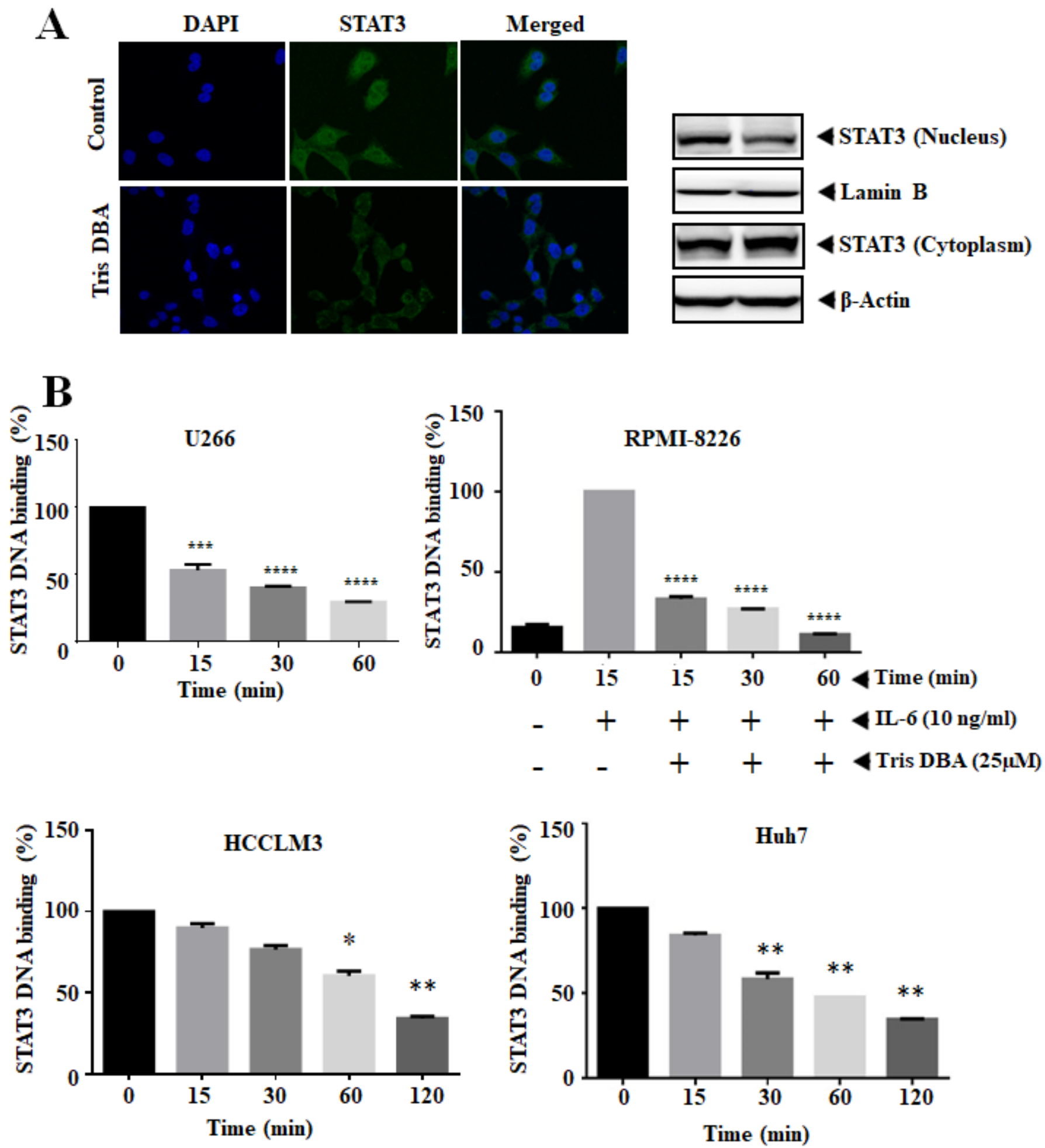

\section{Figure 3}

Tris DBA downregulates nuclear STAT3 and its DNA binding ability. (A) HCCLM3 cells were treated with Tris DBA $(50 \mu \mathrm{M})$ and examined for the cellular compartmentalization of STAT3 by immunocytochemistry. DAPI was used to counterstain and to visualize nuclei. (B) MM (U266, IL-6 induced RPMI-8226), and HCC (HCCLM3, and Huh7) cells were incubated with Tris DBA (25 and $50 \mu \mathrm{M}$ respectively) and nuclear extracts were prepared to analyze DNA interaction of STAT3 as described in 
methods. Bars indicate standard deviation; $n=3 ;{ }^{*} p<0.05,{ }^{*} p<0.01,{ }^{* *} p<0.001,{ }^{*} * \star p<0.0001$ versus no treatment.
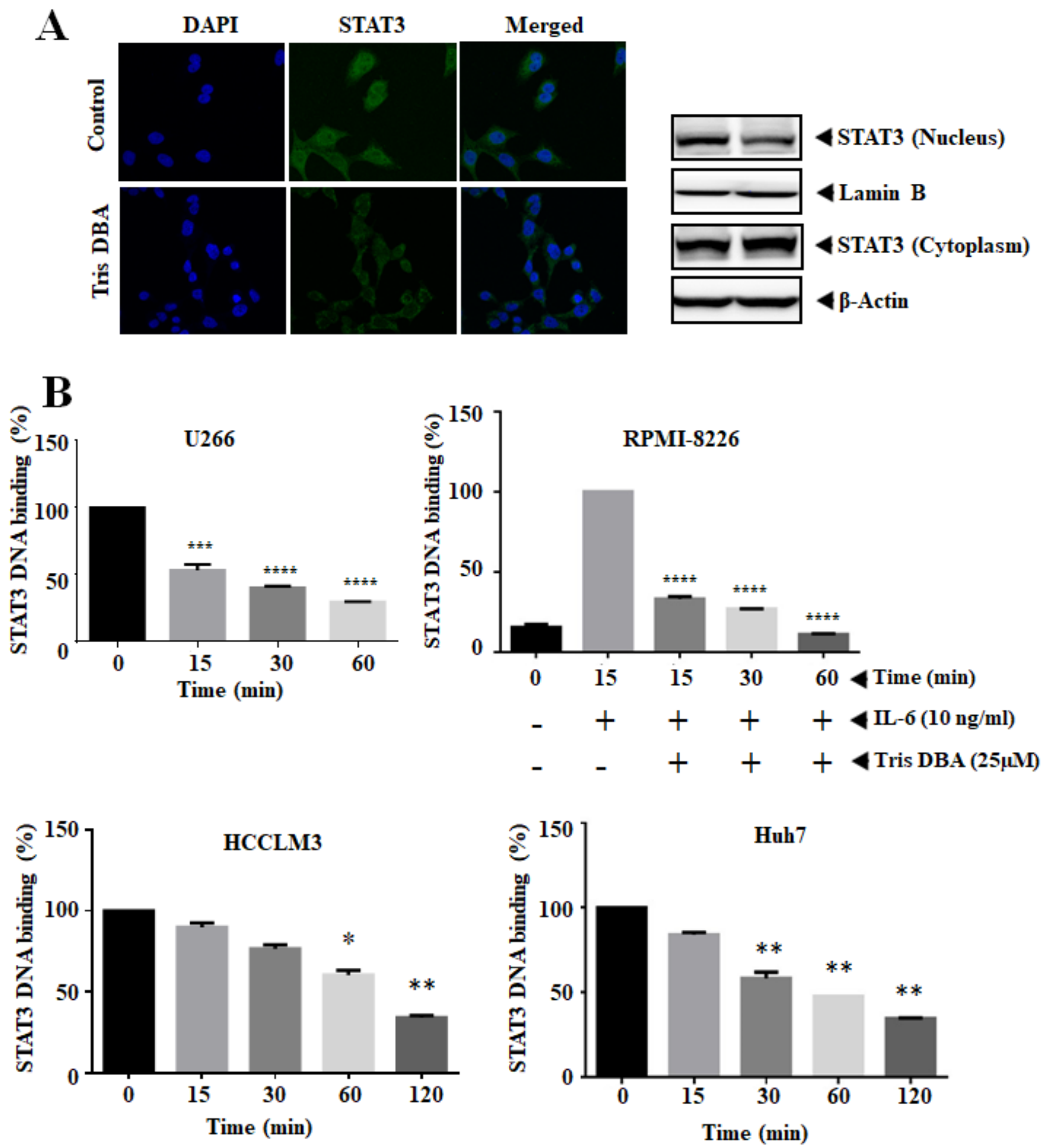

Figure 3

Tris DBA downregulates nuclear STAT3 and its DNA binding ability. (A) HCCLM3 cells were treated with Tris DBA $(50 \mu \mathrm{M})$ and examined for the cellular compartmentalization of STAT3 by immunocytochemistry. DAPI was used to counterstain and to visualize nuclei. (B) MM (U266, IL-6 induced 
RPMI-8226), and HCC (HCCLM3, and Huh7) cells were incubated with Tris DBA (25 and $50 \mu \mathrm{M}$ respectively) and nuclear extracts were prepared to analyze DNA interaction of STAT3 as described in methods. Bars indicate standard deviation; $n=3 ;{ }^{*} p<0.05,{ }^{* \star} p<0.01,{ }^{* \star *} p<0.001,{ }^{* \star * *} p<0.0001$ versus no treatment.
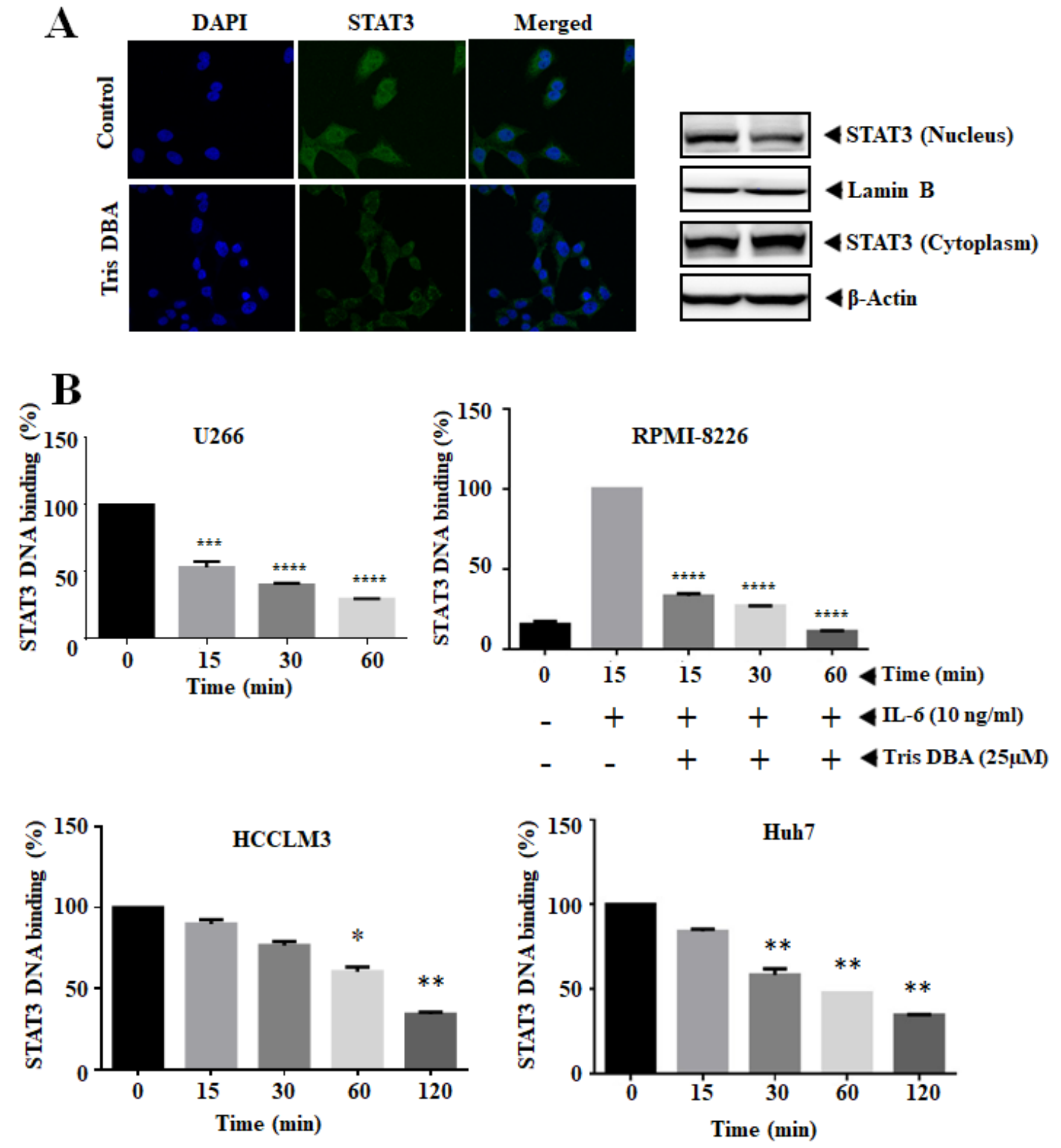

Figure 3 
Tris DBA downregulates nuclear STAT3 and its DNA binding ability. (A) HCCLM3 cells were treated with Tris DBA $(50 \mu \mathrm{M})$ and examined for the cellular compartmentalization of STAT3 by

immunocytochemistry. DAPI was used to counterstain and to visualize nuclei. (B) MM (U266, IL-6 induced RPMI-8226), and HCC (HCCLM3, and Huh7) cells were incubated with Tris DBA (25 and $50 \mu \mathrm{M}$ respectively) and nuclear extracts were prepared to analyze DNA interaction of STAT3 as described in methods. Bars indicate standard deviation; $n=3 ;{ }^{*} p<0.05$, ${ }^{* \star} p<0.01$, ${ }^{* \star} p<0.001,{ }^{\star \star * *} p<0.0001$ versus no treatment.
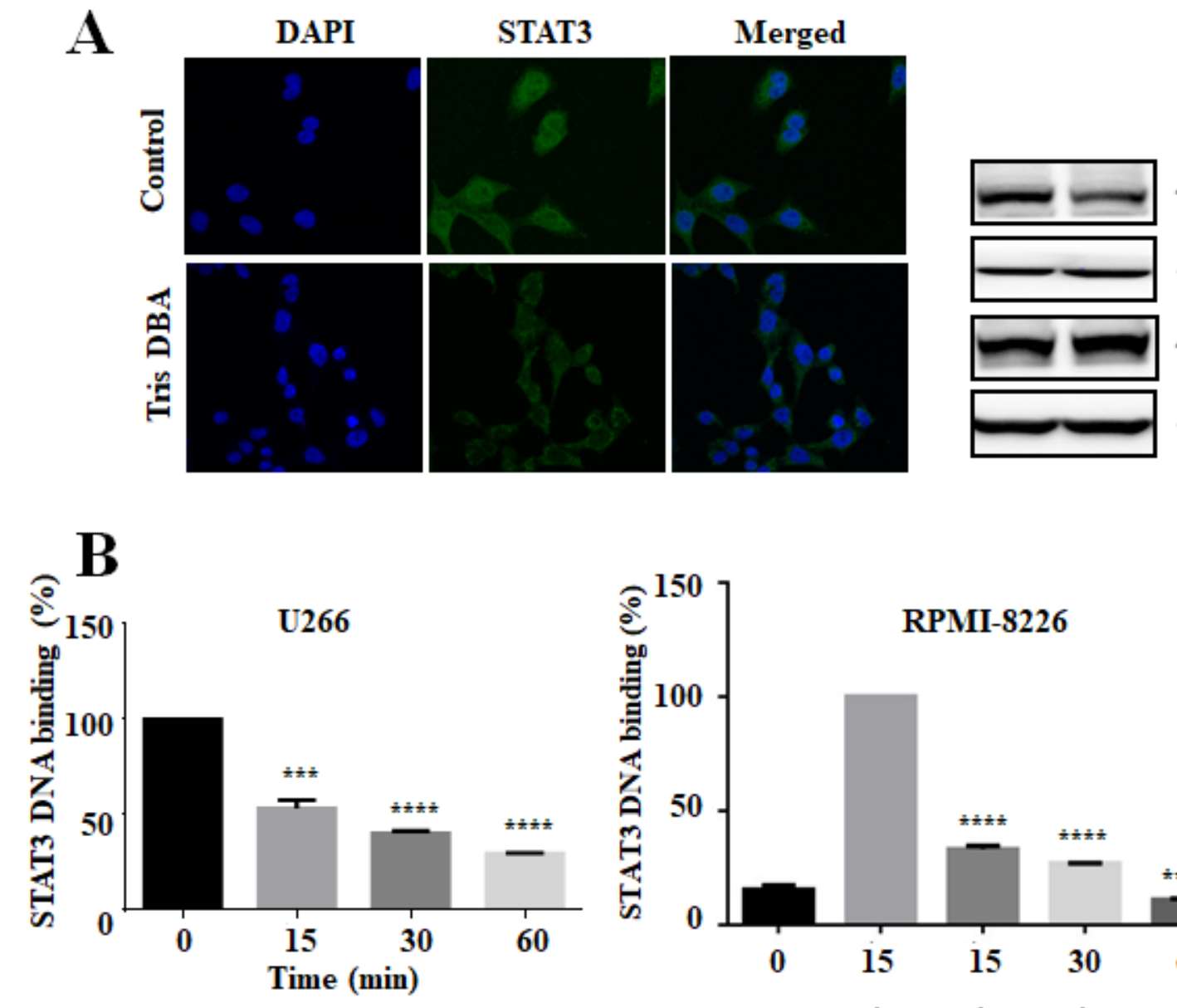

STAT3 (Nucleus)

Lamin B

STAT3 (Cytoplasm)

$\beta$-Actin
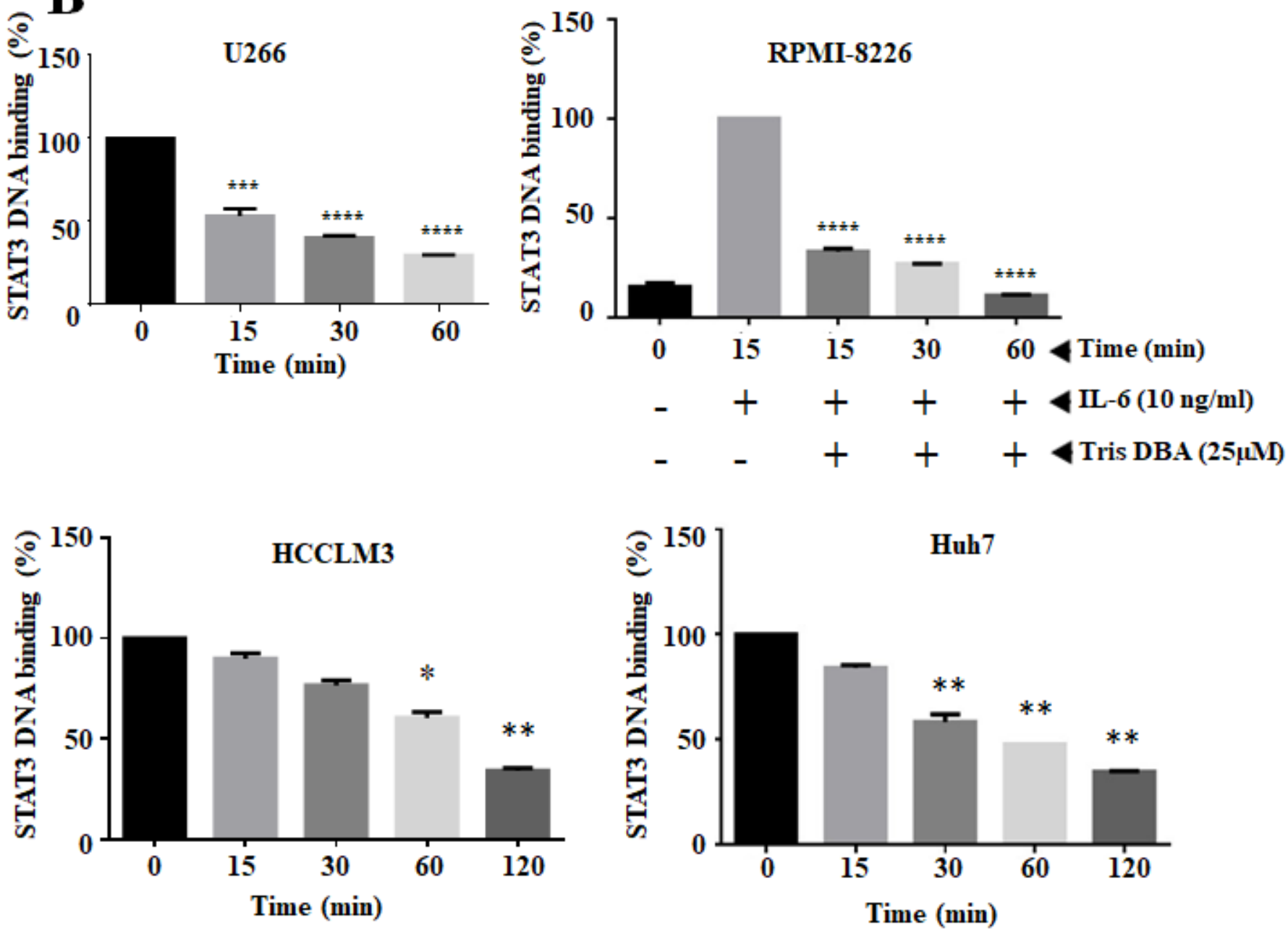


\section{Figure 3}

Tris DBA downregulates nuclear STAT3 and its DNA binding ability. (A) HCCLM3 cells were treated with Tris DBA $(50 \mu \mathrm{M})$ and examined for the cellular compartmentalization of STAT3 by immunocytochemistry. DAPI was used to counterstain and to visualize nuclei. (B) MM (U266, IL-6 induced RPMI-8226), and HCC (HCCLM3, and Huh7) cells were incubated with Tris DBA (25 and $50 \mu \mathrm{M}$ respectively) and nuclear extracts were prepared to analyze DNA interaction of STAT3 as described in methods. Bars indicate standard deviation; $n=3 ;{ }^{\star} p<0.05,{ }^{* \star} p<0.01,{ }^{\star \star *} p<0.001,{ }^{\star \star * \star} p<0.0001$ versus no treatment. 

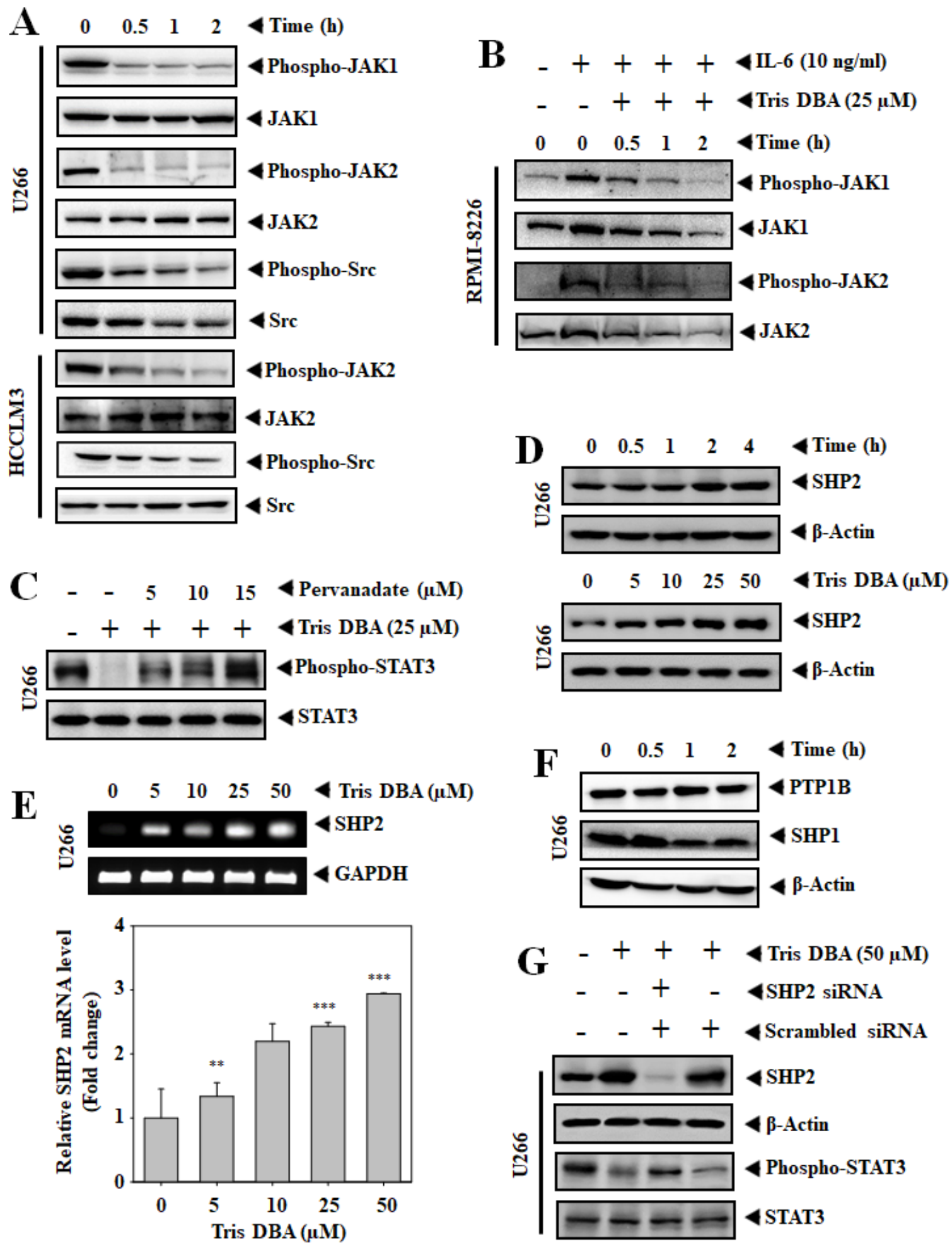

Figure 4

Tris DBA suppresses upstream proteins and enhances the expression of SHP2. (A) U266 and HCCLM3 cells were exposed to Tris DBA ( 25 and $50 \mu \mathrm{M}$ respectively) and cell lysates were used to analyze phosphorylated NRTKs and total proteins expression. (B) RPMI-8226 cells were exposed to Tris DBA (25 $\mu \mathrm{M})$ at indicated time points and stimulated with $\mathrm{IL}-6(10 \mathrm{ng} / \mathrm{ml})$. The cell lysates were used to analyze phosphorylated NRTKs and total protein expression. (C) U266 cells were treated with Tris DBA $(25 \mu \mathrm{M})$ 
and pervanadate at indicated doses to analyze phosphorylated STAT3 and total STAT3 expression. (D and F) Tris DBA treated U266 cells were lysed and analyzed for levels of various phosphatases. (E) Tris DBA treated U266 cells were lysed and used for the analysis of SHP2 mRNA expression. GAPDH was used as input control. Bars indicate standard deviation; $n=3 ; * p<0.05$, ${ }^{* \star} p<0.01,{ }^{\star * *} p<0.001$ versus no treatment. (G) U266 cells were used for transfection experiments. SHP2 siRNA transfected U266 cells were incubated with Tris DBA $(50 \mu \mathrm{M})$. and the cell lysates were analyzed for SHP2 and phospho STAT3/STAT3 expression.

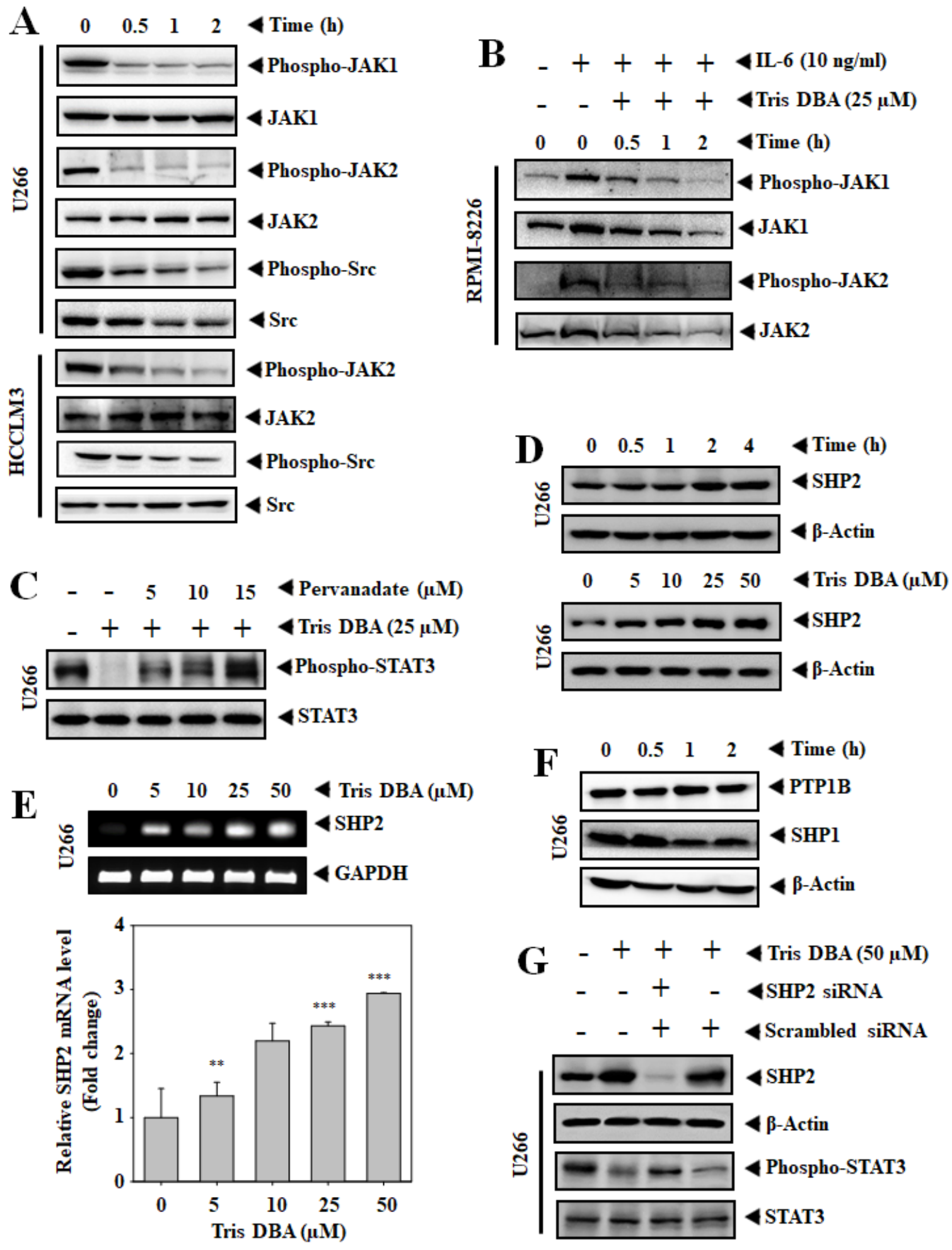




\section{Figure 4}

Tris DBA suppresses upstream proteins and enhances the expression of SHP2. (A) U266 and HCCLM3 cells were exposed to Tris DBA ( 25 and $50 \mu \mathrm{M}$ respectively) and cell lysates were used to analyze phosphorylated NRTKs and total proteins expression. (B) RPMI-8226 cells were exposed to Tris DBA (25 $\mu \mathrm{M})$ at indicated time points and stimulated with $\mathrm{IL}-6(10 \mathrm{ng} / \mathrm{ml})$. The cell lysates were used to analyze phosphorylated NRTKs and total protein expression. (C) U266 cells were treated with Tris DBA ( $25 \mu \mathrm{M})$ and pervanadate at indicated doses to analyze phosphorylated STAT3 and total STAT3 expression. (D and F) Tris DBA treated U266 cells were lysed and analyzed for levels of various phosphatases. (E) Tris DBA treated U266 cells were lysed and used for the analysis of SHP2 mRNA expression. GAPDH was used as input control. Bars indicate standard deviation; $n=3 ;{ }^{*} p<0.05,{ }^{* *} p<0.01$, ${ }^{* \star *} p<0.001$ versus no treatment. (G) U266 cells were used for transfection experiments. SHP2 siRNA transfected U266 cells were incubated with Tris DBA $(50 \mu \mathrm{M})$. and the cell lysates were analyzed for SHP2 and phospho STAT3/STAT3 expression. 

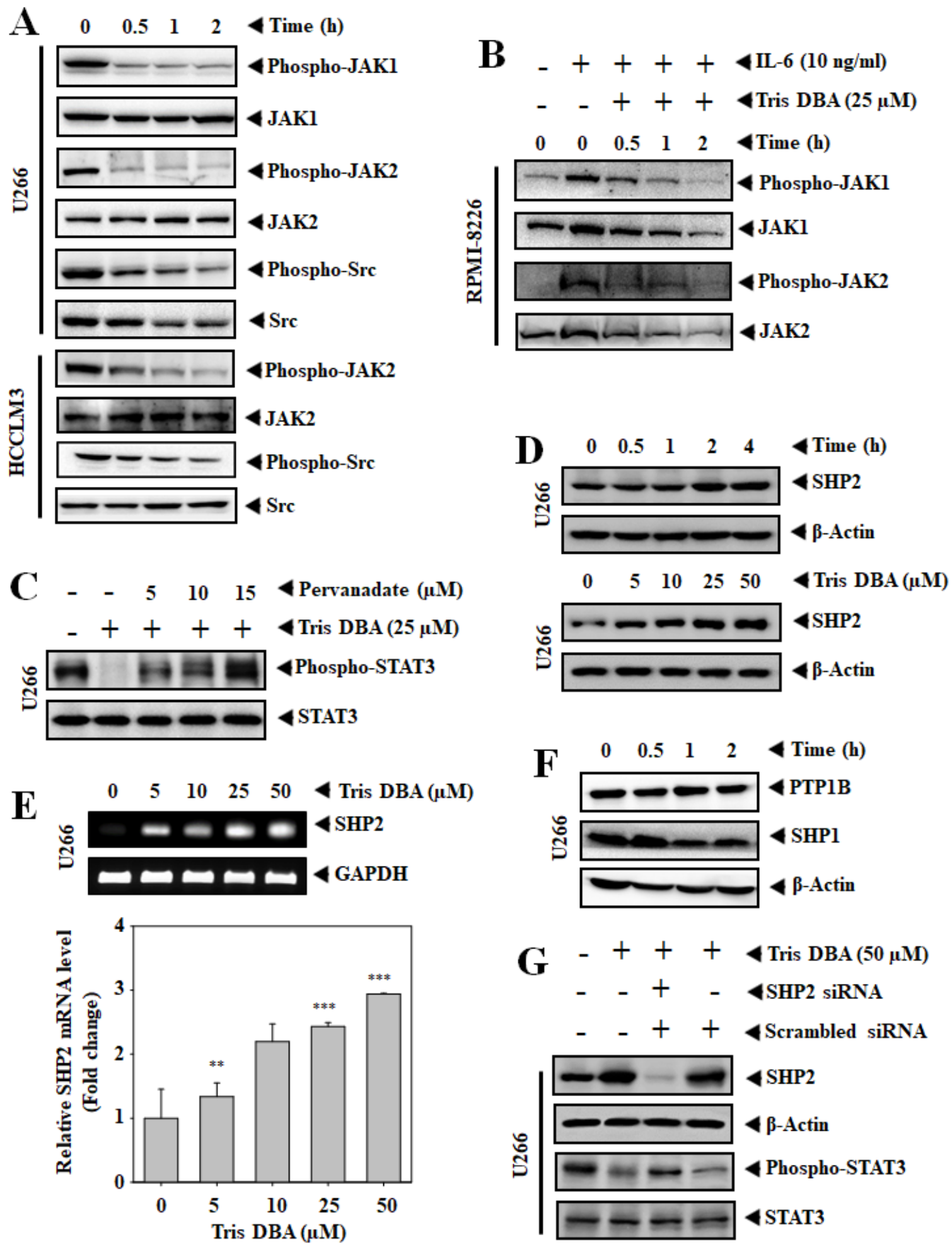

Figure 4

Tris DBA suppresses upstream proteins and enhances the expression of SHP2. (A) U266 and HCCLM3 cells were exposed to Tris DBA ( 25 and $50 \mu \mathrm{M}$ respectively) and cell lysates were used to analyze phosphorylated NRTKs and total proteins expression. (B) RPMI-8226 cells were exposed to Tris DBA (25 $\mu \mathrm{M})$ at indicated time points and stimulated with $\mathrm{IL}-6(10 \mathrm{ng} / \mathrm{ml})$. The cell lysates were used to analyze phosphorylated NRTKs and total protein expression. (C) U266 cells were treated with Tris DBA $(25 \mu \mathrm{M})$ 
and pervanadate at indicated doses to analyze phosphorylated STAT3 and total STAT3 expression. (D and F) Tris DBA treated U266 cells were lysed and analyzed for levels of various phosphatases. (E) Tris DBA treated U266 cells were lysed and used for the analysis of SHP2 mRNA expression. GAPDH was used as input control. Bars indicate standard deviation; $n=3 ; * p<0.05$, ${ }^{* \star} p<0.01,{ }^{\star * *} p<0.001$ versus no treatment. (G) U266 cells were used for transfection experiments. SHP2 siRNA transfected U266 cells were incubated with Tris DBA $(50 \mu \mathrm{M})$. and the cell lysates were analyzed for SHP2 and phospho STAT3/STAT3 expression.

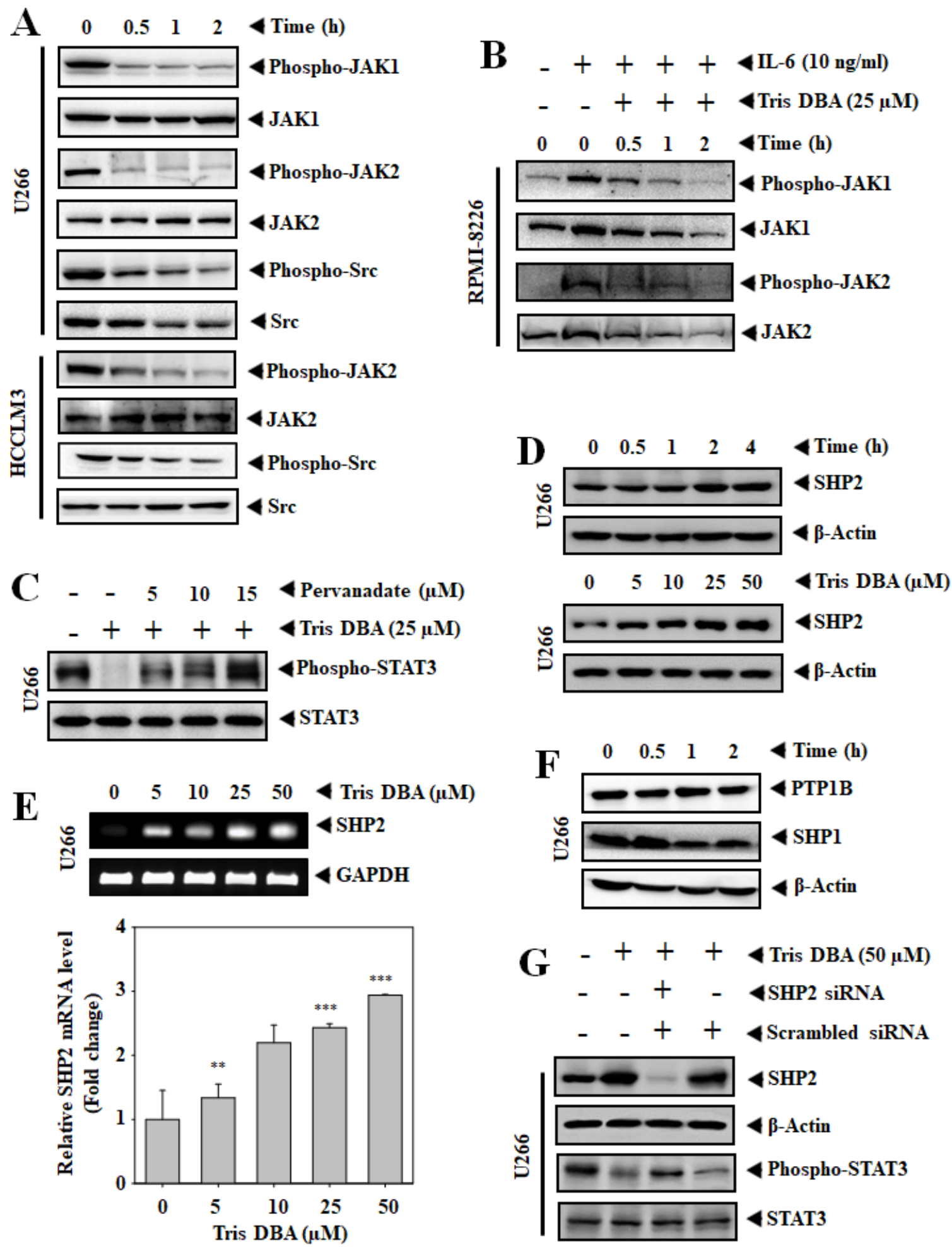




\section{Figure 4}

Tris DBA suppresses upstream proteins and enhances the expression of SHP2. (A) U266 and HCCLM3 cells were exposed to Tris DBA ( 25 and $50 \mu \mathrm{M}$ respectively) and cell lysates were used to analyze phosphorylated NRTKs and total proteins expression. (B) RPMI-8226 cells were exposed to Tris DBA (25 $\mu \mathrm{M})$ at indicated time points and stimulated with $\mathrm{IL}-6(10 \mathrm{ng} / \mathrm{ml})$. The cell lysates were used to analyze phosphorylated NRTKs and total protein expression. (C) U266 cells were treated with Tris DBA ( $25 \mu \mathrm{M})$ and pervanadate at indicated doses to analyze phosphorylated STAT3 and total STAT3 expression. (D and F) Tris DBA treated U266 cells were lysed and analyzed for levels of various phosphatases. (E) Tris DBA treated U266 cells were lysed and used for the analysis of SHP2 mRNA expression. GAPDH was used as input control. Bars indicate standard deviation; $n=3 ;{ }^{*} p<0.05,{ }^{* *} p<0.01$, ${ }^{* \star *} p<0.001$ versus no treatment. (G) U266 cells were used for transfection experiments. SHP2 siRNA transfected U266 cells were incubated with Tris DBA $(50 \mu \mathrm{M})$. and the cell lysates were analyzed for SHP2 and phospho STAT3/STAT3 expression. 


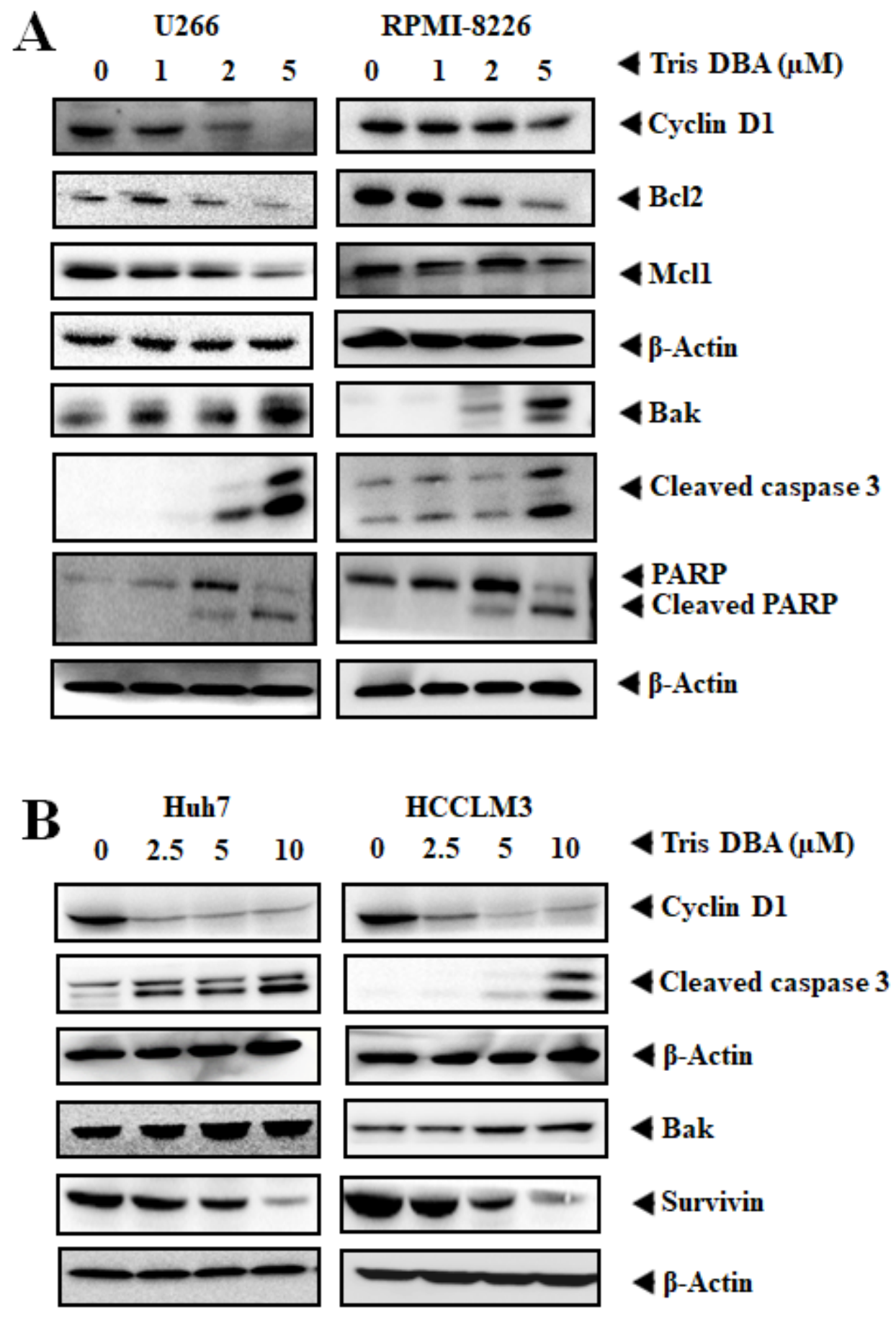

Figure 5

Tris DBA downmodulates STAT3 targeted gene expression and induces apoptosis. (A and B) MM (U266, and RPMI-8226) and HCC (Huh7, and HCCLM3) cells were incubated with given doses of Tris DBA and cell lysates were analyzed for the expression of cyclin D1, Bcl2, Mcl1, Bak, caspase 3, survivin, and PARP expression. 


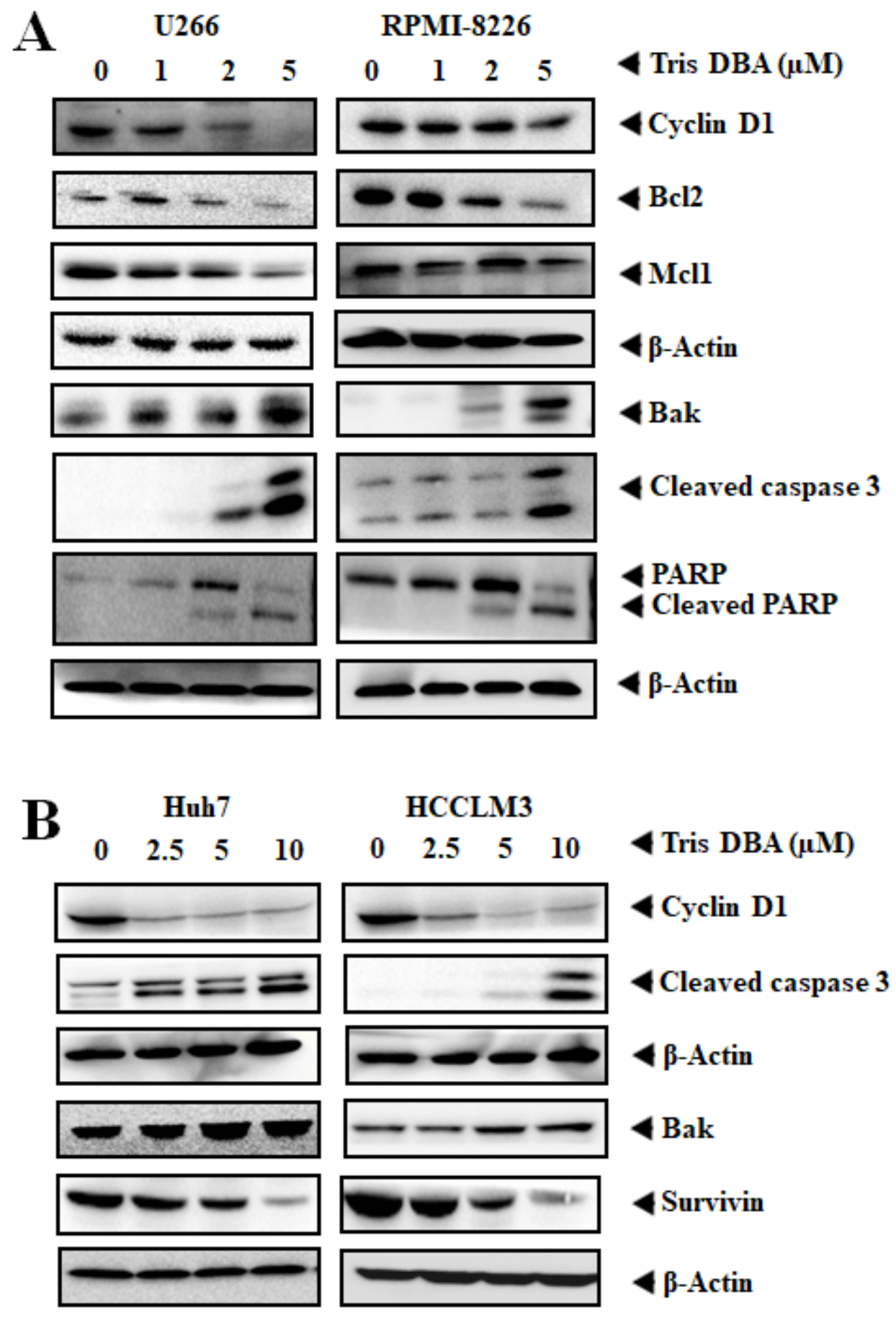

Figure 5

Tris DBA downmodulates STAT3 targeted gene expression and induces apoptosis. (A and B) MM (U266, and RPMI-8226) and HCC (Huh7, and HCCLM3) cells were incubated with given doses of Tris DBA and cell lysates were analyzed for the expression of cyclin D1, Bcl2, Mcl1, Bak, caspase 3, survivin, and PARP expression. 


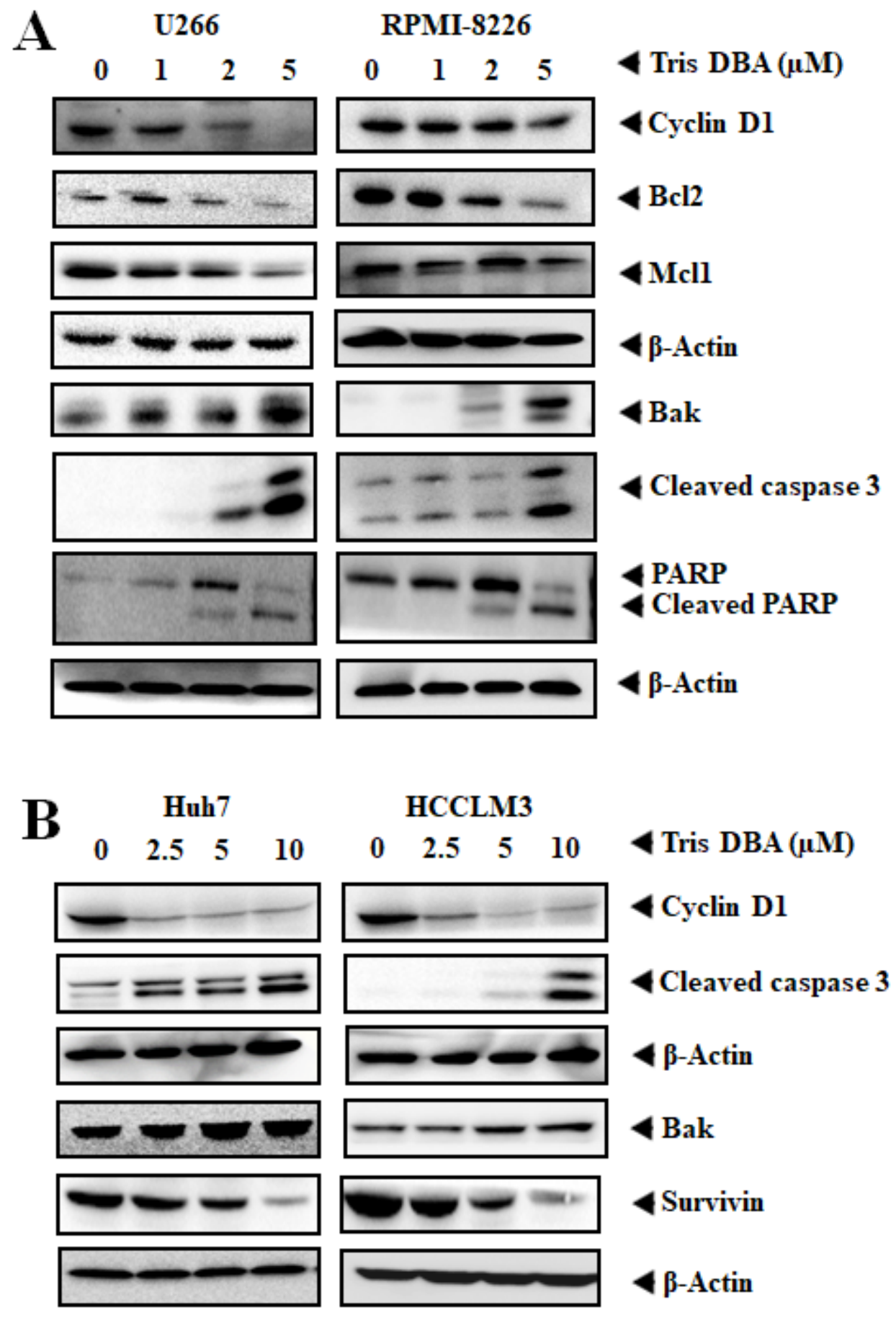

Figure 5

Tris DBA downmodulates STAT3 targeted gene expression and induces apoptosis. (A and B) MM (U266, and RPMI-8226) and HCC (Huh7, and HCCLM3) cells were incubated with given doses of Tris DBA and cell lysates were analyzed for the expression of cyclin D1, Bcl2, Mcl1, Bak, caspase 3, survivin, and PARP expression. 


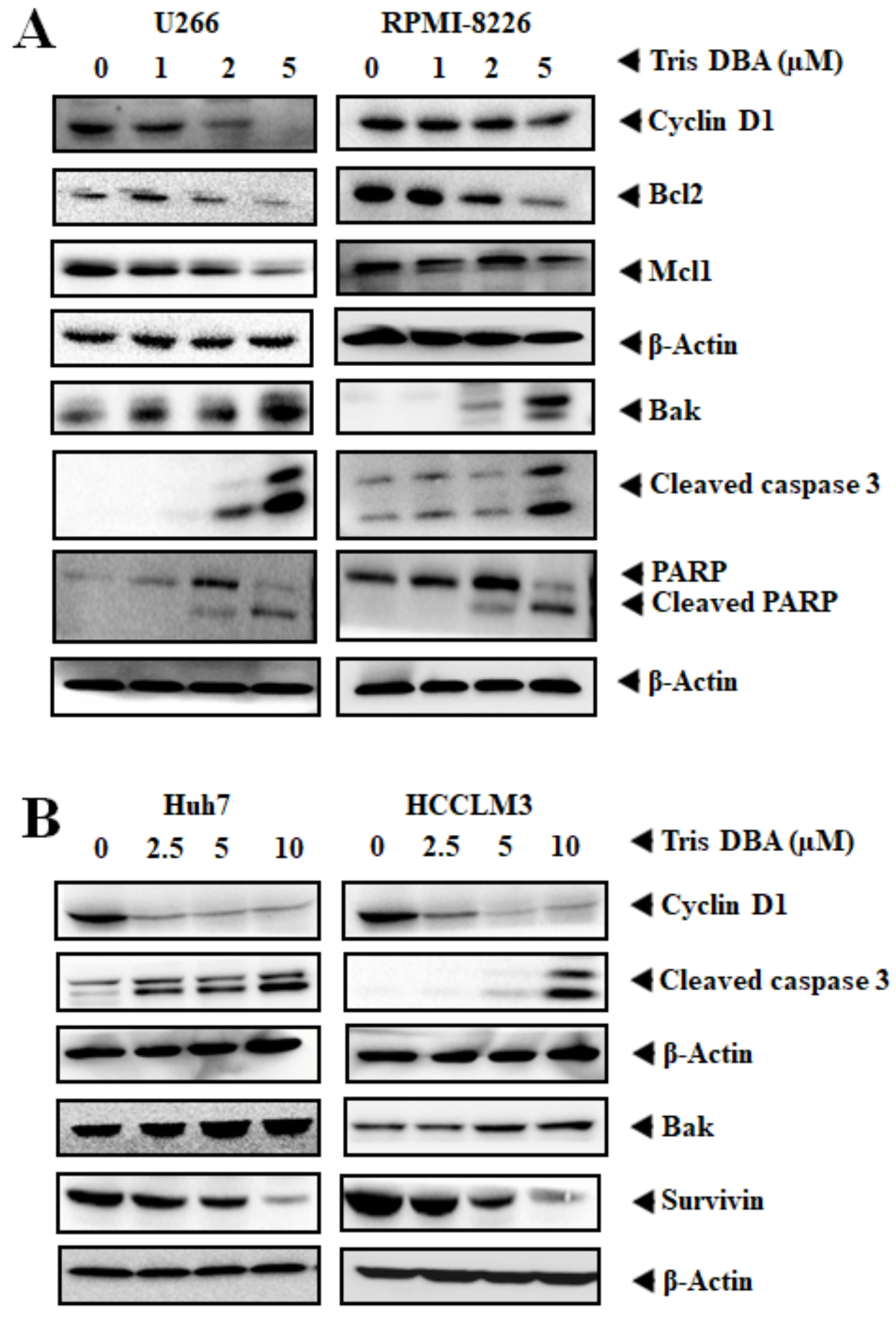

Figure 5

Tris DBA downmodulates STAT3 targeted gene expression and induces apoptosis. (A and B) MM (U266, and RPMI-8226) and HCC (Huh7, and HCCLM3) cells were incubated with given doses of Tris DBA and cell lysates were analyzed for the expression of cyclin D1, Bcl2, Mcl1, Bak, caspase 3, survivin, and PARP expression. 


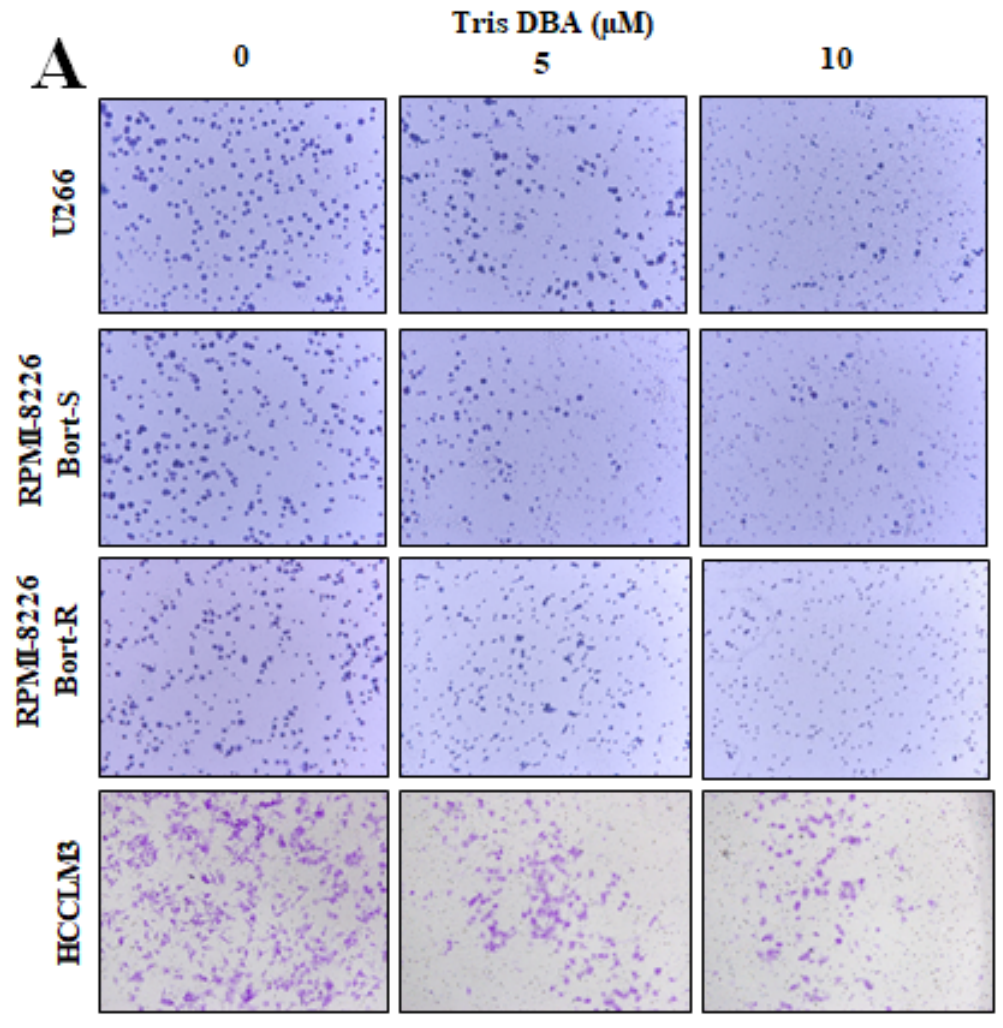

B
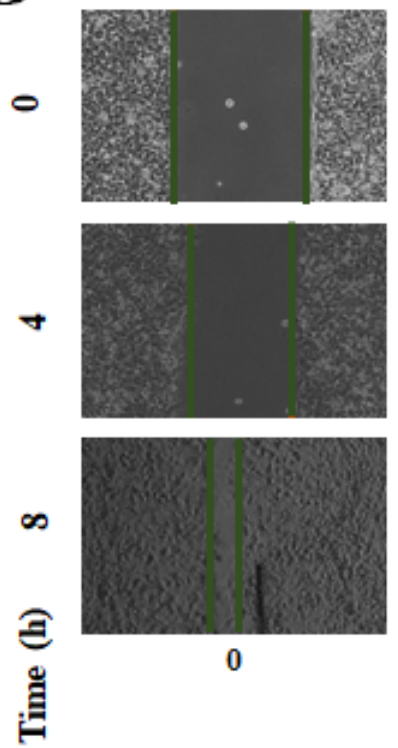
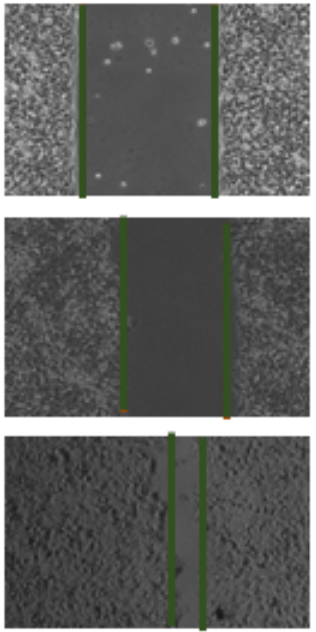

5
Tris DBA ( $\mathrm{uM})$
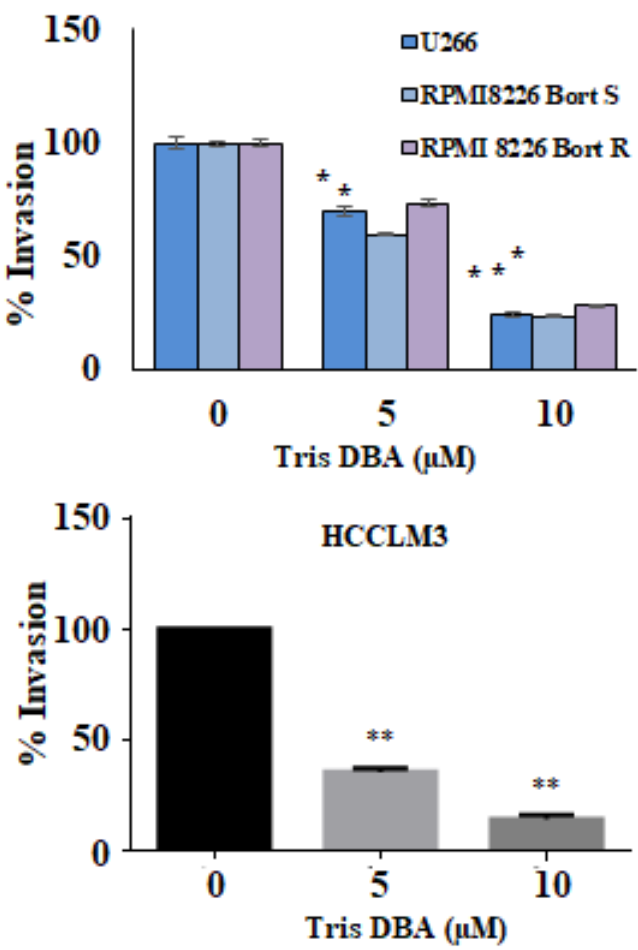

\section{Figure 6}

(A) Tris DBA suppresses the cancer cell invasion and migration. MM (U226, and RPMI-8226) and HCCLM3 cells were incubated with different doses of Tris DBA and seeded in invasion chambers in serum-free media. The lower chamber was filled with FBS supplemented media. After the incubation with the suggested time point, the cells on the upper side were stained with crystal violet to visualize and quantify them. (B) HCCLM3 cells were seeded into a culture vessel that has a culture-insert and the 
removal of this insert creates the cell-free space. The movement of the cell is visualized and measured either on treatment with Tris DBA or untreated samples. Bars indicate standard deviation; $n=3 ;{ }^{*} p<0.05$, $\star * p<0.01$ versus no treatment.
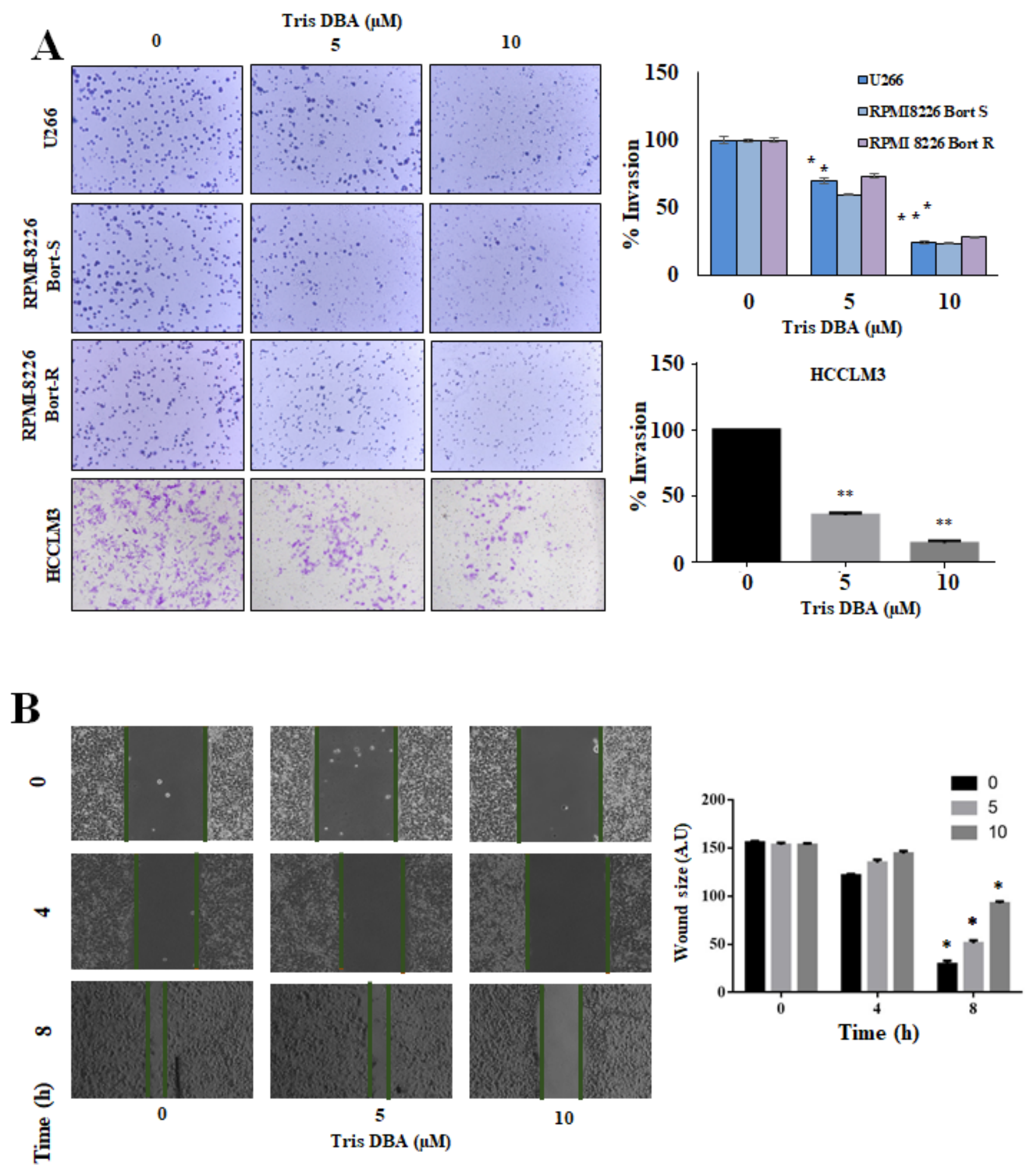

Figure 6

(A) Tris DBA suppresses the cancer cell invasion and migration. MM (U226, and RPMI-8226) and HCCLM3 cells were incubated with different doses of Tris DBA and seeded in invasion chambers in 
serum-free media. The lower chamber was filled with FBS supplemented media. After the incubation with the suggested time point, the cells on the upper side were stained with crystal violet to visualize and quantify them. (B) HCCLM3 cells were seeded into a culture vessel that has a culture-insert and the removal of this insert creates the cell-free space. The movement of the cell is visualized and measured either on treatment with Tris DBA or untreated samples. Bars indicate standard deviation; $n=3 ;{ }^{*} p<0.05$, ${ }^{*} \mathrm{p}<0.01$ versus no treatment.

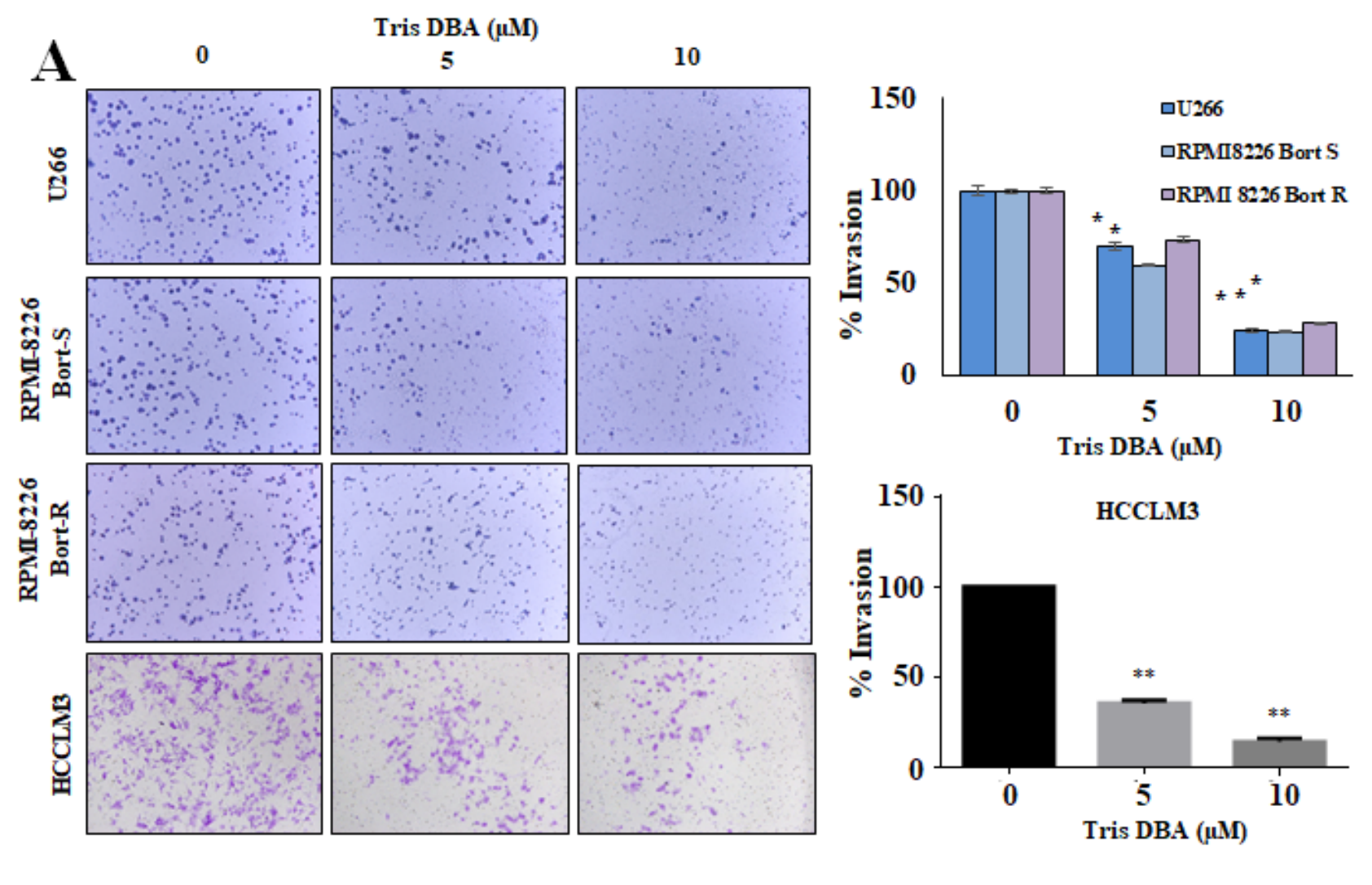

B
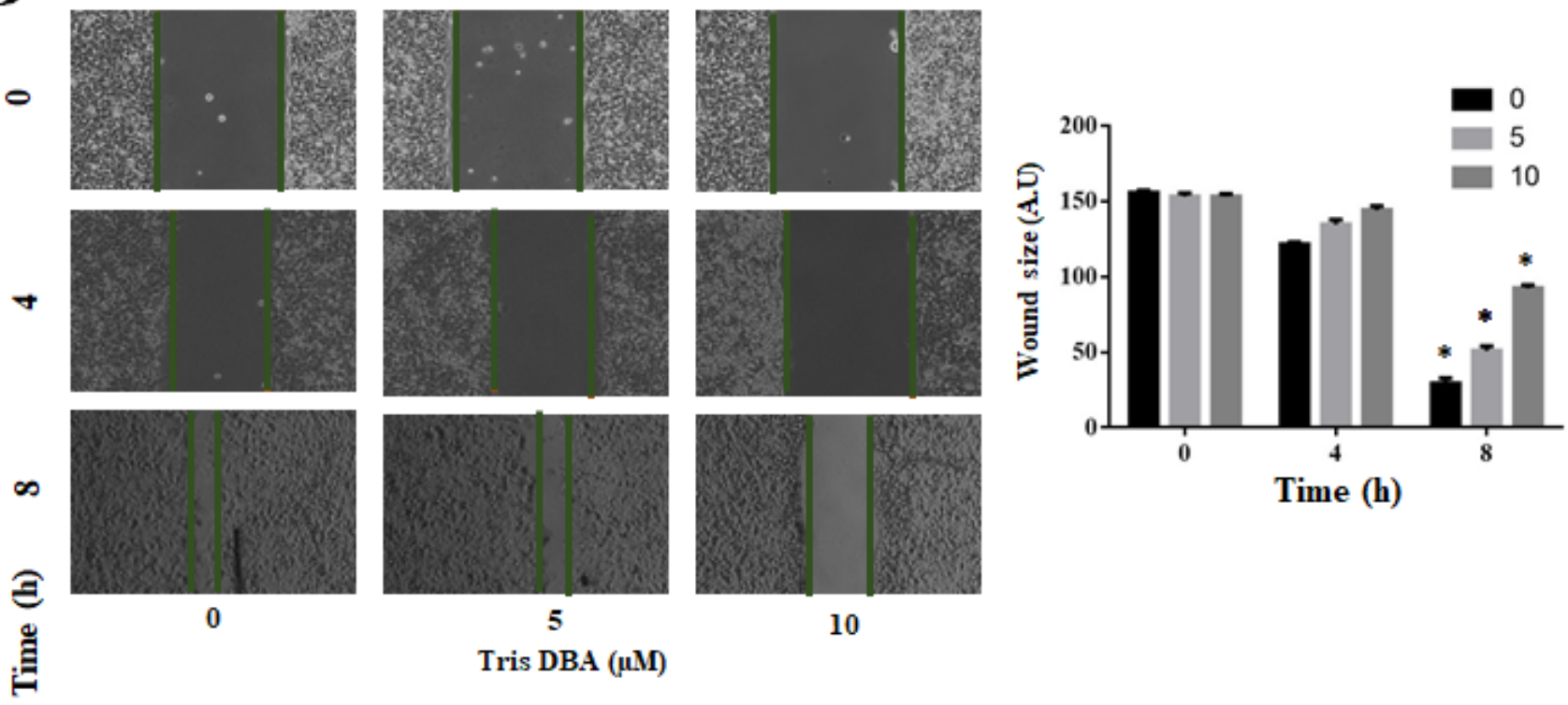

Time (h)
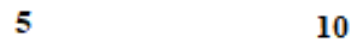

Tris DBA ( $\mu \mathrm{M})$

Figure 6 
(A) Tris DBA suppresses the cancer cell invasion and migration. MM (U226, and RPMI-8226) and HCCLM3 cells were incubated with different doses of Tris DBA and seeded in invasion chambers in serum-free media. The lower chamber was filled with FBS supplemented media. After the incubation with the suggested time point, the cells on the upper side were stained with crystal violet to visualize and quantify them. (B) HCCLM3 cells were seeded into a culture vessel that has a culture-insert and the removal of this insert creates the cell-free space. The movement of the cell is visualized and measured either on treatment with Tris DBA or untreated samples. Bars indicate standard deviation; $n=3 ;{ }^{\star} p<0.05$, $\star * p<0.01$ versus no treatment. 


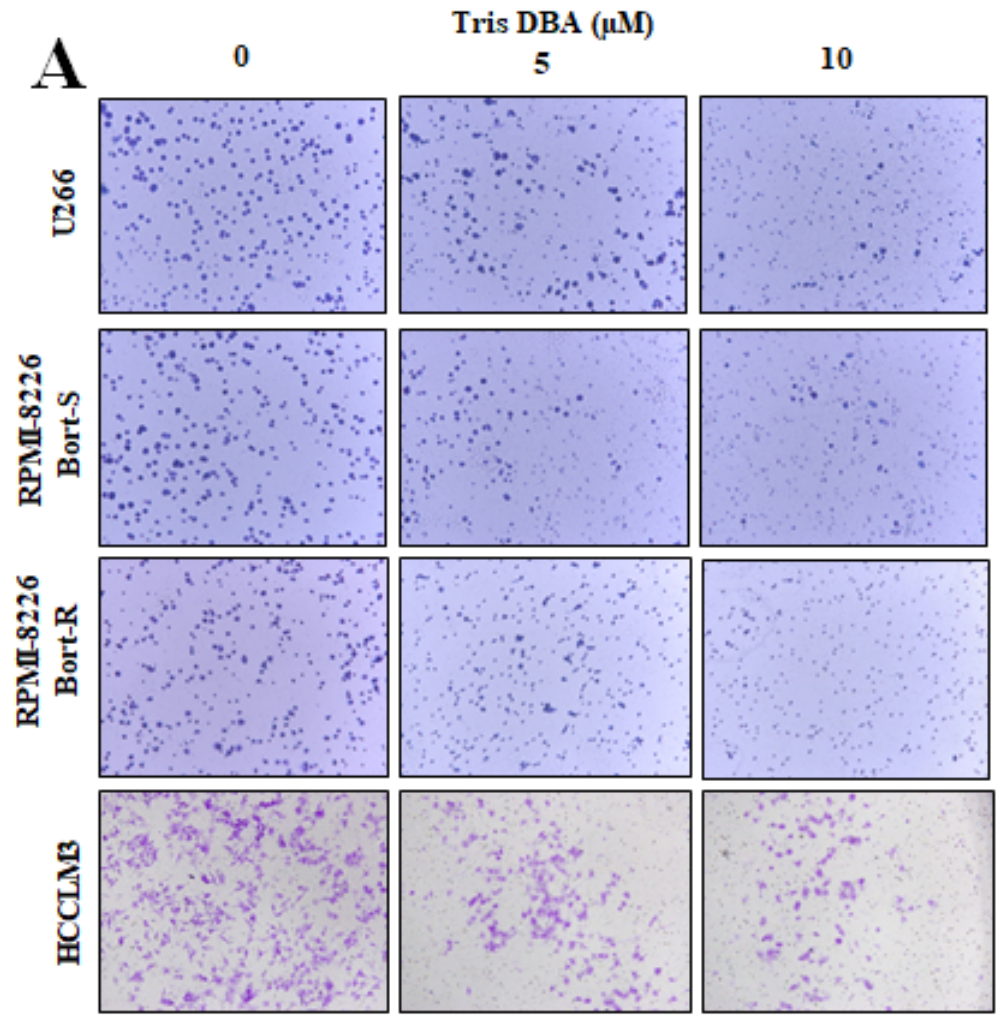

B
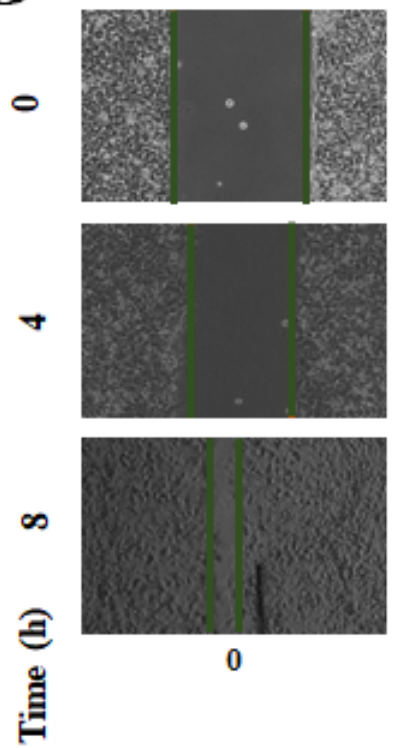
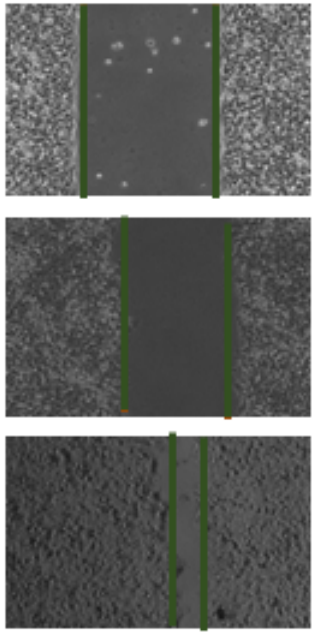

5
Tris DBA ( $\mathrm{uM})$
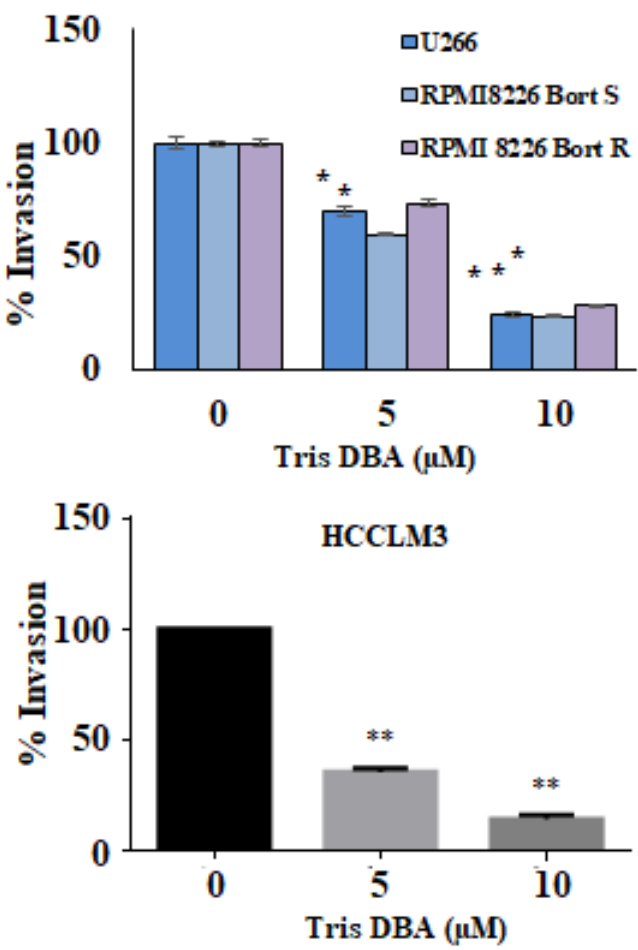

\section{Figure 6}

(A) Tris DBA suppresses the cancer cell invasion and migration. MM (U226, and RPMI-8226) and HCCLM3 cells were incubated with different doses of Tris DBA and seeded in invasion chambers in serum-free media. The lower chamber was filled with FBS supplemented media. After the incubation with the suggested time point, the cells on the upper side were stained with crystal violet to visualize and quantify them. (B) HCCLM3 cells were seeded into a culture vessel that has a culture-insert and the 
removal of this insert creates the cell-free space. The movement of the cell is visualized and measured either on treatment with Tris DBA or untreated samples. Bars indicate standard deviation; $n=3 ;{ }^{*}<<0.05$, $* * p<0.01$ versus no treatment.
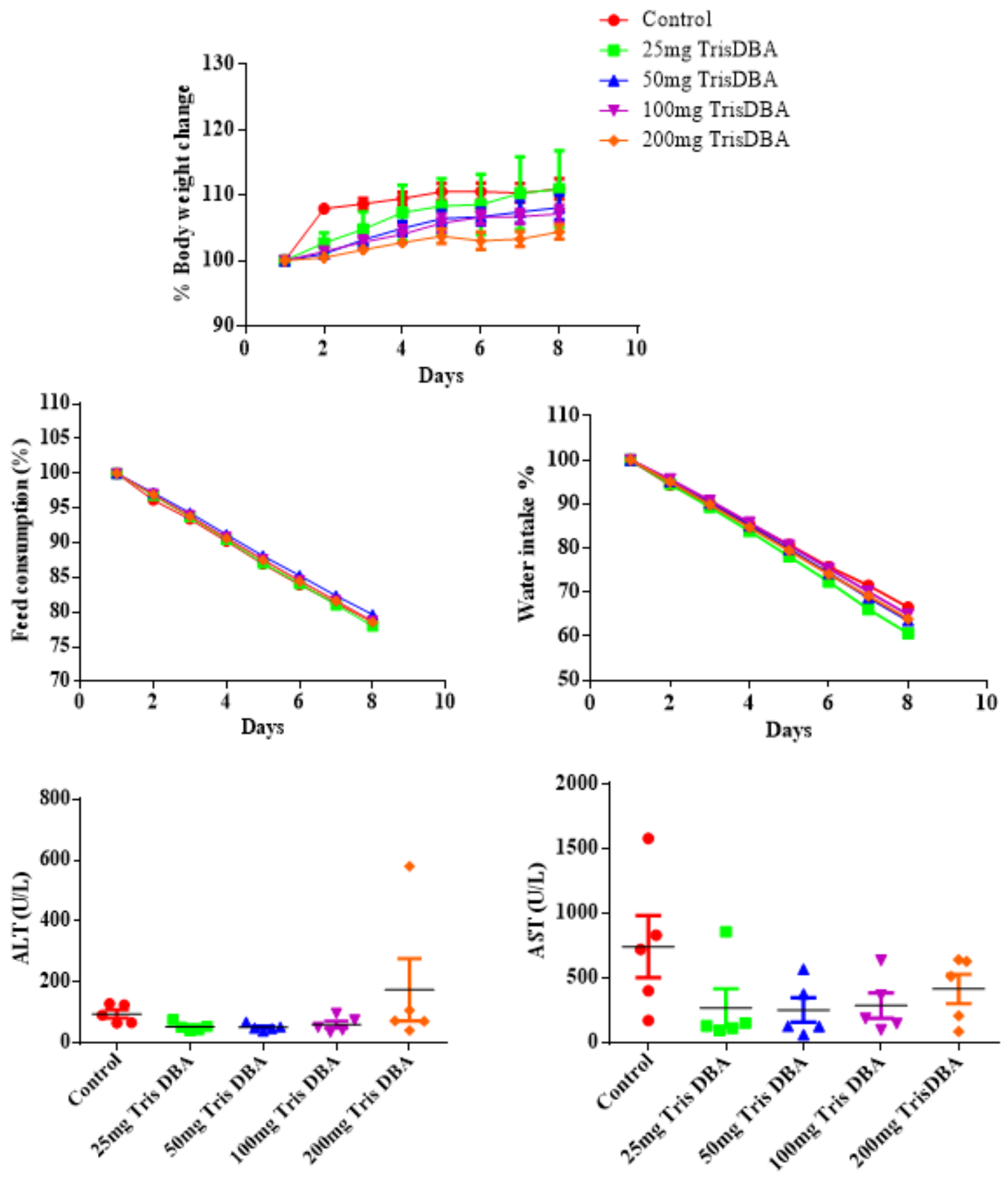

Figure 7

Tris DBA has no significant toxicity in vivo. The nude mice $(n=5)$ per group were treated with one single dose of Tris DBA (25, or 50 , or 100 , or $200 \mathrm{mg} / \mathrm{kg}$ ) and $0.1 \%$ DMSO control intraperitoneally and effect of Tris DBA on body weight, feed consumption, water intake, and various biochemical parameters were measured. 

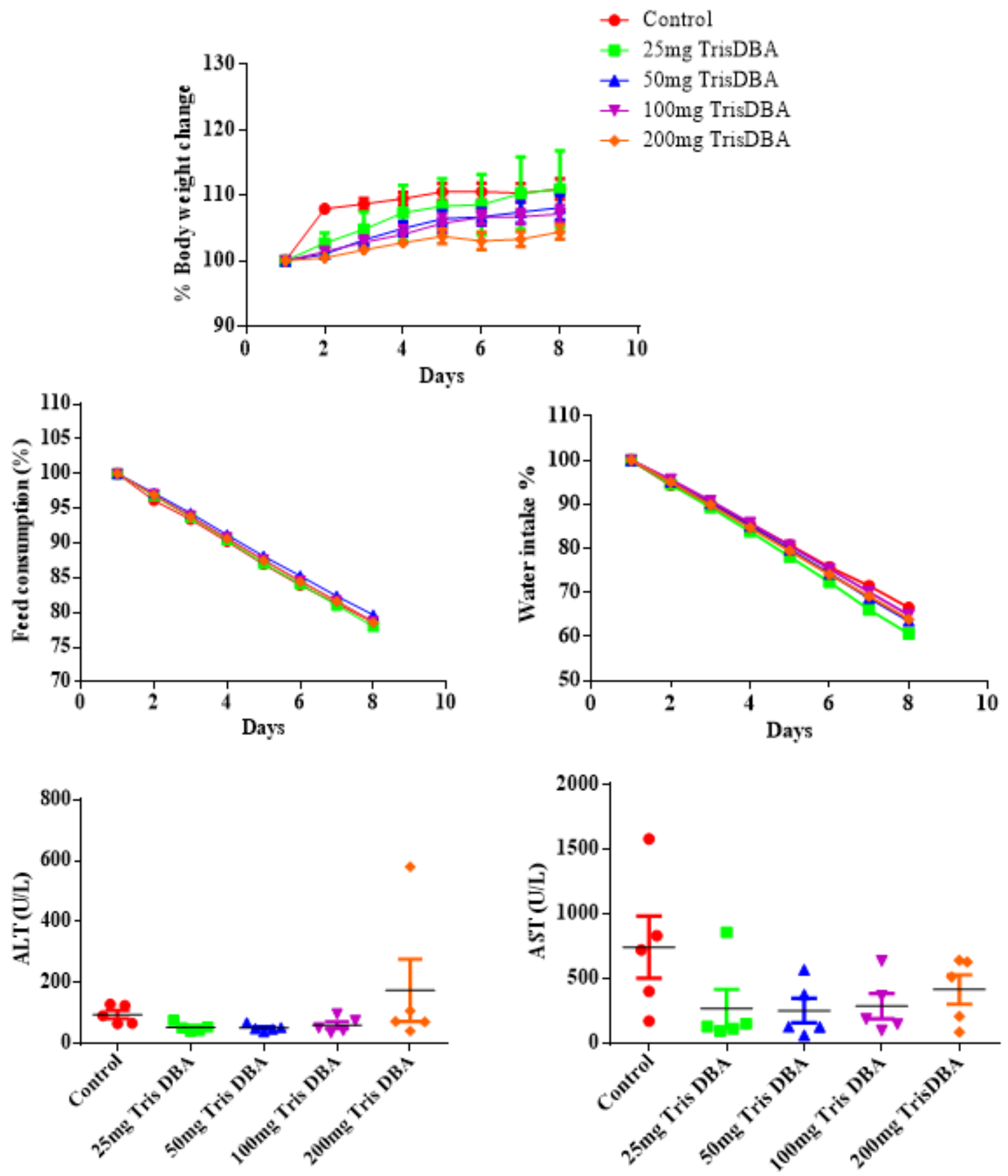

Figure 7

Tris DBA has no significant toxicity in vivo. The nude mice $(n=5)$ per group were treated with one single dose of Tris DBA (25, or 50 , or 100 , or $200 \mathrm{mg} / \mathrm{kg}$ ) and $0.1 \%$ DMSO control intraperitoneally and effect of Tris DBA on body weight, feed consumption, water intake, and various biochemical parameters were measured. 

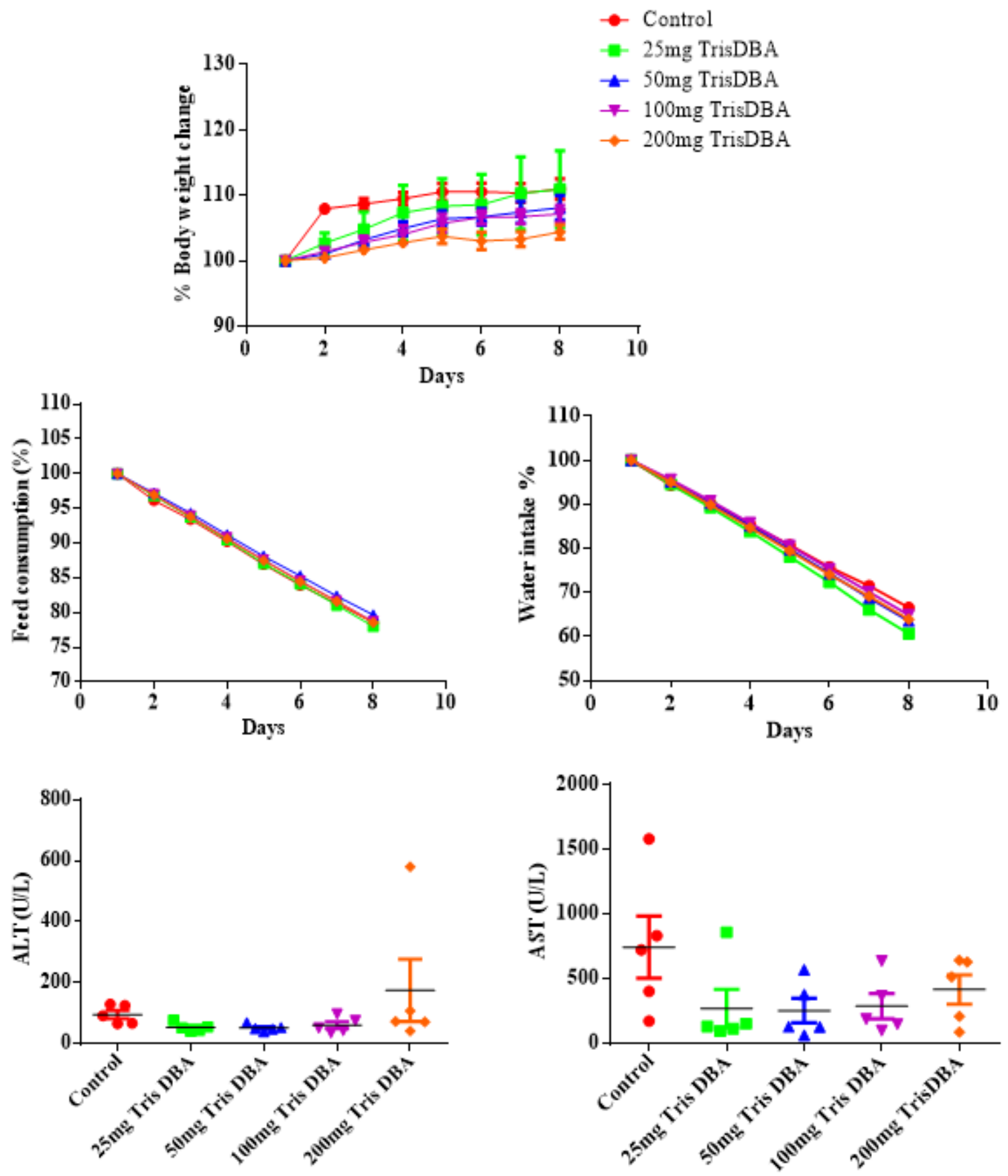

Figure 7

Tris DBA has no significant toxicity in vivo. The nude mice $(n=5)$ per group were treated with one single dose of Tris DBA (25, or 50 , or 100 , or $200 \mathrm{mg} / \mathrm{kg}$ ) and $0.1 \%$ DMSO control intraperitoneally and effect of Tris DBA on body weight, feed consumption, water intake, and various biochemical parameters were measured. 

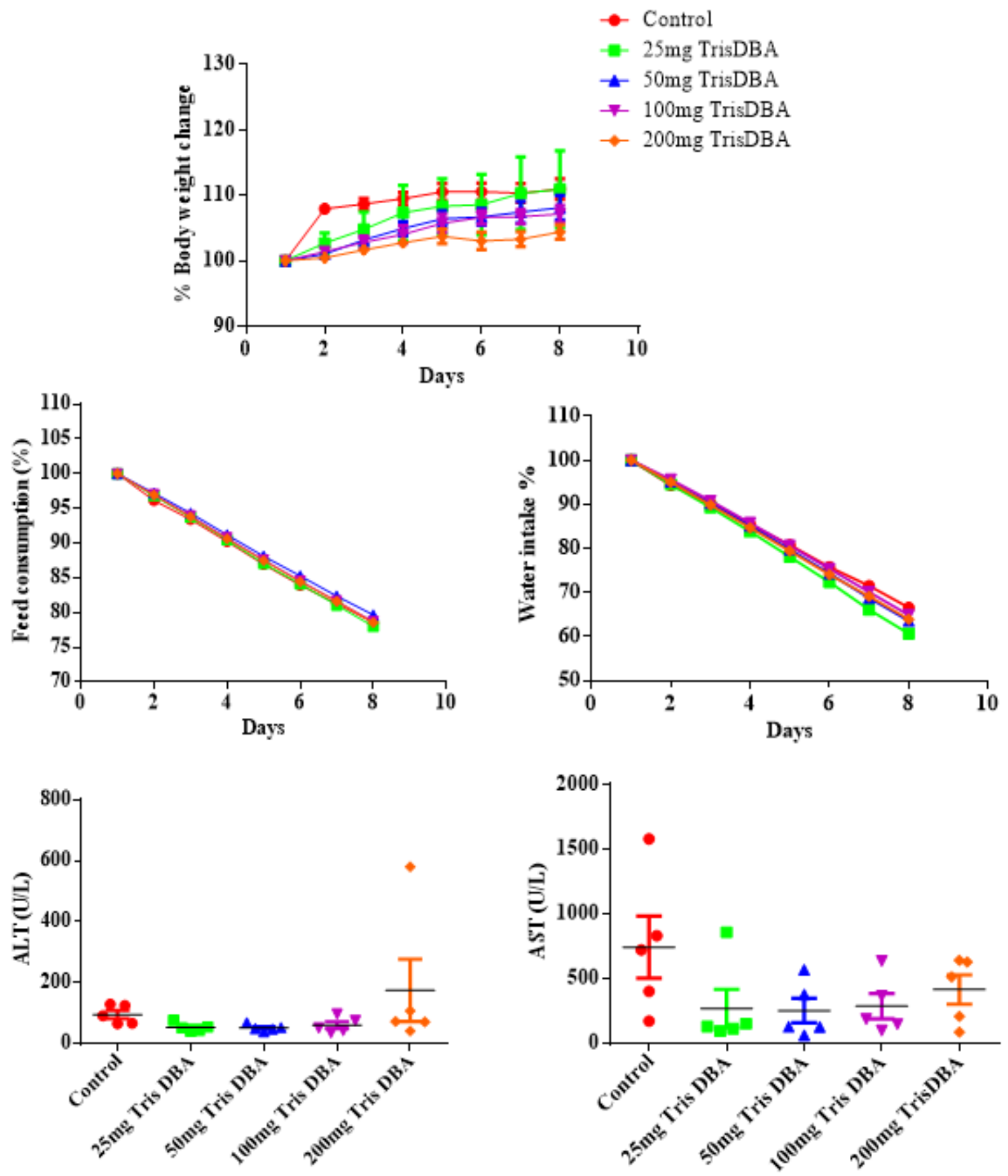

Figure 7

Tris DBA has no significant toxicity in vivo. The nude mice $(n=5)$ per group were treated with one single dose of Tris DBA (25, or 50 , or 100 , or $200 \mathrm{mg} / \mathrm{kg}$ ) and $0.1 \%$ DMSO control intraperitoneally and effect of Tris DBA on body weight, feed consumption, water intake, and various biochemical parameters were measured. 
A
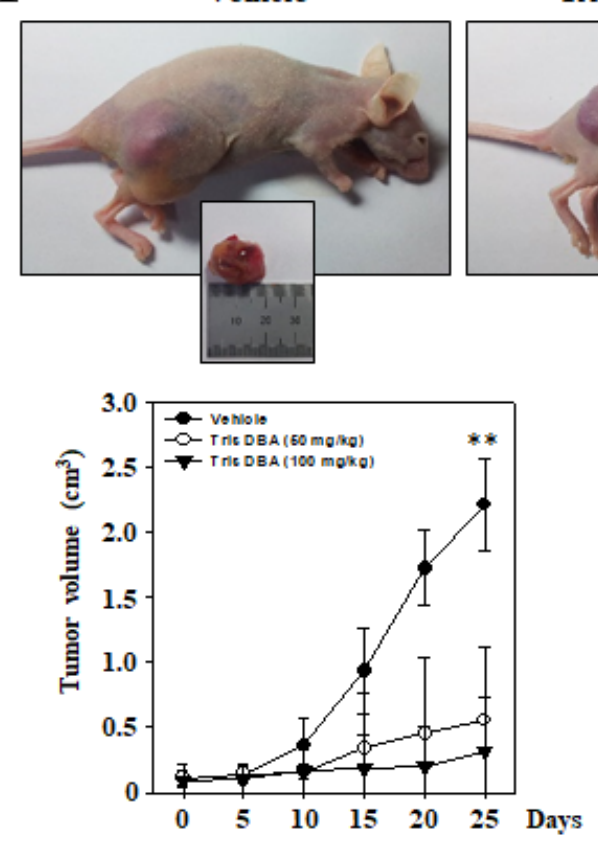

B
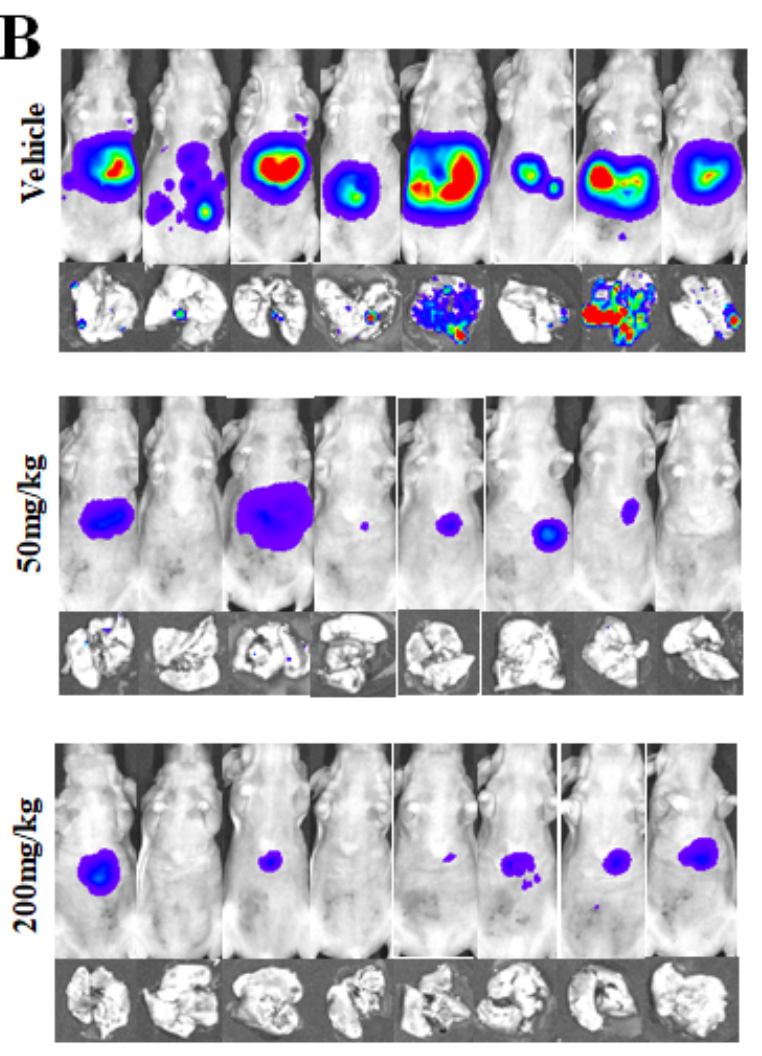

Tris DBA $(50 \mathrm{mg} / \mathbf{k g})$
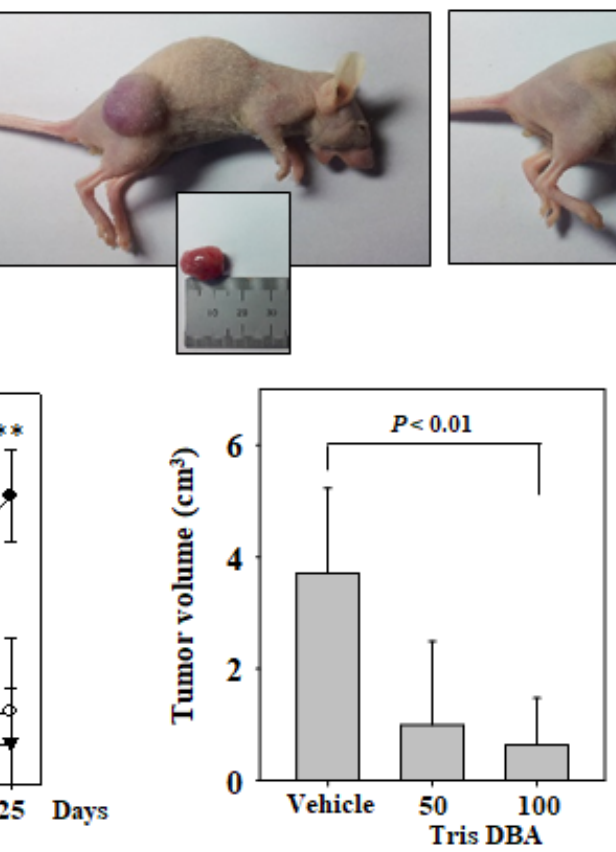

$(\mathrm{mg} / \mathrm{kg})$
Tris DBA (100 mg/kg)
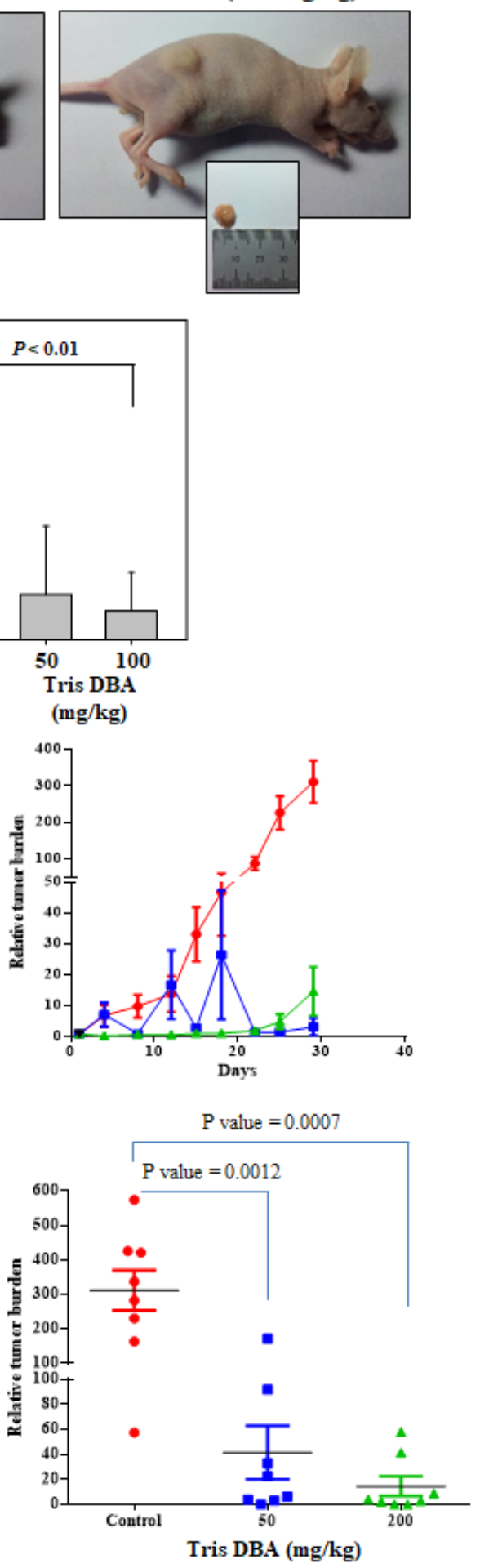

Figure 8

Tris DBA induces antitumor activity in xenograft MM and the orthotopic HCC mice model. (A) U266 cells were subcutaneously injected into xenograft tumors. After tumors reaching $0.25 \mathrm{~cm}$ in diameter, the mice were divided into three groups ( $n=6 /$ group) and administered with $50 \mathrm{mg}$ or $100 \mathrm{mg} / \mathrm{kg}$ body weight. Tumor volume is monitored throughout the study tenure. (B) HCCLM3-Luc cells-induced tumors are orthotopically implanted to the liver tissue followed by treatment with $0.1 \%$ DMSO $(n=7)$ or Tris DBA $(n=7)$ 
(administered $50 \mathrm{mg} / \mathrm{kg}$ or $200 \mathrm{mg} / \mathrm{kg}$ intraperitoneally, thrice a week, for four weeks). The tumor progression/regression was monitored twice a week by quantifying the bioluminescence intensity and the graph is plotted using these values. The scattered plot indicates the tumor burden that was quantified by measuring photon counts before the first administration of Tris DBA and at the last dose. Unpaired t-test with Welch's correction. Bars indicate standard deviation; ** $\mathrm{p}<0.01$.

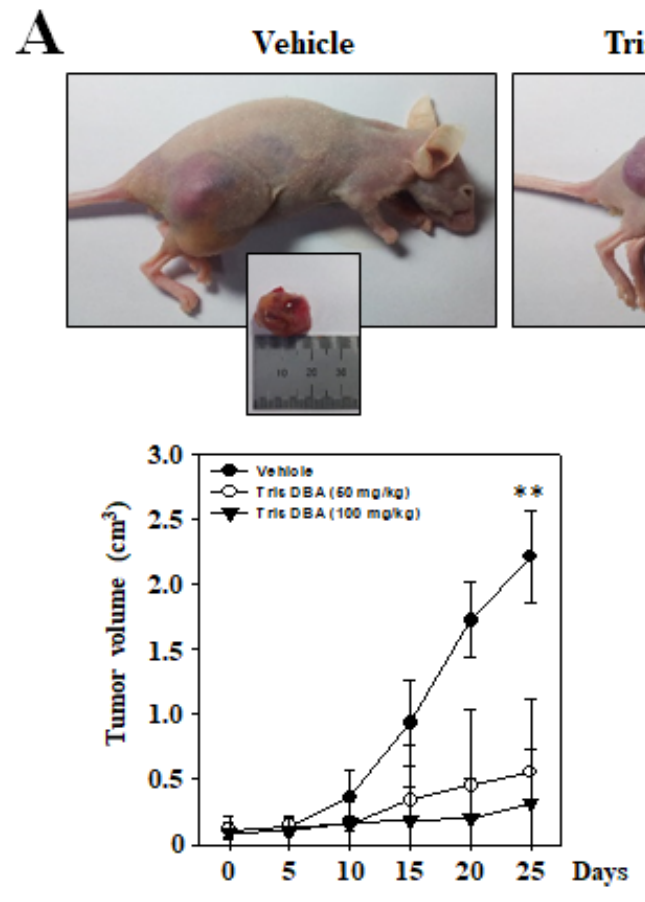

B
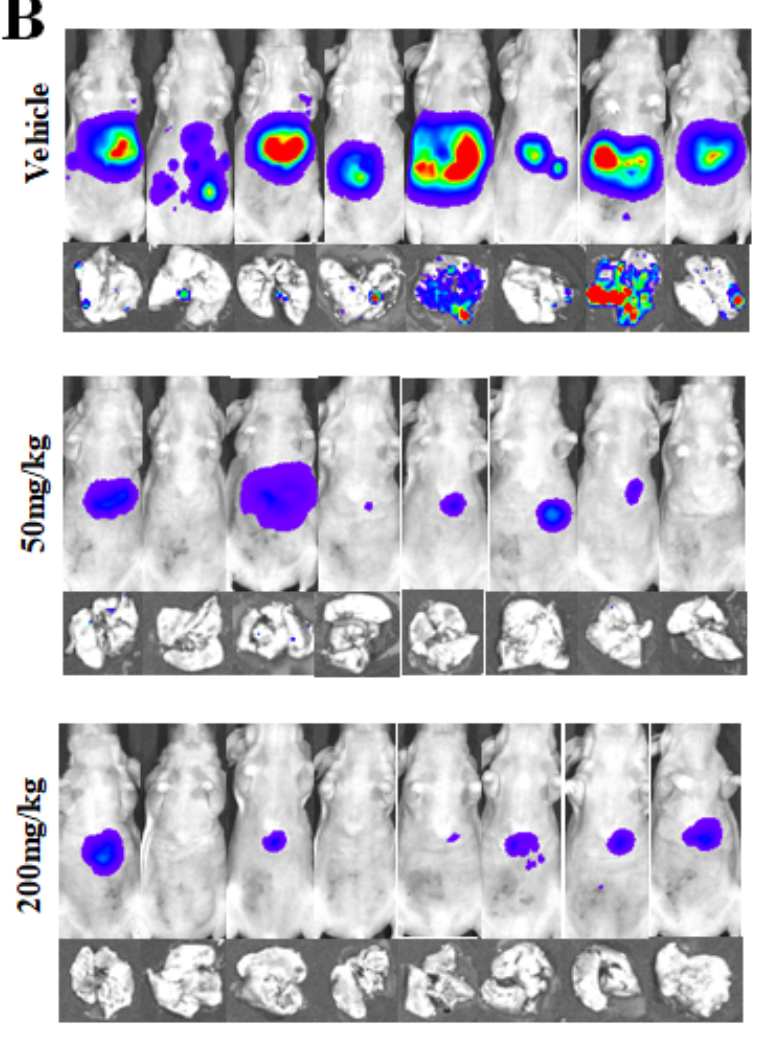

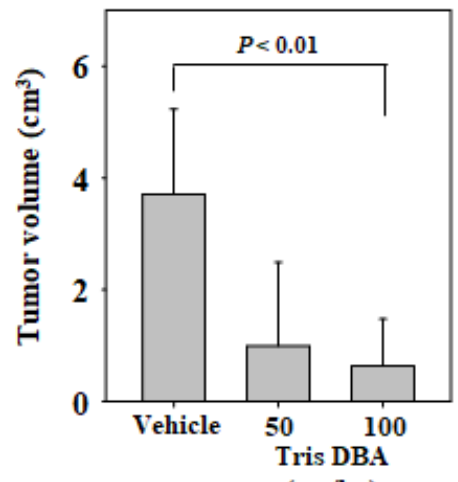

Tris DBA (100 mg/kg)

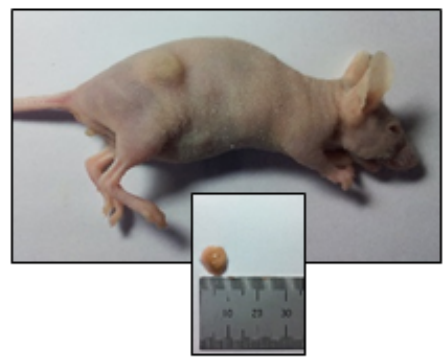

$(\mathrm{mg} / \mathrm{kg})$
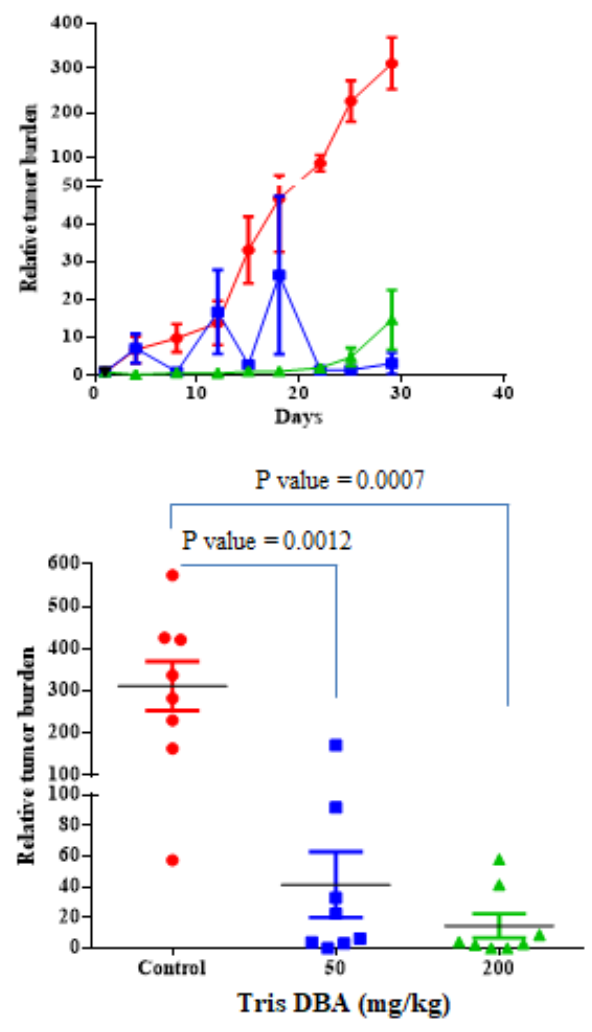

Figure 8 
Tris DBA induces antitumor activity in xenograft MM and the orthotopic HCC mice model. (A) U266 cells were subcutaneously injected into xenograft tumors. After tumors reaching $0.25 \mathrm{~cm}$ in diameter, the mice were divided into three groups ( $\mathrm{n}=6 /$ group) and administered with $50 \mathrm{mg}$ or $100 \mathrm{mg} / \mathrm{kg}$ body weight. Tumor volume is monitored throughout the study tenure. (B) HCCLM3-Luc cells-induced tumors are orthotopically implanted to the liver tissue followed by treatment with $0.1 \%$ DMSO $(n=7)$ or Tris DBA $(n=7)$ (administered $50 \mathrm{mg} / \mathrm{kg}$ or $200 \mathrm{mg} / \mathrm{kg}$ intraperitoneally, thrice a week, for four weeks). The tumor progression/regression was monitored twice a week by quantifying the bioluminescence intensity and the graph is plotted using these values. The scattered plot indicates the tumor burden that was quantified by measuring photon counts before the first administration of Tris DBA and at the last dose. Unpaired t-test with Welch's correction. Bars indicate standard deviation; ** $p<0.01$. 
A

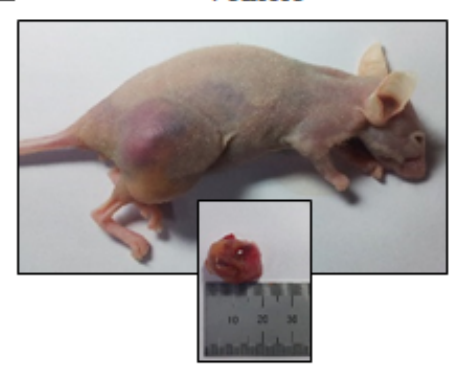

Tris DBA $(50 \mathrm{mg} / \mathrm{kg})$

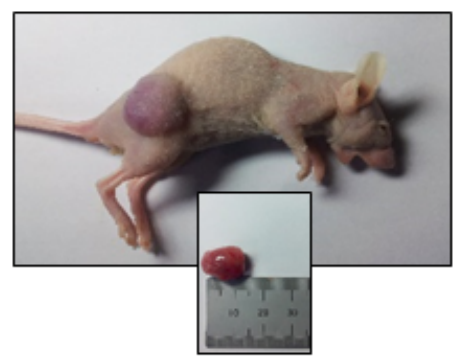

Tris DBA (100 mg/kg)
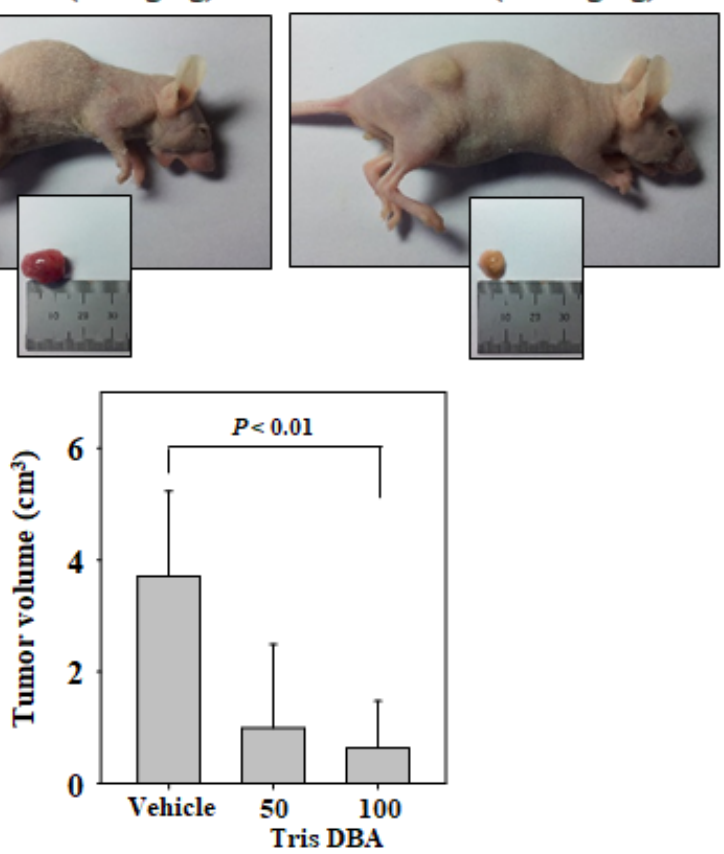

$(\mathrm{mg} / \mathrm{kg})$
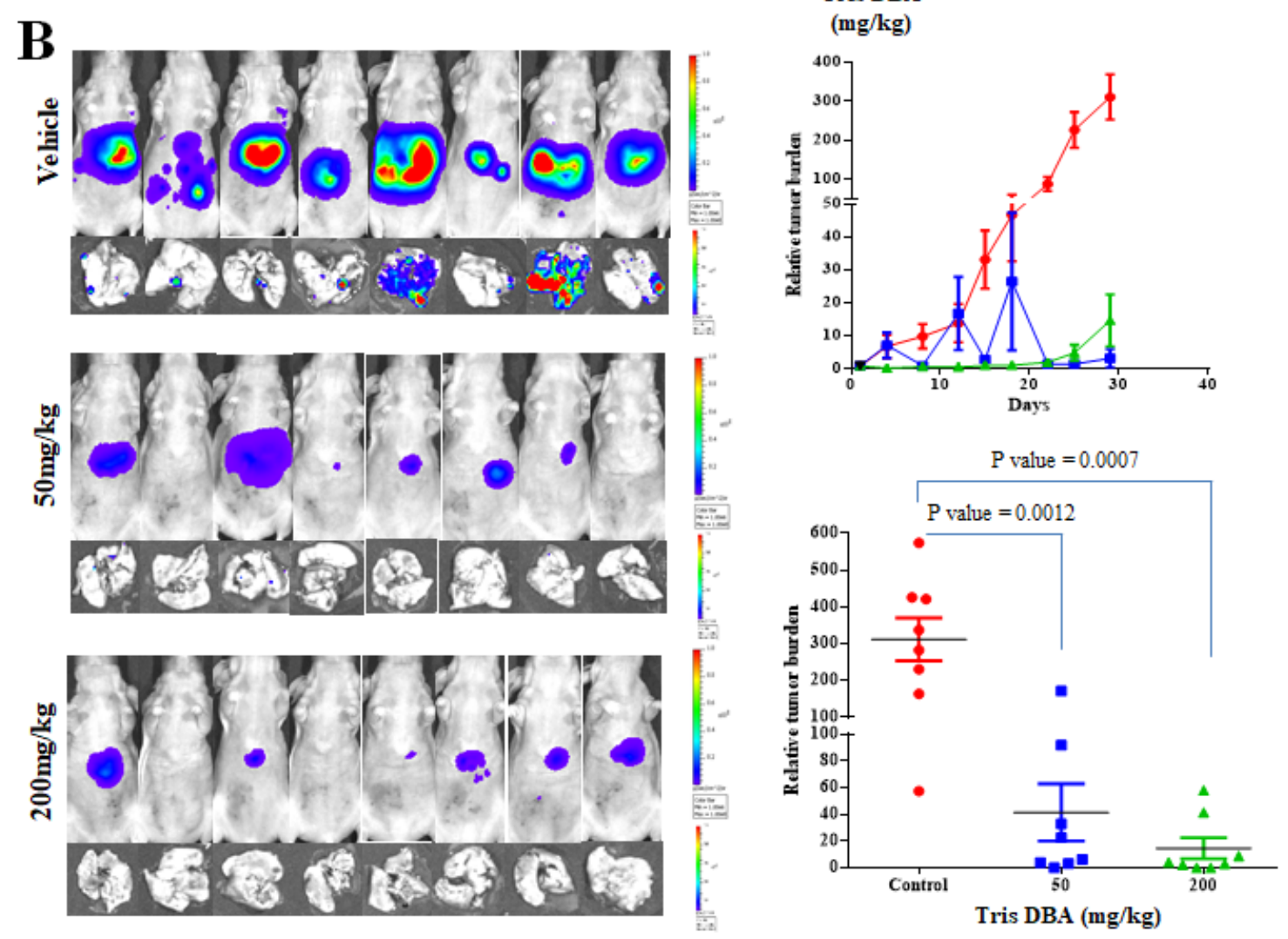

\section{Figure 8}

Tris DBA induces antitumor activity in xenograft MM and the orthotopic HCC mice model. (A) U266 cells were subcutaneously injected into xenograft tumors. After tumors reaching $0.25 \mathrm{~cm}$ in diameter, the mice were divided into three groups ( $\mathrm{n}=6 /$ group) and administered with $50 \mathrm{mg}$ or $100 \mathrm{mg} / \mathrm{kg}$ body weight. Tumor volume is monitored throughout the study tenure. (B) HCCLM3-Luc cells-induced tumors are orthotopically implanted to the liver tissue followed by treatment with $0.1 \%$ DMSO $(n=7)$ or Tris DBA $(n=7)$ 
(administered $50 \mathrm{mg} / \mathrm{kg}$ or $200 \mathrm{mg} / \mathrm{kg}$ intraperitoneally, thrice a week, for four weeks). The tumor progression/regression was monitored twice a week by quantifying the bioluminescence intensity and the graph is plotted using these values. The scattered plot indicates the tumor burden that was quantified by measuring photon counts before the first administration of Tris DBA and at the last dose. Unpaired t-test with Welch's correction. Bars indicate standard deviation; ** $\mathrm{p}<0.01$.

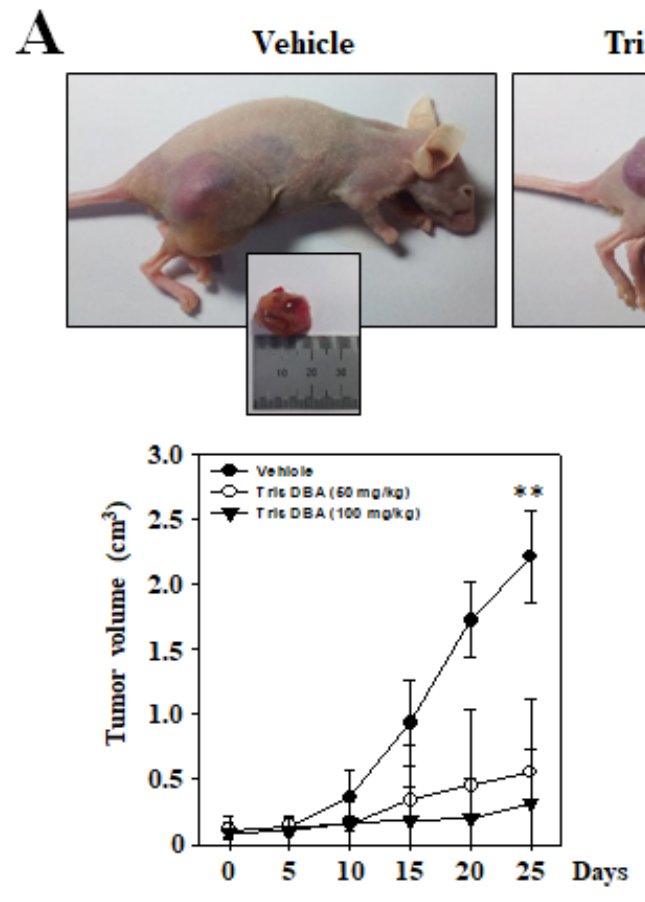

B
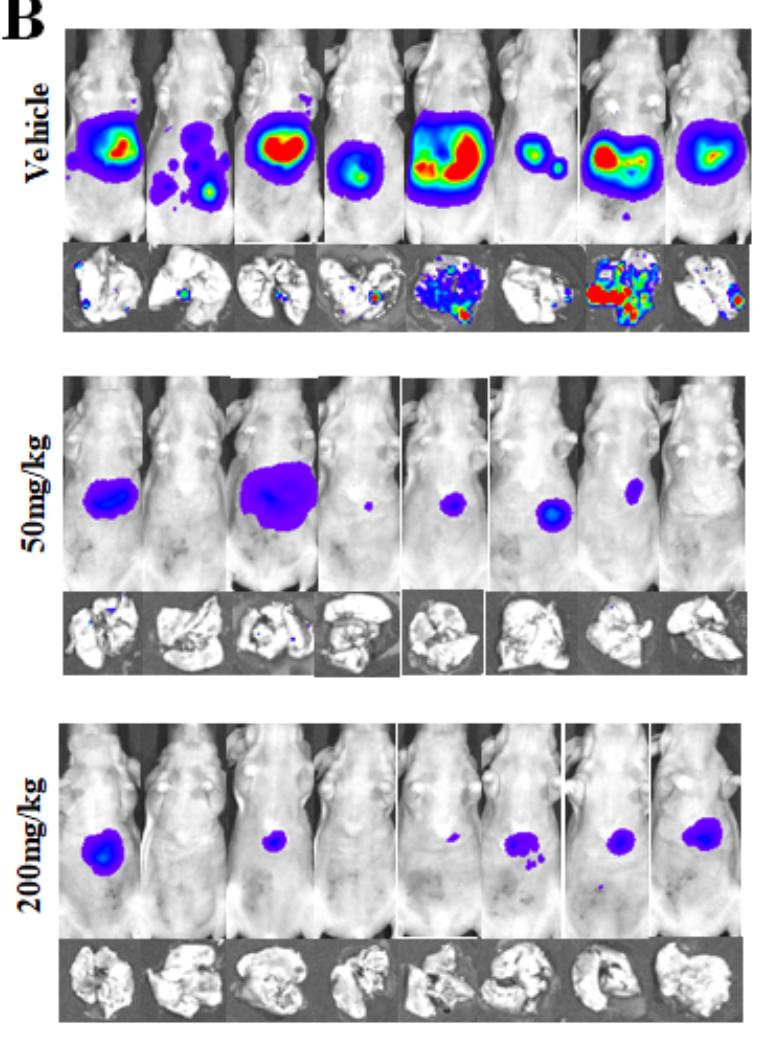

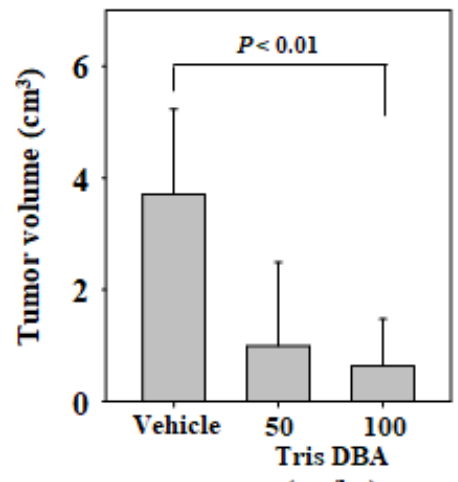

Tris DBA (100 mg/kg)

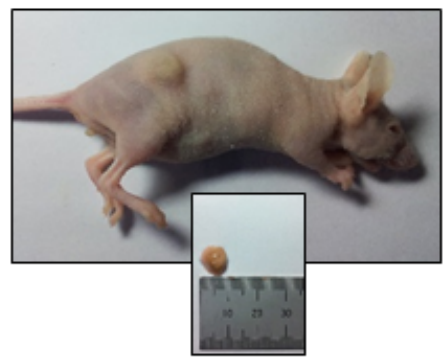

$(\mathrm{mg} / \mathrm{kg})$
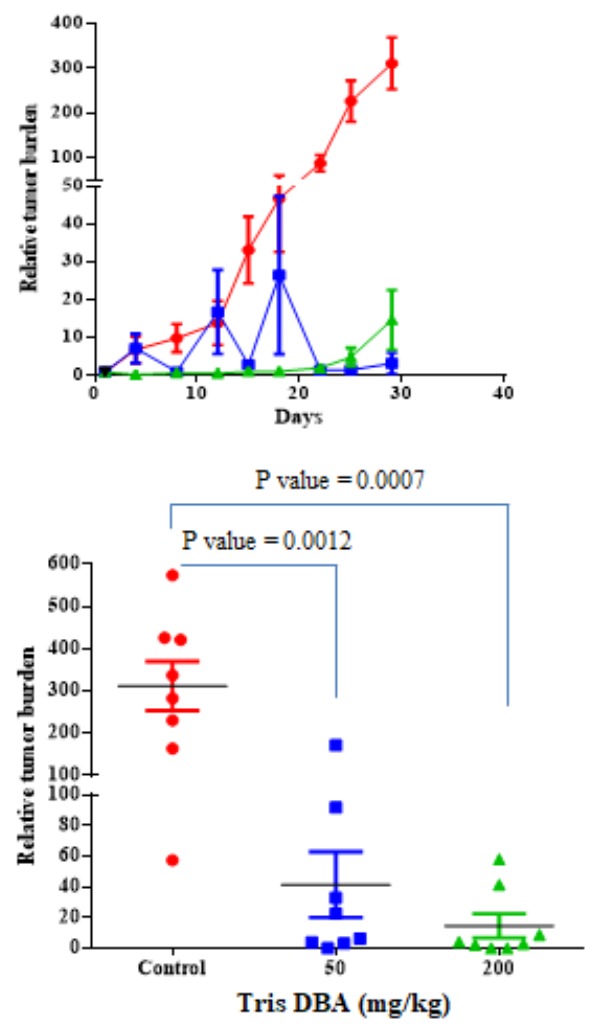

Figure 8 
Tris DBA induces antitumor activity in xenograft MM and the orthotopic HCC mice model. (A) U266 cells were subcutaneously injected into xenograft tumors. After tumors reaching $0.25 \mathrm{~cm}$ in diameter, the mice were divided into three groups ( $\mathrm{n}=6 / \mathrm{group}$ ) and administered with $50 \mathrm{mg}$ or $100 \mathrm{mg} / \mathrm{kg}$ body weight. Tumor volume is monitored throughout the study tenure. (B) HCCLM3-Luc cells-induced tumors are orthotopically implanted to the liver tissue followed by treatment with $0.1 \%$ DMSO $(n=7)$ or Tris DBA $(n=7)$ (administered $50 \mathrm{mg} / \mathrm{kg}$ or $200 \mathrm{mg} / \mathrm{kg}$ intraperitoneally, thrice a week, for four weeks). The tumor progression/regression was monitored twice a week by quantifying the bioluminescence intensity and the graph is plotted using these values. The scattered plot indicates the tumor burden that was quantified by measuring photon counts before the first administration of Tris DBA and at the last dose. Unpaired t-test with Welch's correction. Bars indicate standard deviation; ** $p<0.01$.

A
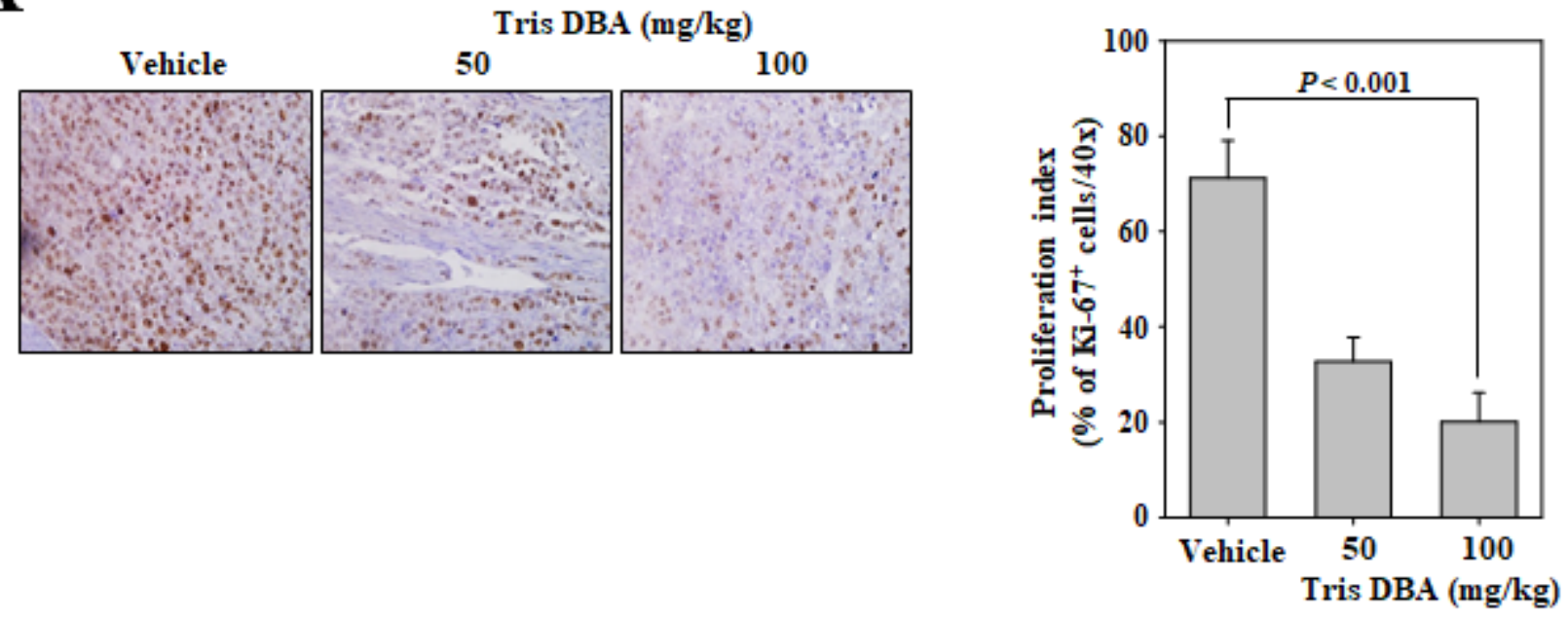

B
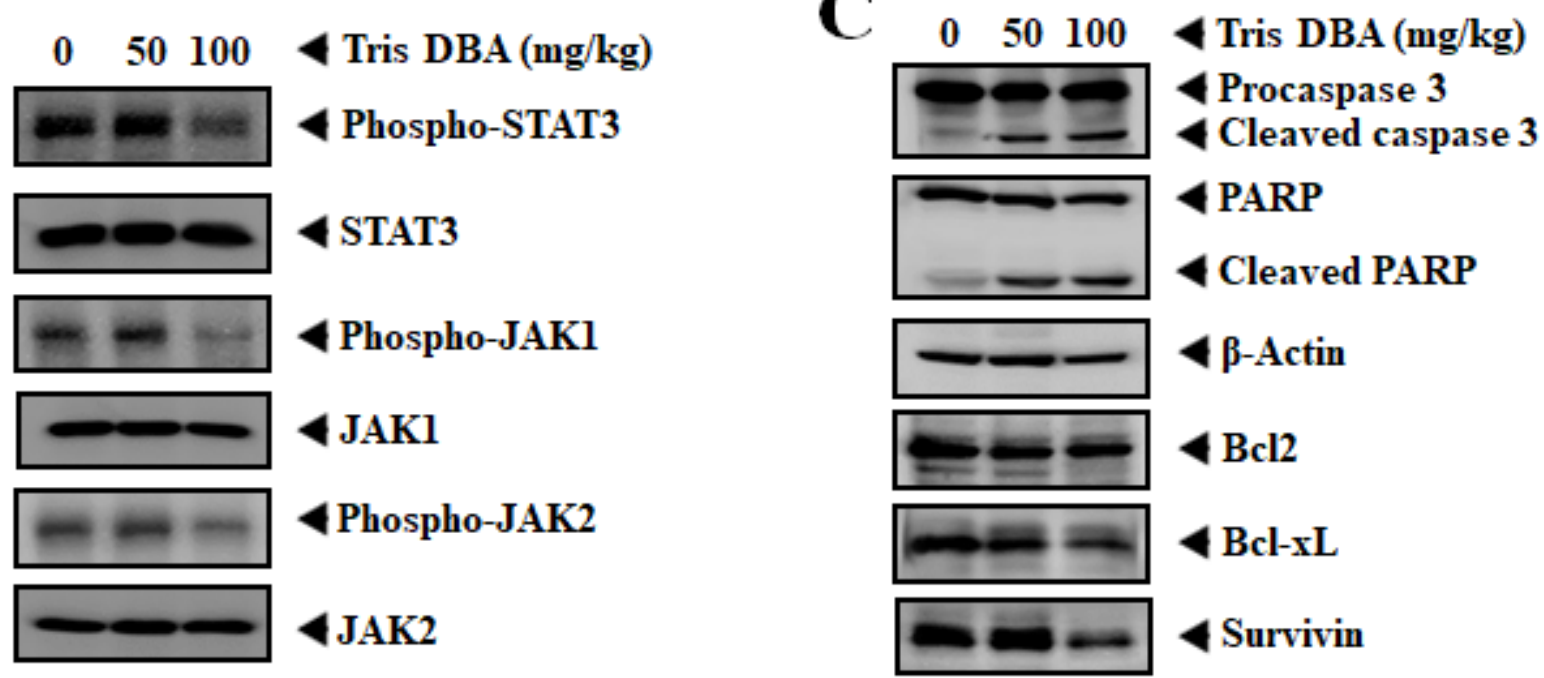

PARP

Cleaved PARP

$\beta$-Actin

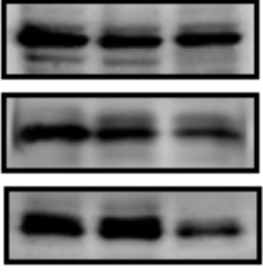

Bcl2

Bcl-xL

Survivin

$\beta$-Actin

Figure 9

Tris DBA decreases the activation of STAT3 and its regulatory proteins as well as the levels of its downstream proteins. (A) MM tumor tissue from Tris-DBA treated and the untreated group was used for 
examination of the expression of Ki-67 by immunohistochemistry analysis. (B and C) The expression of STAT3 signaling pathway proteins and apoptotic markers was examined in MM tumor tissues.

A
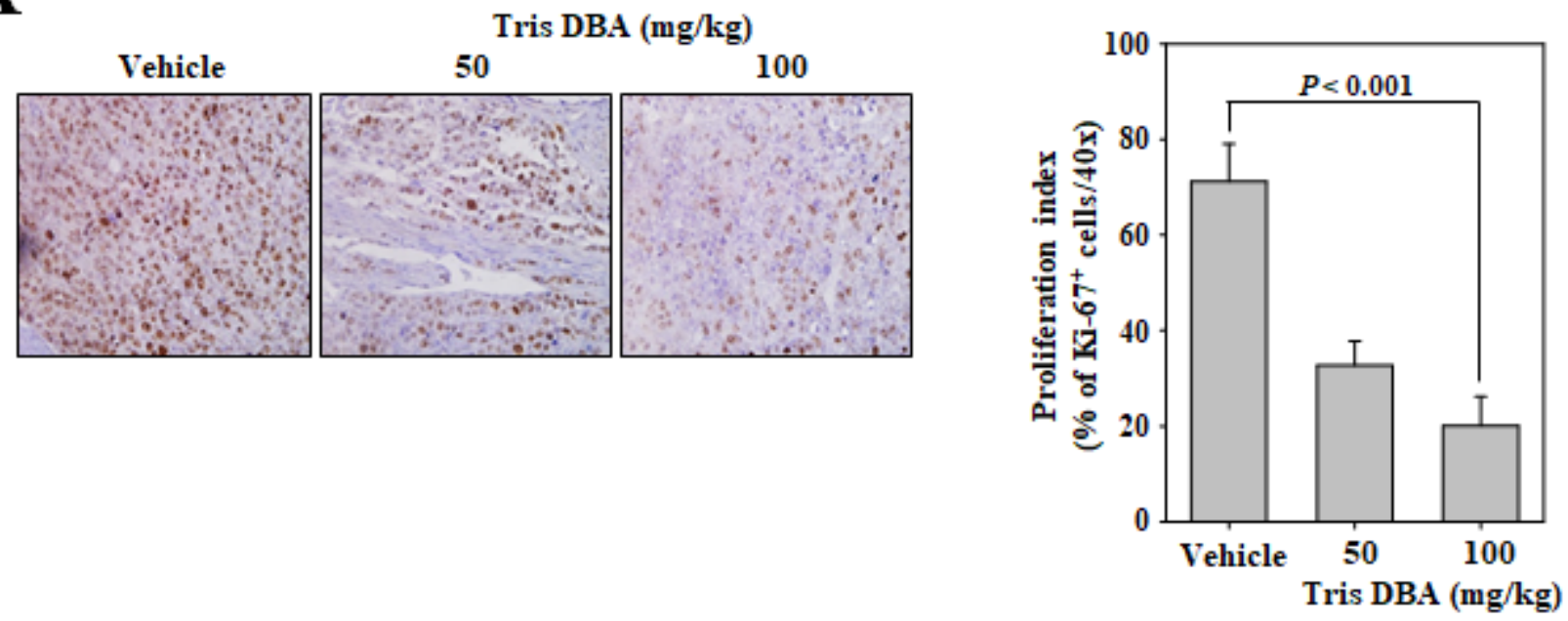

B

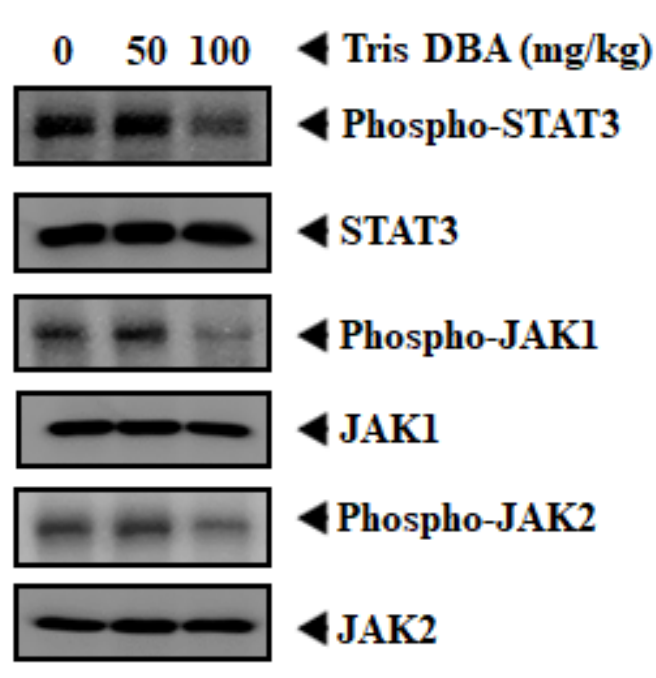

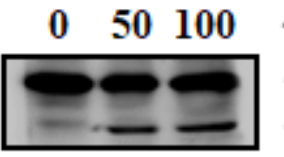
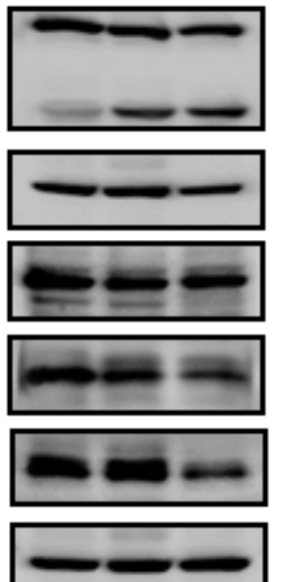

4 Tris DBA (mg/kg)

4 Procaspase 3

4 Cleaved caspase 3

$\triangle$ PARP

Cleaved PARP

$\beta$-Actin

Bcl2

Bcl-xL

Survivin

$\beta$-Actin

Figure 9

Tris DBA decreases the activation of STAT3 and its regulatory proteins as well as the levels of its downstream proteins. (A) MM tumor tissue from Tris-DBA treated and the untreated group was used for examination of the expression of Ki-67 by immunohistochemistry analysis. (B and C) The expression of STAT3 signaling pathway proteins and apoptotic markers was examined in MM tumor tissues. 
A
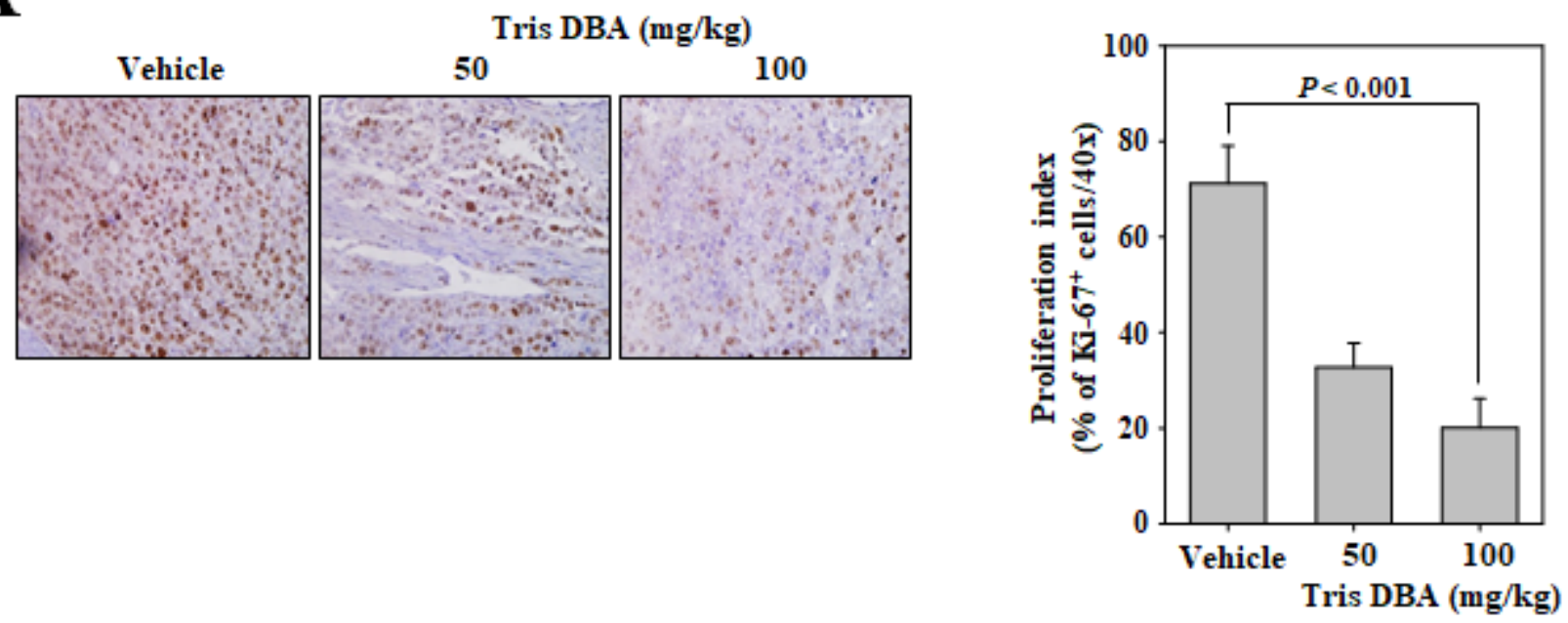

B
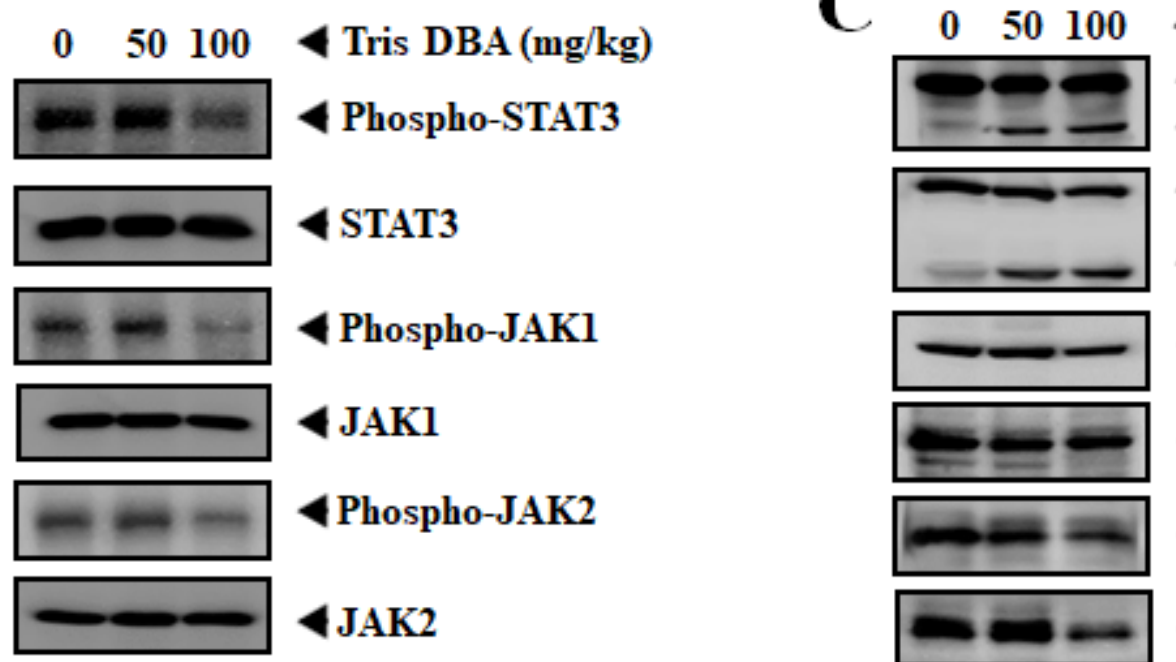

Tris DBA (mg/kg)

4 Procaspase 3

4 Cleaved caspase 3

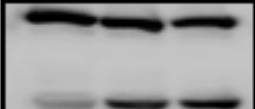

PARP

1 Cleaved PARP

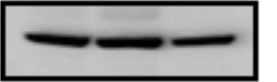

$\beta$-Actin

$4 \mathrm{Bcl} 2$

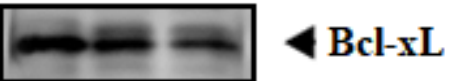

$-\infty-\infty$ Survivin

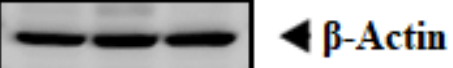

Figure 9

Tris DBA decreases the activation of STAT3 and its regulatory proteins as well as the levels of its downstream proteins. (A) MM tumor tissue from Tris-DBA treated and the untreated group was used for examination of the expression of Ki-67 by immunohistochemistry analysis. (B and C) The expression of STAT3 signaling pathway proteins and apoptotic markers was examined in MM tumor tissues. 
A
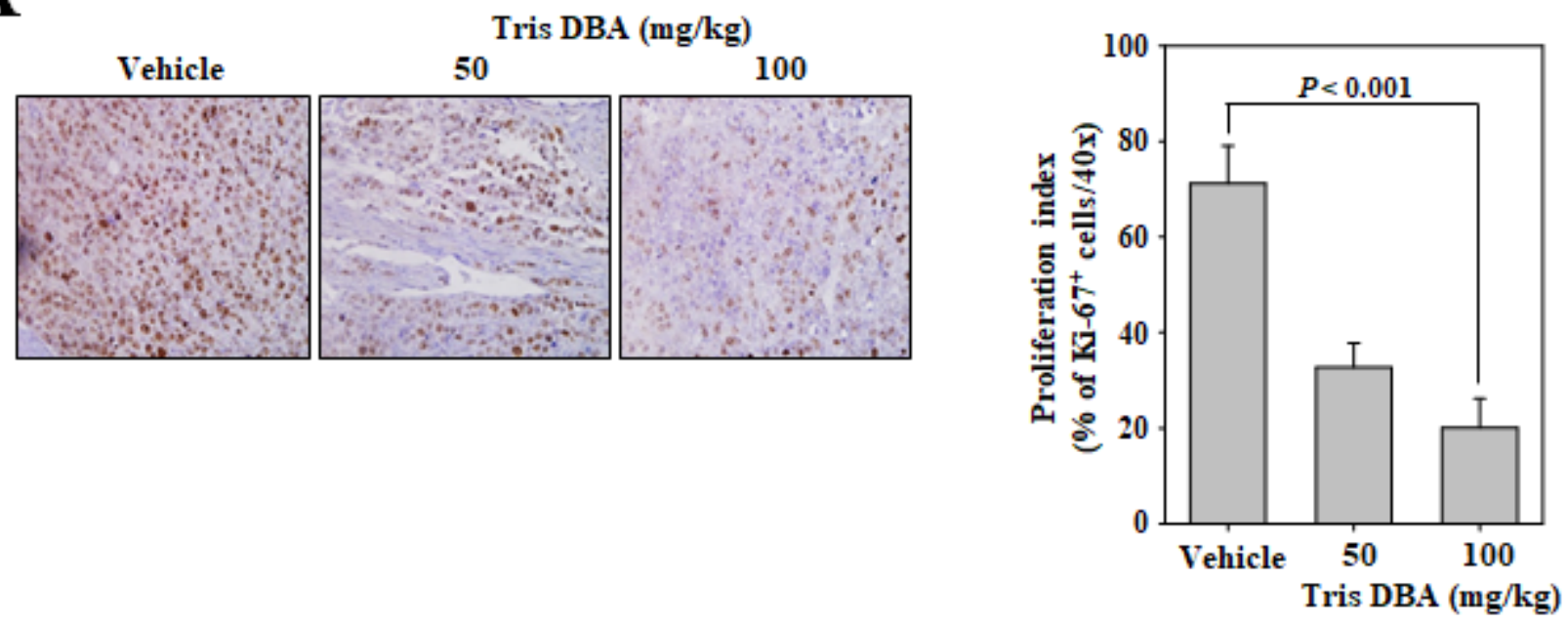

B
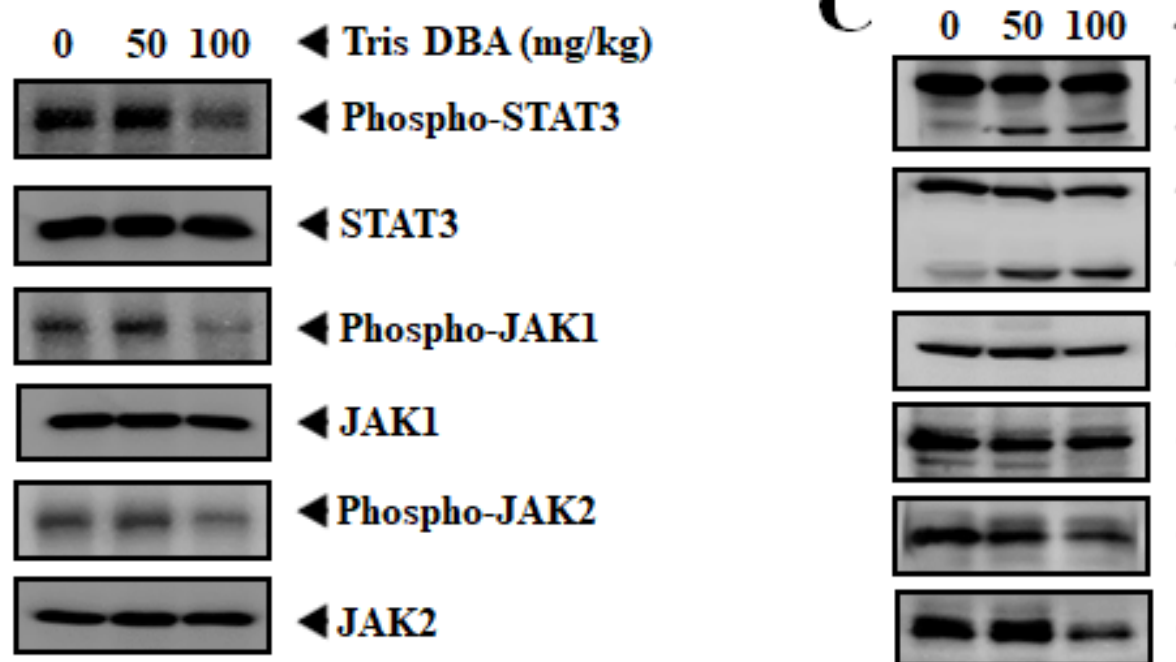

Tris DBA (mg/kg)

4 Procaspase 3

4 Cleaved caspase 3

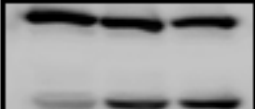

PARP

1 Cleaved PARP

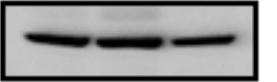

$\beta$-Actin

$4 \mathrm{Bcl} 2$

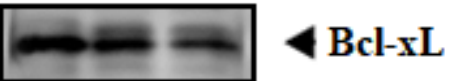

$-\infty-\infty$ Survivin

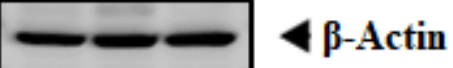

Figure 9

Tris DBA decreases the activation of STAT3 and its regulatory proteins as well as the levels of its downstream proteins. (A) MM tumor tissue from Tris-DBA treated and the untreated group was used for examination of the expression of Ki-67 by immunohistochemistry analysis. (B and C) The expression of STAT3 signaling pathway proteins and apoptotic markers was examined in MM tumor tissues. 


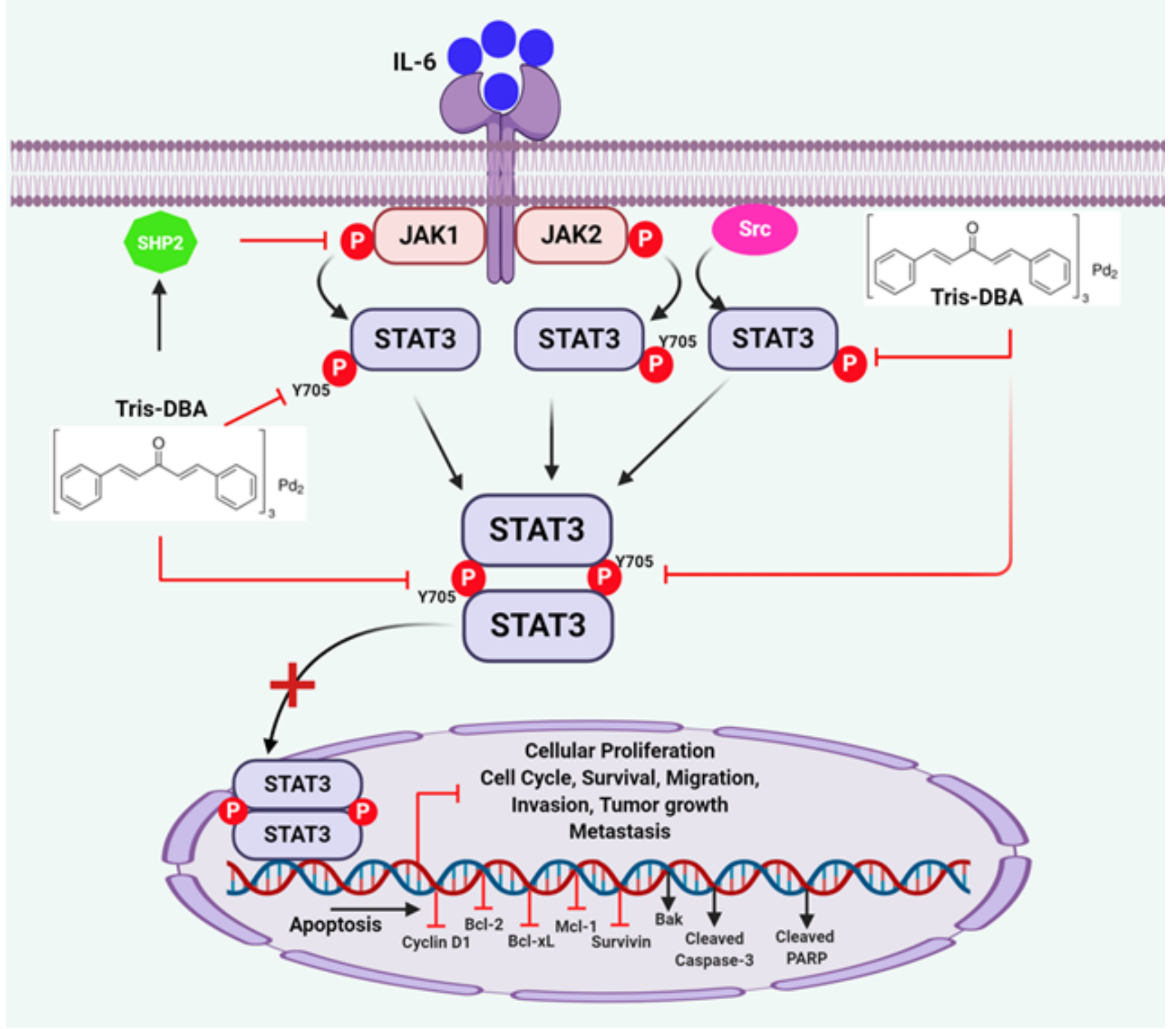

Figure 10

A schematic representation of possible anticancer actions of Tris DBA. 


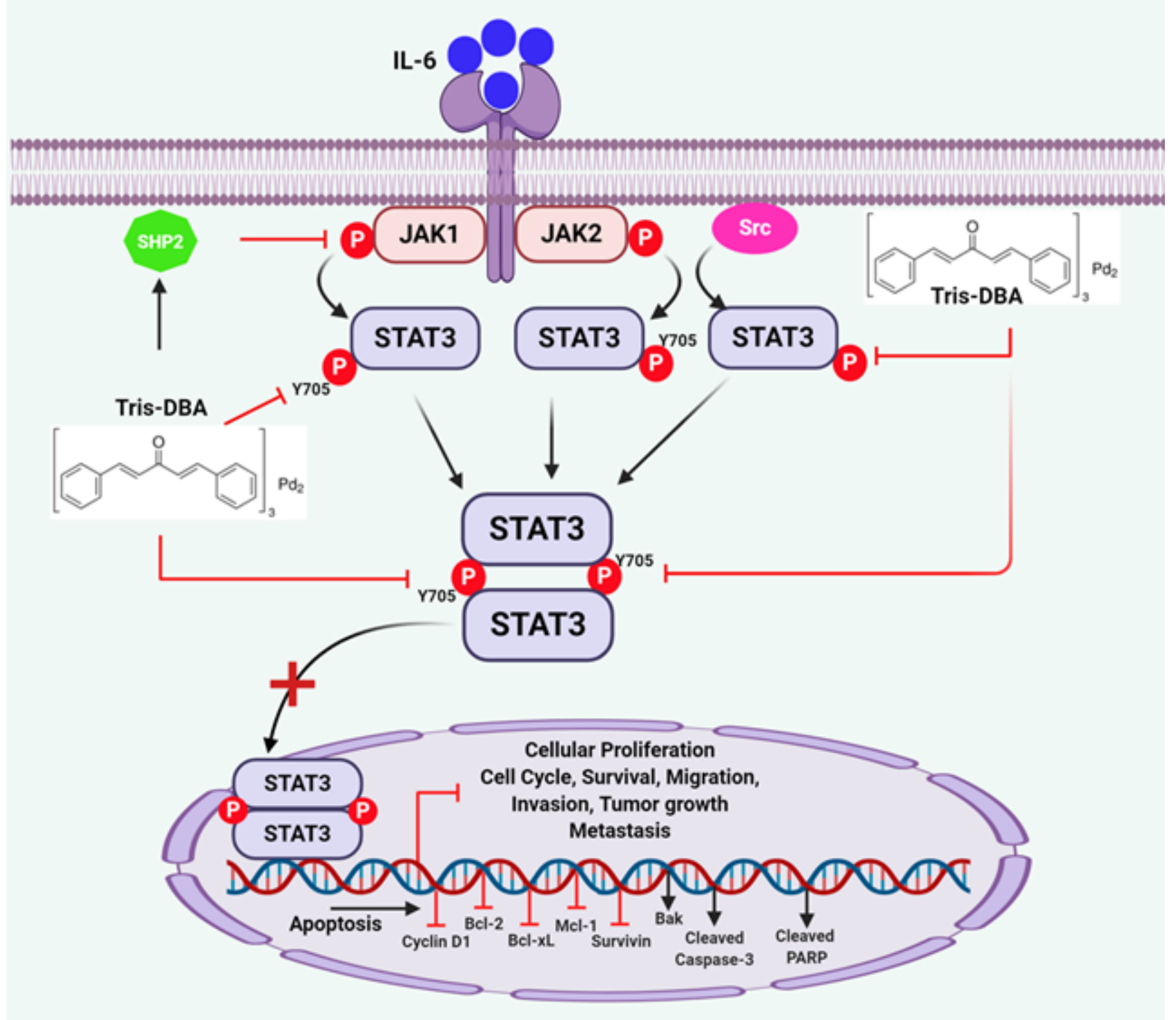

Figure 10

A schematic representation of possible anticancer actions of Tris DBA. 


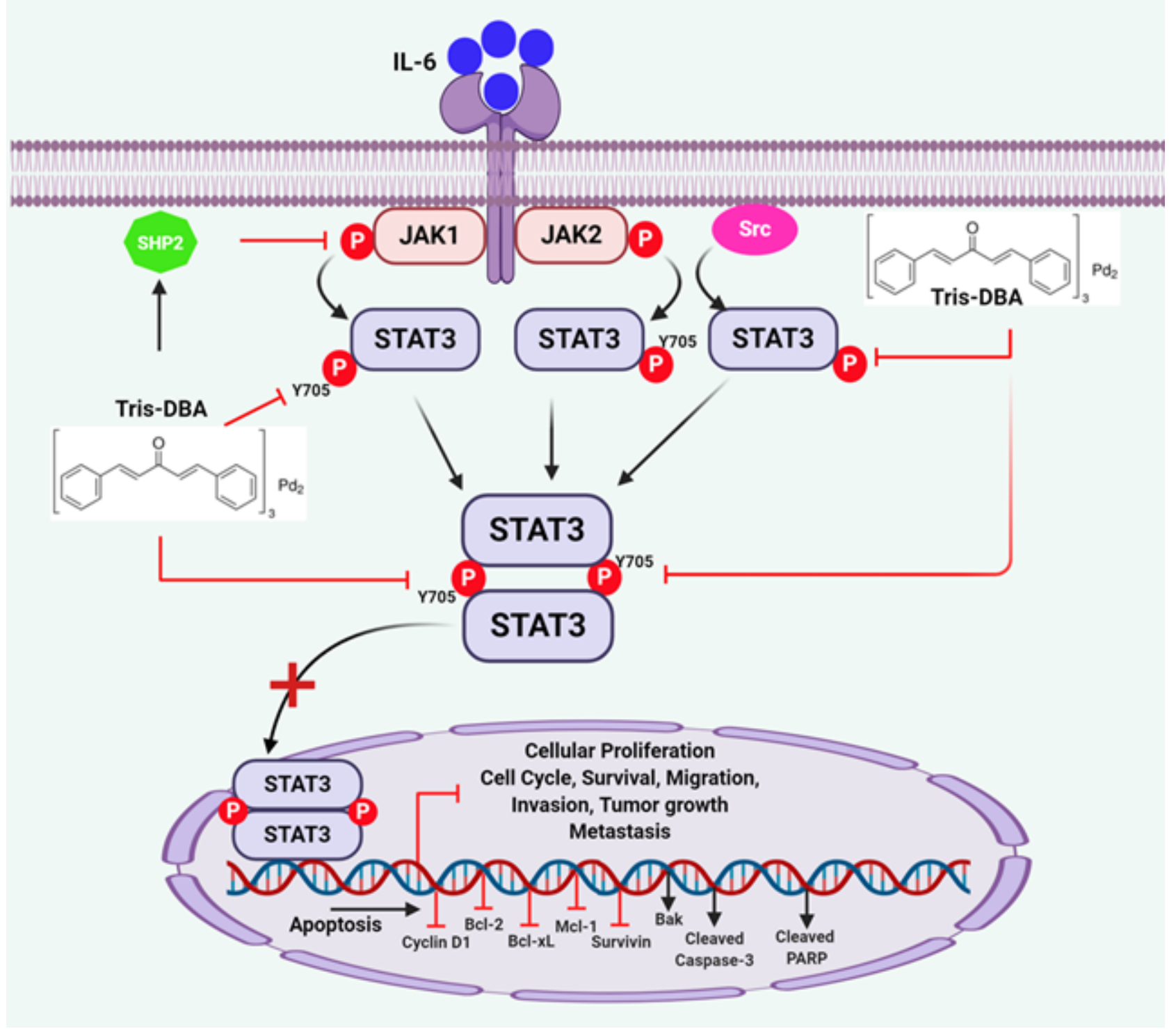

Figure 10

A schematic representation of possible anticancer actions of Tris DBA. 


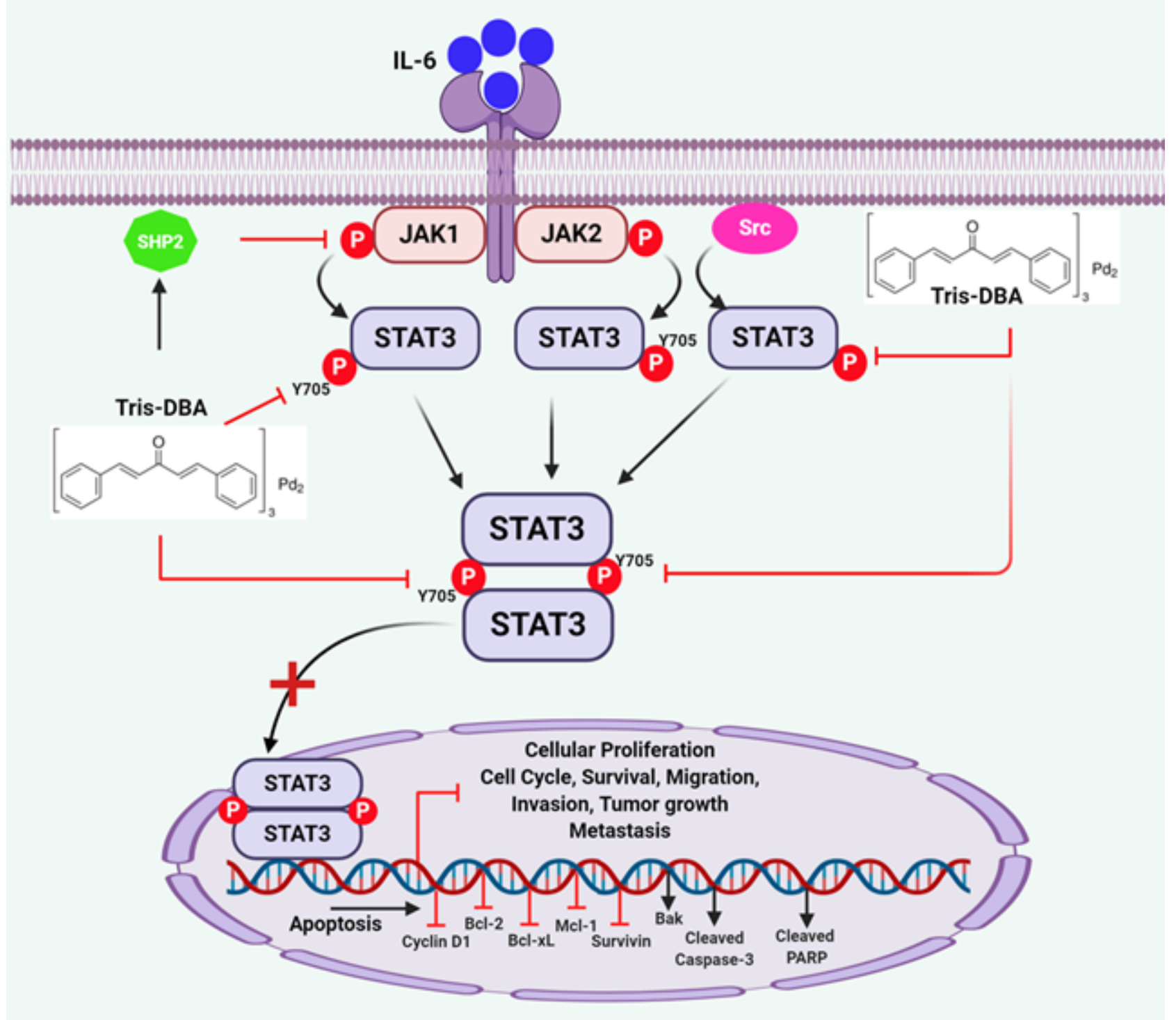

Figure 10

A schematic representation of possible anticancer actions of Tris DBA. 